\title{
Lactate dehydrogenase is C-terminally extended by stop codon read- through which targets this isoform into the peroxisomes
}

\author{
Doctoral Thesis \\ submitted by \\ Rosemol George \\ from \\ Cochin, India
}

In partial fulfillment of the requirements for the degree

"Doctor rerum naturalium (Dr. rer. nat.)"

in the Molecular Medicine Study Program

at the Georg-August University Göttingen

Göttingen 2016 


\section{Members of the Thesis Committee}

1. Prof. Dr. Jutta Gärtner

Department of Pediatrics and Adolescent Medicine

University Medical Center Göttingen

\section{Prof. Dr. Peter Schu}

Department of Cellular Biochemistry

University Medical Center Göttingen

3. Prof. Dr. Markus .T. Bohnsack

Department of Molecular Biology

University Medical Center Göttingen

Date of Disputation: 03.08.2016 


\section{Affidavit}

I hereby confirm that my thesis entitled "Lactate dehydrogenase is C-terminally extended by stop codon read-through which targets this isoform into the peroxisomes" has been written independently with no other sources and aids than quoted.

I certify to the best of my knowledge that any material from the work of other people included in my thesis, published or otherwise, are fully acknowledged in accordance with the standard referencing practices.

I declare that this is a true copy of my thesis and that it has not been submitted or presented for a higher degree to any other University or Institution.

Göttingen, date

(Signature) 
Dedicated to my parents,

Mrs. Simy George and Mr. P. George
And my husband,
Dr. Ranadip Mandal 


\section{Index:}

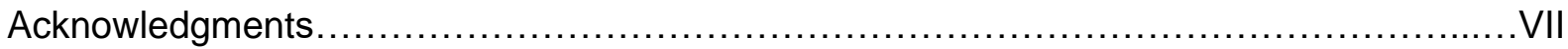

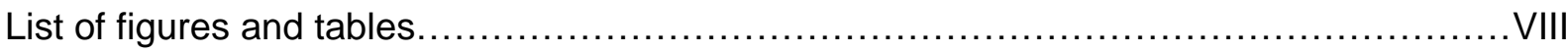

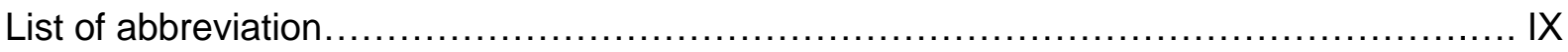

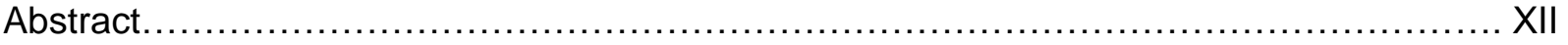

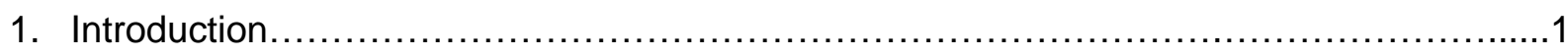

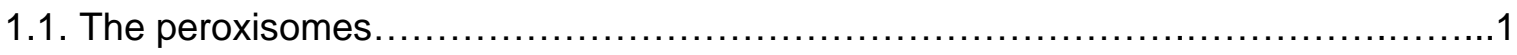

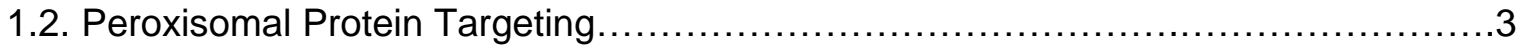

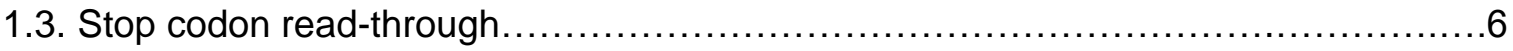

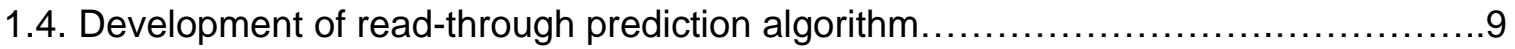

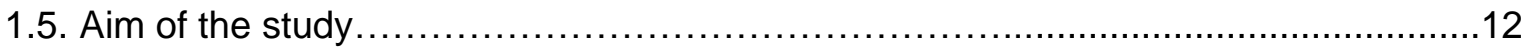

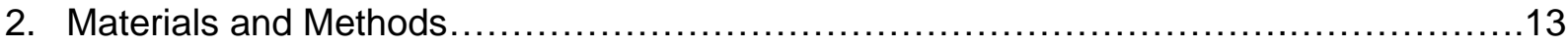

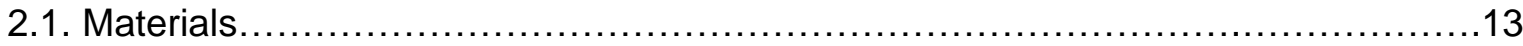

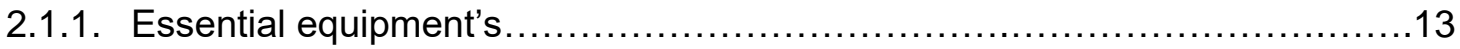

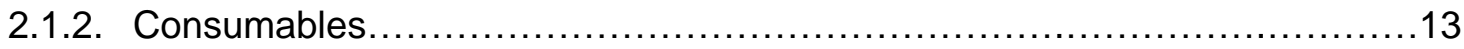

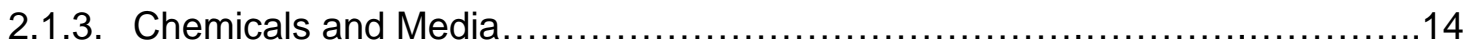

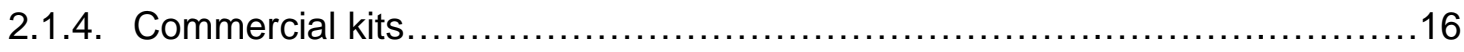

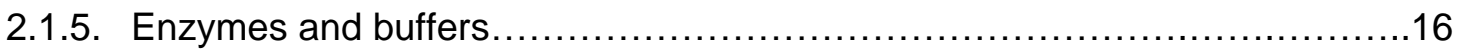

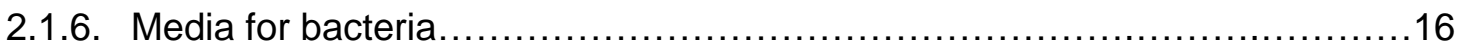

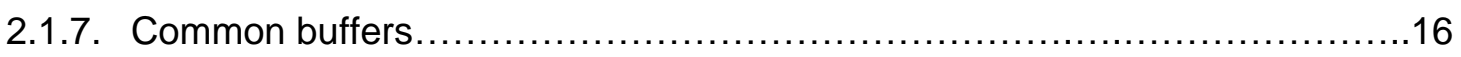

2.1.7.1. Protein lysis buffer.................................................

2.1.7.2. Immunoprecipitation buffer......................................... 17

2.1.7.3. SDS-PAGE buffer and pipetting scheme .............................17

2.1.7.4. Coomassie staining and de-staining buffer............................17

2.1.7.5. Running buffer..................................................... 18

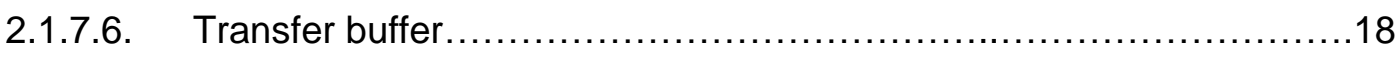

2.1.7.7. Phosphate buffered saline ......................................... 18

2.1.7.8. Buffer for blocking and antibody solution.............................18

2.1.7.9. Buffer for immunofluorescence ........................................18

2.1.7.10. Hanks buffered salt solution..............................................19

2.1.7.10.1. HBSS stock solution..............................................

2.1.7.10.2. HBSS premix solution \& full strength buffer......................19 


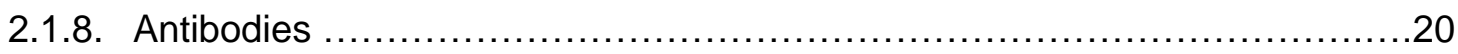

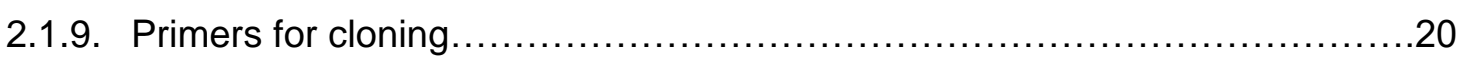

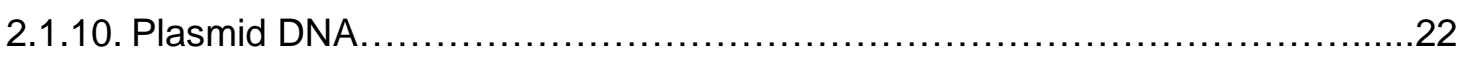

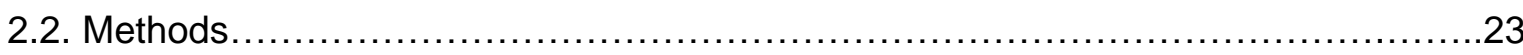

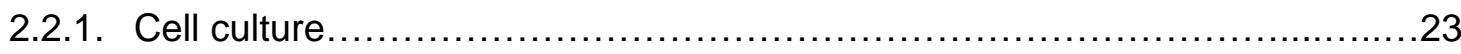

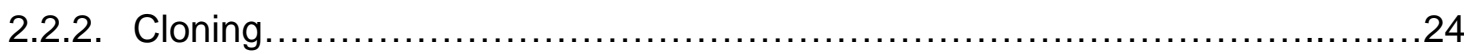

2.2.3. Dual reporter assay and read-through calculation..............................25

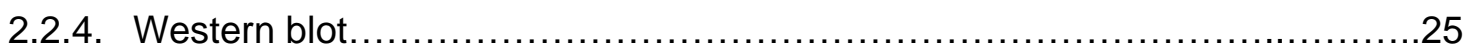

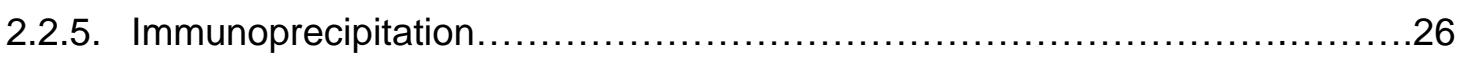

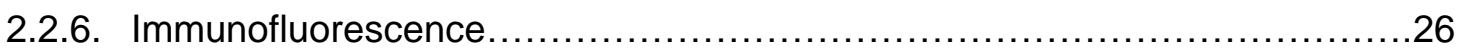

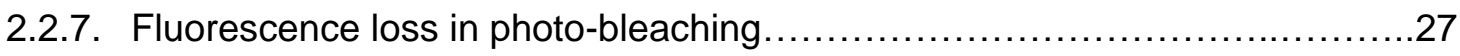

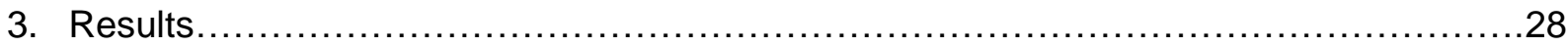

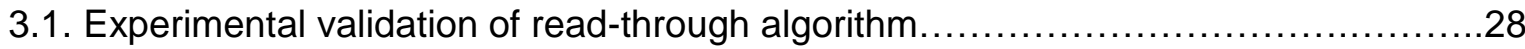

3.2. Investigation of read-through protein extension for functional domain..................31

3.3. Read-through extended LDHB has functional PTS1 .................................. 32

3.4. Read-through LDHBx piggy-backs LDHA inside peroxisomes.......................42

3.5. Detection of potential interaction partners of LDHB.................................. 47

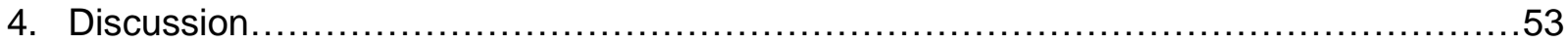

4.1. Establishing and optimizing a dual reporter assay for the experimental assessment of

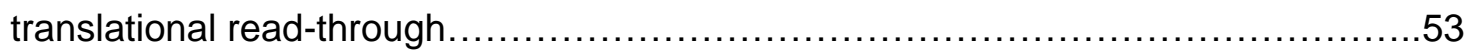

4.2. Identification of functional translational read-through by combining RTP prediction with

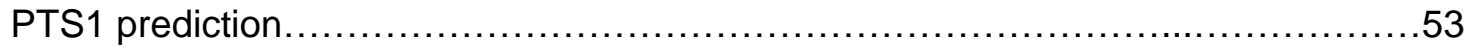

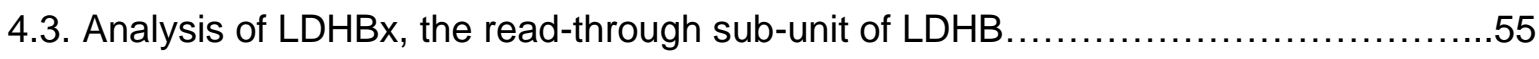

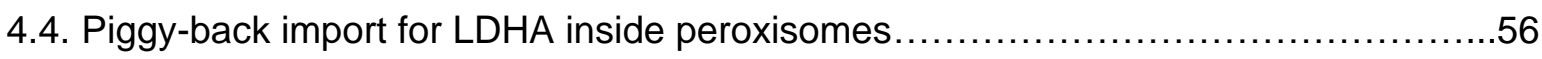

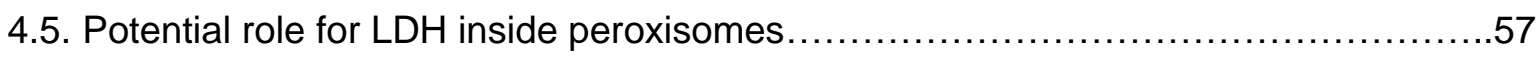

4.6. The quest for amino-acids introduced by read-through..............................57

4.7. GAPDH displays a potential for piggy-back import peroxisomes......................59

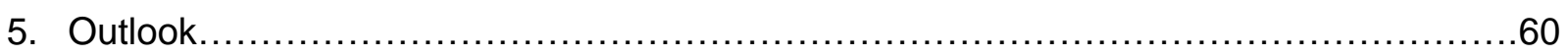

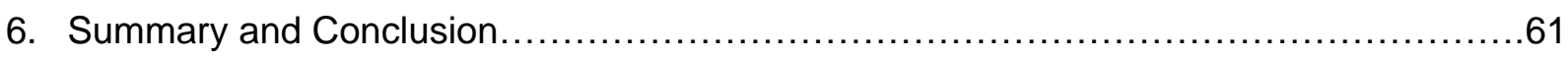

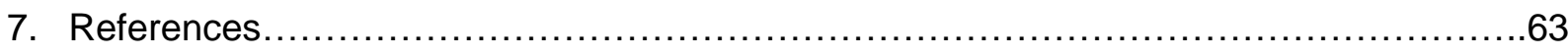

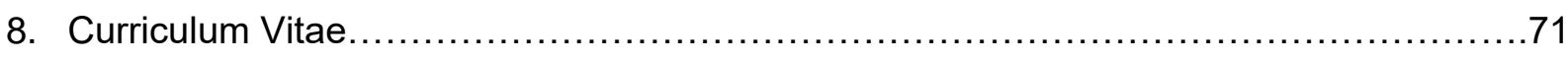




\section{ACKNOWLEDGEMENTS}

I wish to thank Prof. Dr. Jutta Gärtner and Dr. Sven Thoms for entrusting me with one of their interesting research projects, for their guidance, valuable discussions and for offering me the chance to publish my work. I thank sincerely my thesis committee members Prof. Dr. Peter Schu and Prof. Dr. Markus.T. Bohnsack for their constructive discussions and inestimable advices during the progress of my doctoral work. I am grateful to all the members of the examination board for kindly agreeing to be the Prüfungskommissions for my doctoral work. I wish to thank Dr. Thomas Lingner and Fabian Schueren for their support in the bioinformatics analysis and special thanks to Prof. Dr. Blanche Schwappach and Markus Kilisch for giving me the opportunity to use the SPR facility at the Institut für Biochemie II, Göttingen University. I appreciate and thank Dr. Andreas Olenbusch for patiently carrying out the sequencing reactions of my innumerable plasmid DNA without which I certainly would not have gathered amazing data. I profusely thank Dr. Ralf Krätzner, Dr. Julia Hofhuis, Dr. Maria Wiese, Judith Büntzel, all my Megaoffice colleagues and my friends Dr.Neethu Michael, Dr.Jetcy Arackal, Dr. Venkata Marada, Dr. Krishna Pantakani and Dr.Amandeep Singh Arora for their outstanding know-how, unlimited practical and inspirational aid as well as constant motivation that was at all times so open-heartedly given. Finally, I wish to express my sincere gratitude to Corinna Dickel, Ellen Krämer, Tanja Wilke, Kathrin Schreiber, Elisabeth Ehbrecht and Irmgard Cierny for their generous technical assistance during my doctoral work. 


\section{List of figures}

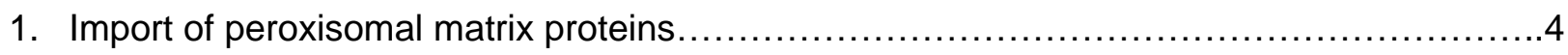

2. Multiple mechanisms of peroxisomal protein targeting .....................................

3. Mechanism of translation termination and stop codon read-through........................... 8

4. Designing of read-through propensity (RTP) algorithm .................................. 10

5. LDHB was identified to demonstrate high $\mathrm{RT}$ and peroxisome targeting probability ...........11

6. Dual reporter assay to test translational read-through selected gene candidates..............30

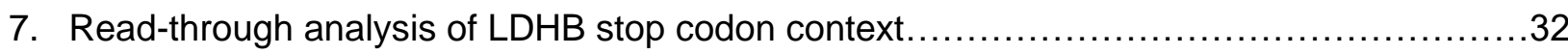

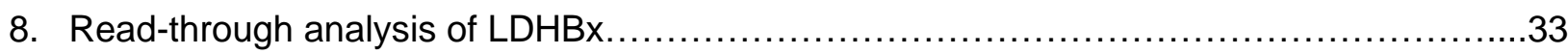

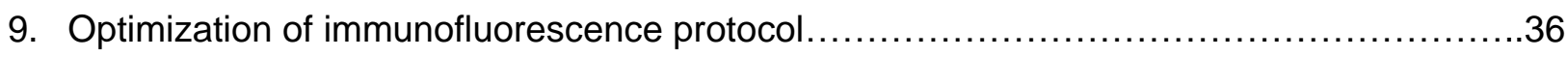

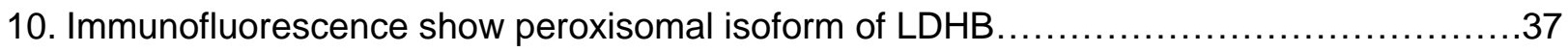

11. Exchange of stop codon affects LDHBx localisation inside peroxisomes.....................38

12. LDHBx localisation inside peroxisomes is dependent on functional PTS1 in the RT extended

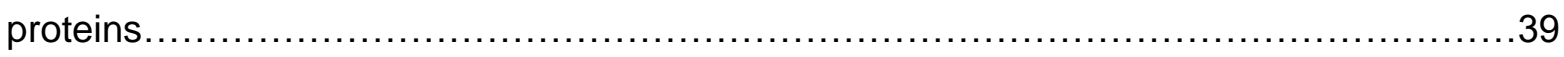

13. Peroxisomal localisation of RT extended LDHB in different cell lines.........................40

14. Peroxisomal localisation of RT extended LDHB in different cell lines..........................41

15. LDHA associates with LDHBx and localises inside peroxisomes.............................43

16. LDHA co-import inside peroxisomes is dependent on the PTS1 of the LDHBx...............44

17. Fluorescent loss in photo-bleaching shows localisation of LDHBx without LDHA.............46

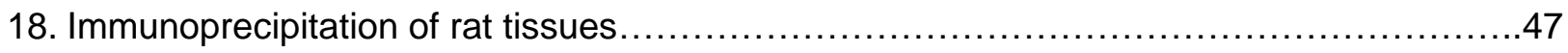

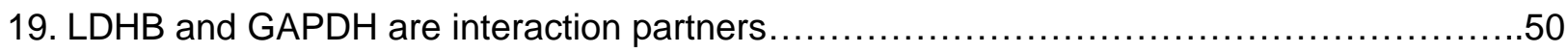

20. GAPDH localisation inside peroxisomes is dependent on RT extended LDHB...............51

21. Role of $L D H$ in recycling and shuttling of redox equivalents..................................58

\section{List of tables}

1. A list of genes obtained from the LIN in silico model which calculated the read-through

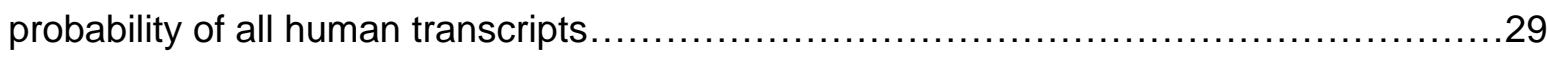

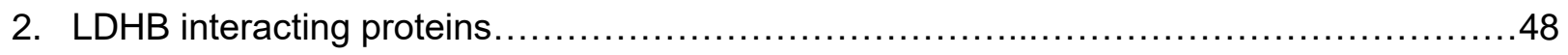




\section{Abbreviations}

\begin{tabular}{|c|c|}
\hline$\alpha$ & anti \\
\hline$\mu$ & micro \\
\hline$\mu l$ & micro \\
\hline$\%$ & percentage \\
\hline$\%(v / v)$ & percent by volume \\
\hline$\%(w / v)$ & percent by weight \\
\hline aa & amino acid \\
\hline bp & base pairs \\
\hline C & centi \\
\hline APS & ammonium persulfate \\
\hline $\mathrm{BCA}$ & bicinchonic acid \\
\hline BSA & bovine serum albumin \\
\hline C & carboxy terminal \\
\hline cDNA & complementary DNA \\
\hline CFP & cyan fluorescent protein \\
\hline $\mathrm{Da}$ & Dalton \\
\hline DAPI & 4',6-diamidino-2-phenylindole \\
\hline $\mathrm{dH}_{2} \mathrm{O}$ & distilled water \\
\hline DMSO & Dimetylsulfoxide \\
\hline DNA & Desoxyribonucleic acid \\
\hline dNTP & deoxyribonucleoside triphosphate \\
\hline DRVL & Dual reporter Venus Luciferase vector \\
\hline DTT & dithiothreitol \\
\hline EDTA & Ethylenediaminetetraacetate \\
\hline ER & endoplasmatic reticulum \\
\hline $\mathrm{EtOH}$ & Ethyl alcohol \\
\hline FBS & fetal bovine serum \\
\hline for & (primer) forward \\
\hline g & gram \\
\hline GFP & green fluorescent protein \\
\hline $\mathrm{h}$ & hours or human \\
\hline
\end{tabular}




\begin{tabular}{|c|c|}
\hline HA & hemagglutinin \\
\hline $\mathrm{HCl}$ & Hydrochloric acid \\
\hline HRP & horseradish peroxidase \\
\hline IF & immunofluorescence \\
\hline $\lg G$ & Immunoglobulin G \\
\hline $\mathrm{k}$ & kilo \\
\hline K & lysine \\
\hline $\mathrm{KCl}$ & potassium chloride \\
\hline $\mathrm{kDa}$ & kilo Dalton \\
\hline $\mathrm{KH}_{2} \mathrm{PO}_{4}$ & Monopotassium phosphate \\
\hline L & leucine \\
\hline I & liter \\
\hline LB & Luria broth \\
\hline $\mathrm{m}$ & meter or milli \\
\hline M & molar \\
\hline MCT & Mono-carboxylate transporter \\
\hline $\mathrm{MeOH}$ & methanol \\
\hline $\mathrm{mg}$ & Milligram \\
\hline $\mathrm{MgCl}_{2}$ & magnesium chloride \\
\hline $\mathrm{MgCl}_{2}$ & Magnesium chloride \\
\hline $\mathrm{MgSO}_{4}$ & Magnesium sulfate \\
\hline $\min$ & Minute \\
\hline $\mathrm{Mn}$ & manganese \\
\hline $\mathrm{mol}$ & mol \\
\hline mRNA & messenger RNA \\
\hline$N$ & amino terminal \\
\hline $\mathrm{NAD+}+\mathrm{NADH}$ & Nicotinamide adenine dinucleotide \\
\hline $\mathrm{n}$ & nano \\
\hline $\mathrm{NaCl}$ & Sodium chloride \\
\hline $\mathrm{NaOH}$ & Sodium hydroxide \\
\hline $\mathrm{nmol}$ & nano mol \\
\hline
\end{tabular}

$\mathrm{Na}_{2} \mathrm{HPO}_{4} .12 \mathrm{H}_{2} \mathrm{O} \quad$ Sodium dihydrogen phosphate dodecahydrate 


\begin{tabular}{|c|c|}
\hline NP40 & Nonidet-P40 \\
\hline$\stackrel{\circ}{\circ}$ & degree Celsius \\
\hline PBS & phosphate Buffered Saline \\
\hline PBST & phosphate buffered saline with $1 \%$ tween 20 \\
\hline PCR & polymerase chain reaction \\
\hline PFA & paraformaldehyde \\
\hline PMSF & phenylmethylsulfonyl fluoride \\
\hline PTSs & peroxisome targeting signal \\
\hline $\mathrm{R}$ & Arginine \\
\hline $\mathrm{ROI}$ & Region of interest \\
\hline rev & (primer) reverse \\
\hline $\mathrm{RF}$ & Release factor \\
\hline RIPA & radio-Immunoprecipitation Assay \\
\hline RNA & ribonucleic acid \\
\hline rpm & rounds per minute \\
\hline $\mathrm{RT}$ & reverse transcriptase or room temperature \\
\hline RTP & readthrough probability \\
\hline$S$ & serine \\
\hline$S$ & Serine \\
\hline s & Seconds \\
\hline SCC & Stop codon context \\
\hline SDS & sodium dodecyl sulfate \\
\hline SDS-PAGE & SDS polyacrylamide gel electrophoresis \\
\hline TEMED & $\mathrm{N}, \mathrm{N}, \mathrm{N}^{\prime}, \mathrm{N}^{\prime}$-Tetramethylethan-1,2-diamin \\
\hline TAE & tris-acetate \\
\hline Tris & tris-(hydroxymethyl)-aminomethane \\
\hline$U$ & unit \\
\hline UTR & untranslated region \\
\hline VS. & versus \\
\hline WT & wild-type \\
\hline
\end{tabular}




\section{$\underline{\text { Abstract }}$}

In this work, the functional significance of stop codon read-through was investigated in relation to the human peroxisomes. When the ribosomes translating a messenger RNA encounter a stop codon, they usually stop the translation leading to the release of the polypeptide chain. However, when the translation continues uninterrupted by the erroneous incorporation of an amino acid at the stop codon, it leads to stop codon read-through. Although, this process appears to generate protein variants in viruses, yeasts and fungi, it had not been clear if in human's read-through proteins have other functions than their parent proteins. Understanding the molecular mechanisms of read-through can be pivotal to treat rare genetic diseases caused due to nonsense mutations. Therefore, in our study we have developed and analysed a computational model which estimates the read-through propensity (RTP) of stop codon contexts (defined as the stop codon and approximately 12 nucleotides in its vicinity). Coupling of this model with another algorithm which predicts proteins targeted to the peroxisomes identified lactate dehydrogenase B (LDHB) variant with a high propensity for read-through and peroxisome localisation. Developing and employing reporter assays and immunofluorescence studies, we have confirmed the generation of a readthrough variant called LDHBx which has a functional peroxisome targeting signal (PTS1). Mass spectrometric analysis of LDHB immunoprecipitates from rat tissues identified glyceraldehyde -3phosphate dehydrogenase (GAPDH) as an interaction partner. Preliminary studies showed piggyback import of GAPDH inside peroxisomes in the presence of read-through extended LDHBx. We therefore conclude, that the stop codon context of LDHB trigger efficient read-through to generate protein variant with peroxisome targeting. This variant aids in co-import of non-peroxisomal

proteins such as GAPDH inside the organelle which we speculate may be involved with LDH in maintenance of redox homeostasis. 


\section{Introduction}

\subsection{The Peroxisomes}

Peroxisomes are ubiquitous organelles present in all the eukaryotes except the Archaezoa. They are single membrane bounded intra-cytoplasmic structures, spherical in shape (0.1-1 $\mu \mathrm{m})$ and are associated with various processes that are essential for the survival of most organisms. Their metabolic activity, morphology, abundance and protein composition usually vary in response to cellular demand or physiologic stimuli. (Brown and Baker, 2008; Mast et al., 2015; Platta and Erdmann, 2007; Saraya et al., 2010). The most conserved and notable tasks of peroxisomes consist of beta-oxidation of very long-chain fatty acids and metabolism of hydrogen peroxide $\left(\mathrm{H}_{2} \mathrm{O}_{2}\right)$. In plants and fungi, fatty acid metabolism is exclusively carried out in the peroxisomes while in mammalian cells, mitochondria also share the responsibility of beta-oxidation with the peroxisomes. Other well defined functions of peroxisomes include detoxification of reactive oxygen species, biosynthesis of cholesterol, bile acids and phospholipids, oxidation of amino acids, hydroxyacids and purines (Islinger et al., 2012; Smith and Aitchison, 2013; Wanders and Waterham, 2006).

In addition to their metabolic functions, peroxisomes also elicit innate immune response upon viral infection thus serving as an intra-cellular signalling platform (Dixit et al., 2010). Further, their role in cell differentiation and development is illustrated by the signalling lipids as well as the reactive oxygen and reactive nitrogen species (ROS and RNS respectively) which bind and activate a set of transcription factors. This causes a global change in the gene expression profile that influence cellular development and differentiation processes (del Rio et al., 2006; Titorenko and Rachubinski, 2004). The role of peroxisomes is further highlighted by the specialized structures called glycosomes and glyoxysomes. In the family Trypanosomatidae of the order Kinetoplastida, glycosomes harbour the major part of glycolytic enzymes that regulate metabolic pathways indispensable for the development of the parasite, their motility and their viability in the blood stream (Haanstra et al., 2015; Kalel et al., 2015). Glyoxysomes present in germinating oil seedlings and senescing leaves contain glyoxylate cycle enzymes, for mobilization of storage lipids, beta-oxidation of fatty acids and biosynthesis of hormones (Hayashi et al., 2005; Maruyama et al., 2012). A structural role for peroxisomes is presented by the highly specialized peroxisomederived organelle called Woronin bodies. These are unique organelles in filamentous ascomycetes that seal the septal pores of wounded hyphal filaments in order to prevent leakage of cytoplasmic contents (Jedd, 2011; Pieuchot and Jedd, 2012). Thus, peroxisomes are actively 
involved in a variety of tasks suggesting a continued cross-talk between different subcompartments of the cell.

The close proximity of the endoplasmic reticulum (ER) to peroxisomes in ultrastructural studies postulated that peroxisomes originate at the ER (Grabenbauer et al., 2000). Studies showed that deletion of peroxins or Pex proteins (a set of cytosolic and membrane proteins involved in peroxisome biogenesis) such as Pex3p, Pex19p or Pex16p resulted in the loss of peroxisomal structures while, their re-introduction led to de novo synthesis of peroxisomes (Hettema et al., 2000; South and Gould, 1999). Another organelle that has been closely associated with peroxisomes is the mitochondria. They not only display a metabolic co-operation by maintaining lipid homeostasis but also share key proteins for organelle division such as dynamin like GTPase DLP1/Drp1, tail anchored membrane proteins Fis1 and Mf (Schrader et al., 2012). It was observed that when the organelle division proteins were deficient it resulted in elongated peroxisomes and mitochondria. Additionally, it was observed that excessive generation of ROS inside peroxisomes negatively affected redox balance of mitochondria causing mitochondrial fragmentation (Ivashchenko et al., 2011). Moreover, severe abnormalities were observed in patient fibroblasts with a DLP1 deficiency as well as in DLP1 knock out mice (Ishihara et al., 2009). Lack of peroxisomal activity in PEX5 knock out mice caused a drastic reduction of the activities of respiratory chain complexes and collapse of the inner membrane potential of the mitochondria. Besides the abnormal structure of inner mitochondrial membrane, proliferation of smooth ER and accumulation of lysosomes and lipid droplets were also observed (Baumgart et al., 2001; Dirkx et al., 2005).

Furthermore, the significance of this vital organelle in humans is emphasised by rare genetic disorders caused due to impairment in peroxisomal functions. These disorders are classified into the following two groups including (1) the peroxisome biogenesis disorders (PBDs) and (2) the single peroxisomal enzyme deficiencies. The PBDs include Zellweger syndrome (ZS), neonatal adrenoleukodystrophy (NALD), infantile Refsum disease (IRD) and rhizomelic chondrodysplasia punctata (RCDP) type 1 . The single enzyme deficiencies comprise $\mathrm{X}$-linked adrenoleukodystrophy and adrenomyeloneuropathy, D-bifunctional protein deficiency, Refsum disease, rhizomelic chondrodysplasia punctata (RCDP) type 2 and type 3 (Braverman et al., 2015; Poll-The and Gartner, 2012; Thoms et al., 2009). The cells and tissues of patients suffering from above mentioned peroxisomal disorders accumulate very long chain fatty acids (VLCFA), display abnormal pipecolic acid levels in urine (Peduto et al., 2004), demonstrate elevated levels of dihydroxycholestanoic acid (DHCA) and trihydroxycholestanoic acid (THCA) in blood and urine 
(Wanders and Waterham, 2006) and show a reduction in erythrocyte plasmalogens (Steinberg et al., 2006). Patients are mostly infants and children who manifest severe developmental malformations of the vital organs leading to life-threatening multiple organ failures eventually resulting in their death at a very young age. These tiny organelles thus play a pivotal role either directly or indirectly in human physiology which necessitates study of the mechanistic details of peroxisome biogenesis, its interaction and co-operation with other sub-cellular organelles and protein targeting mechanisms. The current study is focussed on understanding aspects of protein targeting in peroxisomes.

\subsection{Peroxisomal Protein Targeting}

Peroxisomes lack DNA and hence all peroxisomal proteins are encoded in the nucleus. The matrix proteins and membrane proteins are synthesized on cytosolic ribosomes and are imported posttranslationally. The matrix proteins are directly targeted to the organelle lumen whereas some membrane proteins reach the peroxisomes via the ER (Johnson and Olsen, 2001; Kim and Hettema, 2015; Miyata and Fujiki, 2005; Platta et al., 2005; Purdue and Lazarow, 2001). Peroxisome membrane proteins (PMPs) interact with the Pex19p receptor in the cytosol and then docks the receptor-cargo complex to the anchor proteins Pex3p or Pex16p (Pinto et al., 2006; Sacksteder et al., 2000). An alternative route for targeting of PMPs is by integrating into the ER membrane via the Sec61 translocon and the GET complex followed by a vesicular transport into the peroxisomal membrane (Thoms et al., 2012; van der Zand et al., 2010).The import of matrix proteins engage peroxisome targeting signal (PTS), either a PTS1 consisting of a carboxy-terminal tripeptide prototype SKL or sequence variants thereof or a PTS2 with consensus sequence $(\mathrm{R} / \mathrm{K}) /(\mathrm{L} / \mathrm{V} / \mathrm{I}) \mathrm{X5}(\mathrm{H}(\mathrm{Q}))(\mathrm{L} / \mathrm{A})$ at the amino-terminal (Dammai and Subramani, 2001; Legakis and Terlecky, 2001; Liu et al., 2012; Ma and Subramani, 2009; Subramani, 1998). The import of peroxisomal matrix proteins is illustrated in figure1. The PTS1 receptor Pex5 or PTS2 receptor Pex7 interacts with the cargo proteins in the cytoplasm, docks at the docking complex consisting of Pex7, Pex13 and Pex14 and is then integrated into the peroxisomal membrane to form the transport channel aided by Pex14. Upon release of cargo protein, the receptors Pex5 or Pex7 are ubiquitiylated and recycled back in an ATP-dependent manner.

Interestingly, proteins that do not contain either a PTS1 or PTS2 are also sorted to the peroxisomes by a non-classical targeting mechanism called piggy-back import. It was shown in Saccharomyces cerevisiae that $\mathrm{N}$-terminal truncated 3-ketoacylCoA thiolase lacking the PTS2 was mislocalised to cytosol however, upon co-expression with full length thiolase the dimers were associated with peroxisomes (Glover et al., 1994). Similarly, the non-PTS1 subunit of bacterial 


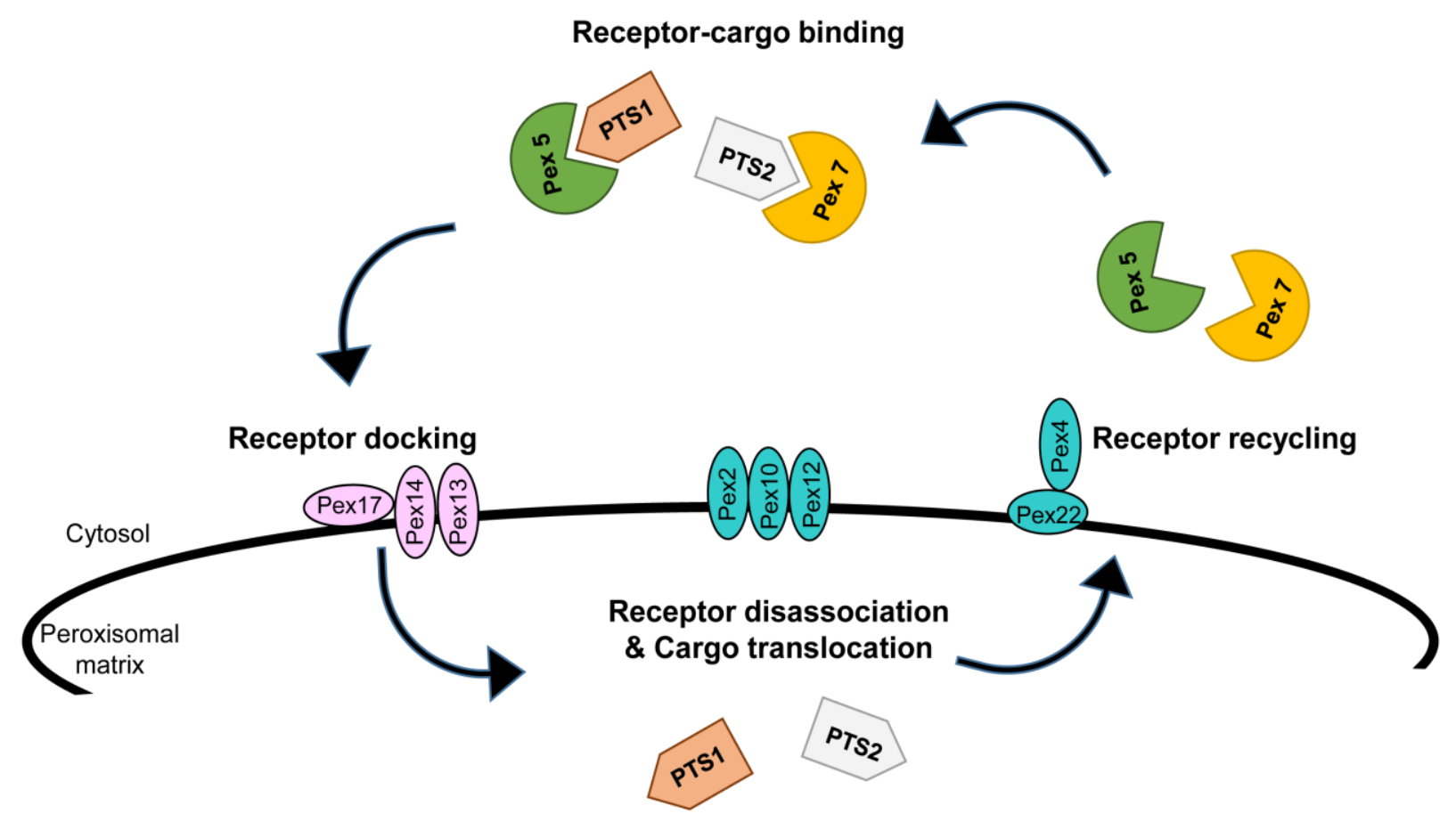

Figure 1: Import of peroxisomal matrix proteins. The import of matrix protein containing the peroxisomal targeting signals (PTS1) or (PTS2)-containing cargo is shown here. The cargo proteins interact with the PTS1 receptor Pex5 or PTS2 receptor Pex7 in the cytoplasm and they are transported to the surface of peroxisomes. Here the docking complex consisting of Pex17, Pex13 and Pex14 intercepts the receptorcargo complex. A transport pore consisting of Pex2, Pex10 and Pex12 aids in the disassociation of receptor and release of cargo into the peroxisomal matrix. The PTS1 or PTS2 receptors are then recycled back into the cytosol with the help of Pex22 and Pex4 proteins. Pex, peroxin. Receptor is either Pex5 or Pex7 and cargo is either PTS1 or PTS2. The figure is adapted from (Smith and Aitchison, 2013)

chloramphenicol acetyltransferase (CAT) formed heterotrimers in the cytosol with CAT-G9-AKL (PTS1 with nine glycines) before translocating to the peroxisomes (McNew and Goodman, 1994). Other enzymes that demonstrate piggy-back import are homo-oligomers of castor bean isocitrate lyases (Parkes et al., 2003), hetero-oligomers of Dci1p and Eci1p (Yang et al., 2001) and peroxisomal malate dehydrogenase (MDH3) (Elgersma et al., 1996). Piggy-back import of proteins also supports the argument that proteins in folded or oligomeric state could be transported across the peroxisomal membrane (McNew and Goodman, 1996).

Although, sorting of proteins to different sub-compartments of cell is governed by recognition of defined targeting motifs by specific receptors some protein isoforms use various mechanisms to acquire multiple targeting (figure 2). Specifically, enzymes that maintain redox homeostasis 
commonly exhibit dual localization. Malate dehydrogenase and NADPH dependent isocitrate dehydrogenase in Saccharomyces cerevisiae generate three distinct isoforms encoded by different genes that localize them in the cytosol, mitochondria and peroxisome. These isoforms not only adopt different functions and possess different enzyme kinetics but also they are regulated differently at the transcriptional level (Ast et al., 2013; Henke et al., 1998; Steffan and McAlister-Henn, 1992). Likewise, NADP dependent isocitrate dehydrogenase in Aspergillus

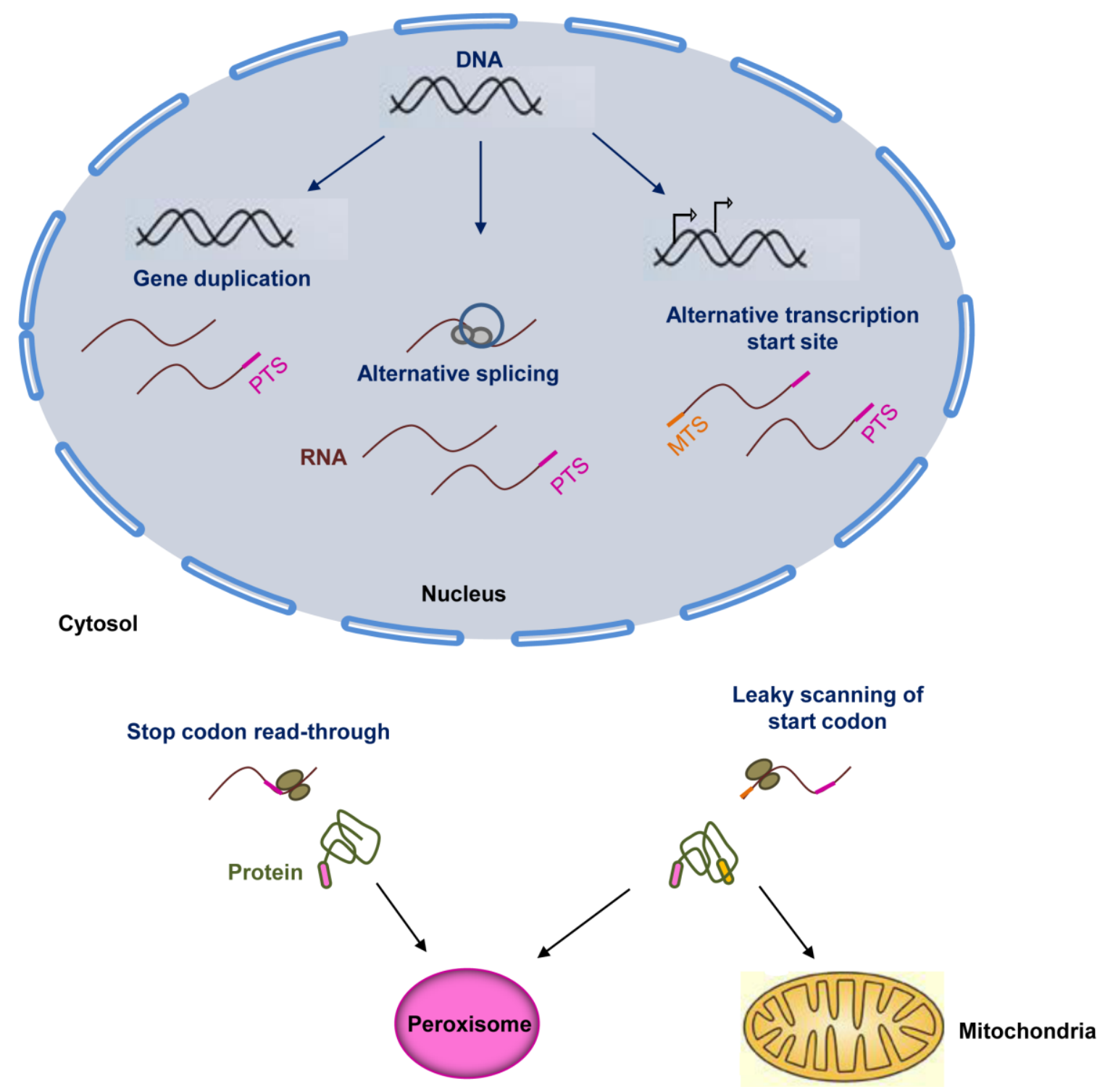

Figure 2: Multiple mechanisms of peroxisomal protein targeting. The figure shows different mechanisms used by the cell to achieve multiple targeting of peroxisomal proteins. Gene duplication generates a copy of gene containing a peroxisome targeting signal (PTS). Post-transcriptional processes such as alternative splicing or alternative transcription initiation generates transcripts from a single gene 
Introduction

that may contain multiple targeting signals such as PTS or mitochondrial targeting signal (MTS). Similarly, stop codon read-through or leaky scanning of initiation codons are other mechanisms used to achieve dual or multiple localization. PTS are indicated in pink while MTS are indicated in yellow. The figure is adapted from (Ast et al., 2013).

nidulans uses a single gene but two transcription start points to generate a shorter isoform with a PTS1 and a longer isoform containing a mitochondrial targeting signal (MTS) at the N-terminal and a C-terminal PTS1. In situations like these where two competing targeting signals are present the protein products are most likely to be targeted to the mitochondria due to the dominance of $\mathrm{N}$ terminal sequences (Danpure, 1997; Szewczyk et al., 2001). In rare occasions however, environmental factors can also influence the competing targeting signals and direct the protein localization. For instance, in case of the enzyme Catalase A of Saccharomyces cerevisiae when cultured in peroxisome inducing oleate rich medium, maximum beta-oxidation and an increased $\mathrm{H}_{2} \mathrm{O}_{2}$ production was demonstrated that in turn favoured peroxisome targeting. Conversely, when grown on non-fermentable carbon source such as raffinose, Catalase A was co-targeted to the mitochondrial matrix despite the absence of an N-terminal MTS (Petrova et al., 2004). Yet another mechanism which facilitate partial localization of cytosolic proteins to peroxisomes is stop codon read-through $(R T)$. Pathogenic fungi demonstrated the glycolytic enzymes glyceraldehyde 3phosphate dehydrogenase (GAPDH), phosphoglycerate kinase (PGK) and triose-phosphate isomerase (TPI) localised inside peroxisomes by translational RT (Ast et al., 2013).In the following section, the mechanism of translational RT or stop codon RT is explained in detail.

\subsection{Stop codon read-through}

Stop codons (TAA, TAG and TGA) are important signals for the ribosome to stop the translation of mRNA transcript and therefore translation termination is as important as the initiation of protein synthesis (Beznoskova et al., 2015). Termination of polypeptide chain synthesis is signalled by occurrence of one of the three non-sense codons in both prokaryotes and eukaryotes and are discussed here separately. In prokaryotes, two classes of peptide release factors (RF) are involved. Class I release factors, RF1 and RF2 identifies the stop codons (TAA/TAG) and (TAA/TGA) respectively in the ribosome A site, trigger the hydrolysis of the peptidyl-tRNA bond and release the newly synthesised polypeptide chain. After the release of nascent polypeptide chain, class II RF3 induces a conformational change in the ribosome leading to the recycle of RF1 or RF2 in a GTP-dependent manner (Gao et al., 2007; Zavialov et al., 2002). In contrast, release factor eRF1 precisely recognizes all three stop codons in eukaryotic cells. The release factor, 
Introduction

eRF3 forms a complex with eRF1 and facilitate translation termination through a GTP-dependent mechanism (Jackson et al., 2012; Loh and Song, 2010; Mitkevich et al., 2006; Uchida et al., 2002).

Translation termination is quite an efficient process with minimal error in the range of $0.001 \%-$ 0.1\% (Keeling et al., 2004; Loftfield and Vanderjagt, 1972; Stansfield et al., 1998). When a stop codon is in the ribosomal A-site, polypeptide chain release factors are summoned which specifically bind to these stop codons and mediate release of the polypeptide chain by hydrolysing the bond between peptidyl-tRNA and the polypeptide (figure 3A). However, when stop codon is suppressed by natural suppressor tRNAs or cellular tRNAs amino acids are erroneously incorporated into the polypeptide chain continuing translation until the next in-frame stop codon is encountered (see figure 3B). In recoding events where non-standard amino acid such as selenocysteine is incorporated, specific tRNA and particular elongation factor is required suggesting that translational recoding is not accidental but programmed (Bertram et al., 2001; Bidou et al., 2012; Cassan and Rousset, 2001; Dabrowski et al., 2015; von der Haar and Tuite, 2007). Viruses deliberately employ RT of their stop codon to expose their C-terminal domain and expand their limited genome (Beier and Grimm, 2001). Using this mechanism more than one protein isoforms can be generated from a single gene thus providing a regulatory mechanism of gene expression. For instance, in RNA phage Q $\beta$ the stop TGA is decoded by tRNA Trp to yield an elongated coat protein essential for viral propagation (Weiner and Weber, 1973). Likewise, for normal propagation of murine leukaemia virus (MuLV) in animal tissue expression of gag-pol fusion polypeptide is mediated by the suppression of TAG stop by inserting amino acid glutamine (Beier et al., 1984; Bradley and Craigie, 2003; Yoshinaka et al., 1985). In the yeast $S$ cerevisiae either mutations in genes encoding release factors eRF1(Sup45) or eRF3 (Sup35) or conversion of eRF3 to prion form modulates translation termination thus displaying an epigenetic control (Keeling et al., 2004).

This led several researchers to investigate the parameters that compromise translational termination. It was observed that the rate of stop suppression is highly influenced by the stop codon and surrounding nucleotide sequence. RT of stop codons TGA and TAG have been reported in prokaryotes and eukaryotes but there is not much evidence about read-through of TAA stop codon (Engelberg-Kulka and Schoulaker-Schwarz, 1988). Also, it has been shown that context nucleotides can contribute to the leakiness of stop codon by altering efficiency of termination process (Bonetti et al., 1995; Namy et al., 2001). For instance, the stop codon TGA show highest level of read-through and the leakiness is modulated by the presence of cytosine (C) nucleotide in the position immediately after stop codon making TGA C the leakiest stop 
Introduction
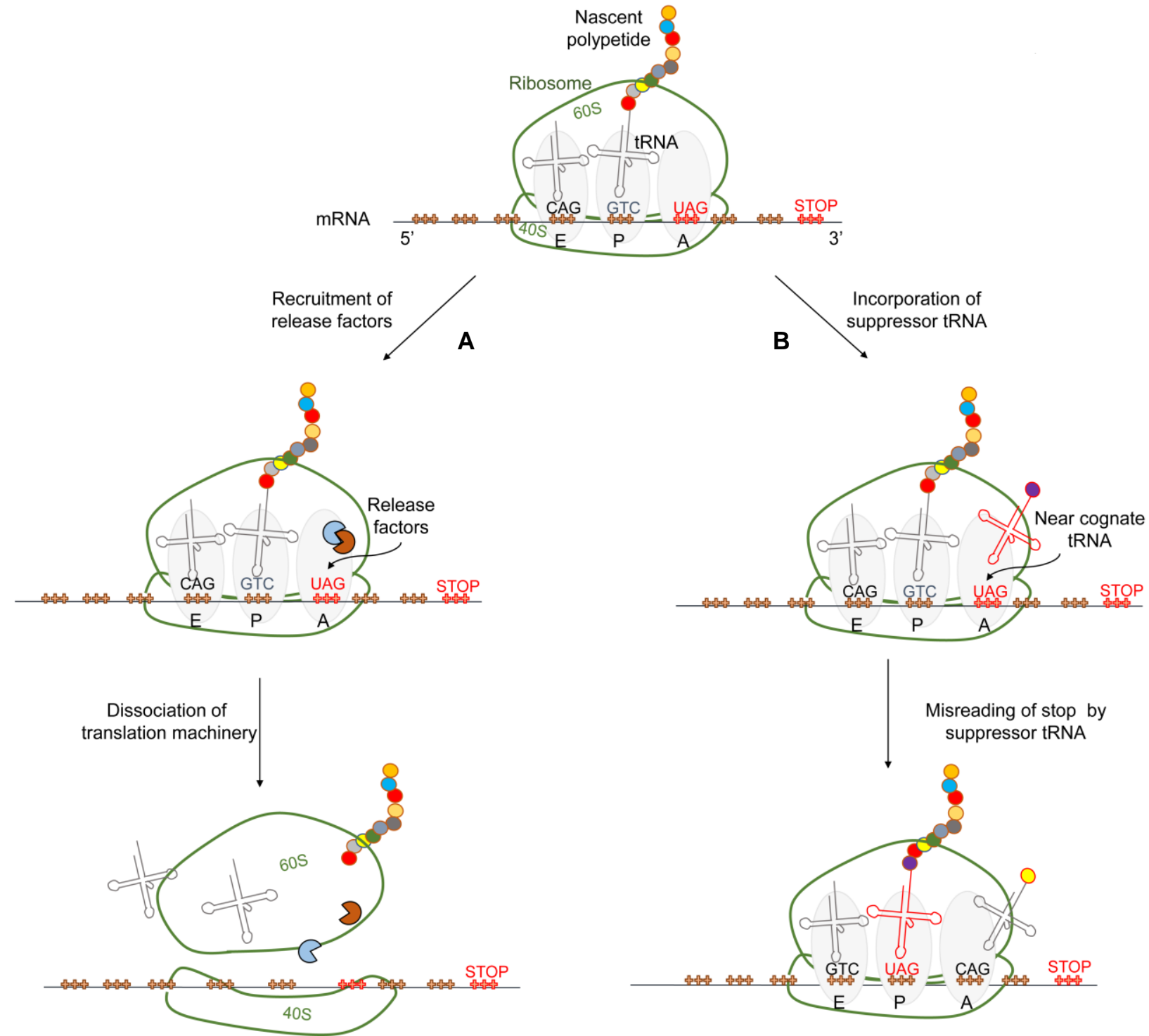

Figure 3: Mechanism of translation termination and stop codon read-through. A) When ribosome encounters a termination codon (UGA) in its A-site, no tRNAs recognizes the stop codon and instead protein release factors are recruited. Release factors recognizes the stop signal and cause release of nascent polypeptide chain. This dissociates the translation machinery and brings the protein synthesis to a halt. B) Alternatively, when a near-cognate tRNA competes with release factors and recognizes stop codon it misreads the stop signal and decodes the termination codon as sense codon. Ribosome thus continues translation in the same reading frame until the next stop codon is encountered resulting in the synthesis of an extended polypeptide. A-site is the acceptor site for amino acyl tRNA. P-site is the peptidyl-tRNA site which accommodates the growing polypeptide chain. E-site is the exit site for discharged tRNA. Stop codon and near cognate tRNA are indicated in red. 
codon context (Floquet et al., 2012). Studies carried out in Drosophila melanogaster also showed similar findings with a very high incidence of RT in genes containing TGA C stop codon context (Jungreis et al., 2011).

Examples of other determinants that influenced stop suppression were presence of selenocysteine insertion sequence (SCIS) in the 3'- untranslated region (UTR), the acidic/basic property of the last two amino acids in the nascent polypeptide chain, the concentration of tRNA or release factors (Mottagui-Tabar et al., 1994; Mottagui-Tabar et al., 1998) or presence of two adenine $(A)$ residues in the ribosome P-site upstream of the stop codon (Tork et al., 2004). Compounds such as aminoglycoside antibiotics (gentamicin, geneticin, negamycin) induce the binding of near cognate tRNA to the stop codon inserting random amino acids and thus proceed with translation beyond the stop codon in the same reading frame (Keeling and Bedwell, 2011). Several compounds have been evaluated for their potential to suppress premature termination codon (PTC) in cells from patients suffering from cystic fibrosis, muscular dystrophy, Hurler syndrome and ataxia-telangiectasia which led to the development of nonsense suppression therapies. Low-molecular weight compounds were used to recode a nonsense codon into a sense codon (Bedwell et al., 1997; Du et al., 2009; Du et al., 2002; Howard et al., 2000; Keeling et al., 2001). Analysis of the susceptibility of stop codons to induce RT in the presence of these antibiotic drugs showed that the TAG or TAA stop codons were miscoded to glutamine while tryptophan was inserted at the TGA codon (Brooks et al., 2006; Nilsson and Ryden-Aulin, 2003; Perez et al., 2012).

Therefore, it is important to study the basal RT ability of human genes to understand molecular mechanisms at play that can be exploited to treat rare genetic diseases caused due to nonsense mutations. In this direction we developed a computational algorithm that predicts read-through propensity (RTP) of human genes which led to the observation that the nucleotide consensus motif (TGA CTA G) favoured high basal read-through (Schueren et al., 2014).

\subsection{Development of read-through prediction algorithm}

To develop the algorithm that predicted RTP of human genes stop codon contexts (SCCs) of 200,000 transcripts from Ensemble database were analysed. For evaluation, 15 nucleotides 
consisting of three nucleotides of the stop codon and six nucleotides upstream and downstream of the stop codon were considered. The SCCs were formalized using a binary vector that represented it in 51-dimensional vector space. Regression coefficients were calculated between the SCCs and their experimental RT frequencies to develop LIN model (first model trained with experimental values of 66 sequences from human non-sense mutations) and an improved LINiter model (second model trained with 66+15 additional candidates) which assigned RTP score for a particular stop context by adding up the position-specific regression coefficients. This developed model was then applied to predict RTP of the SCC of the whole transcriptome (Schueren et al., 2014). The flow chart below (figure 4) describes step by step development of the RT prediction algorithm. The RTP algorithm was then coupled with a PTS1 prediction algorithm which scanned for a potential peroxisome targeting signal in the C-terminal extensions of the RT proteins. A plant PTS1 prediction tool was already available which predicted stress inducible, low abundant and novel peroxisomal proteins in agronomically important plants. Classification of proteins, by the PTS1 tool, as peroxisomal or non-peroxisomal were based on the targeting ability of the amino acid sequences, experimental validation of the PTS1 tripeptide and position specific score for a particular amino acid residue in the C-terminal of the protein (Lingner et al., 2011; Reumann et al., 2012).
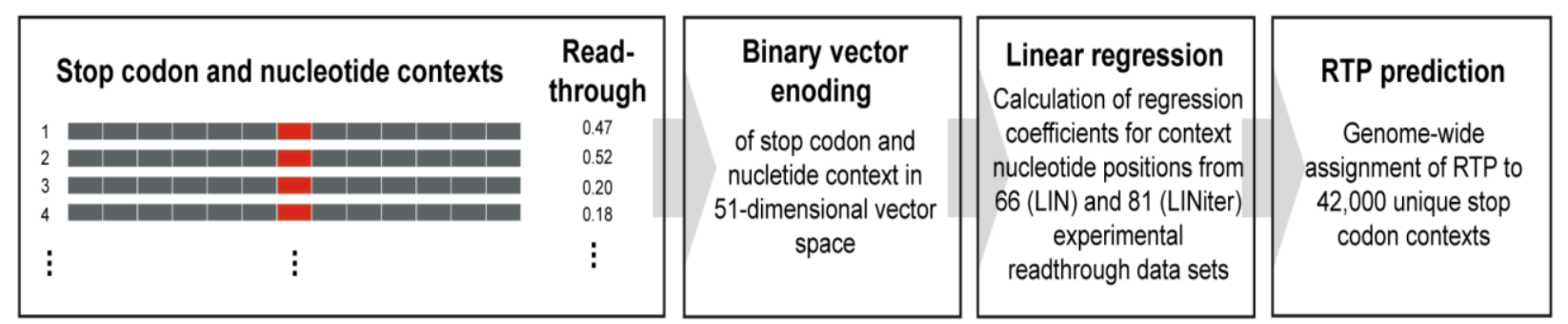

Figure 4: Designing of read-through propensity (RTP) algorithm. The stop codon (red blocks) and the neighbouring six nucleotides (grey blocks) upstream and downstream of the stop codon were selected to develop the prediction algorithm. Using binary vector encoding the stop codon and nucleotide context surrounding the stop were represented in 51 dimensional vector space. Regression coefficients for stop contexts were calculated from experimental read-through values which were then used to assign RTP score for a particular stop context by adding up the position-specific regression coefficients. Using this prediction tool the RTP of the whole genome was evaluated. The figure is taken from our publication (Schueren et al., 2014).

We first adapted the plant PTS1 prediction tool to classify human peroxisomal proteins by assigning a PTS1 posterior probability score. This was done by conducting orthologue searches 
on 24 known human PTS1 sequences. Then we coupled the two algorithms resulting in combined RTP and PTS1 scores, to predict peroxisomal proteins in humans generated by stop codon RT (Schueren et al., 2014). This combined model projected lactate dehydrogenase-B (LDHB) as a top RT candidate with high RTP and PTS1 scores (figure 5A). The presence of a well-known cytosolic protein, LDHB, inside the peroxisomes has been known for many years but its entry into the peroxisomal matrix despite lacking a targeting signal was intriguing (Baumgart et al., 1996; Gronemeyer et al., 2013; McClelland et al., 2003). Using our RTP*PTS1 algorithm, we may have identified a hitherto unknown targeting signal in the RT extended LDHB (henceforth LDHBx) protein. Our observation was also supported by the orthologue analysis of LDHBx in vertebrates where we identify a conserved stop codon (TGA) and a conserved PTS1 sequence (SRL or sequence variants) in the RT extension of LDHBx (figure 5B).
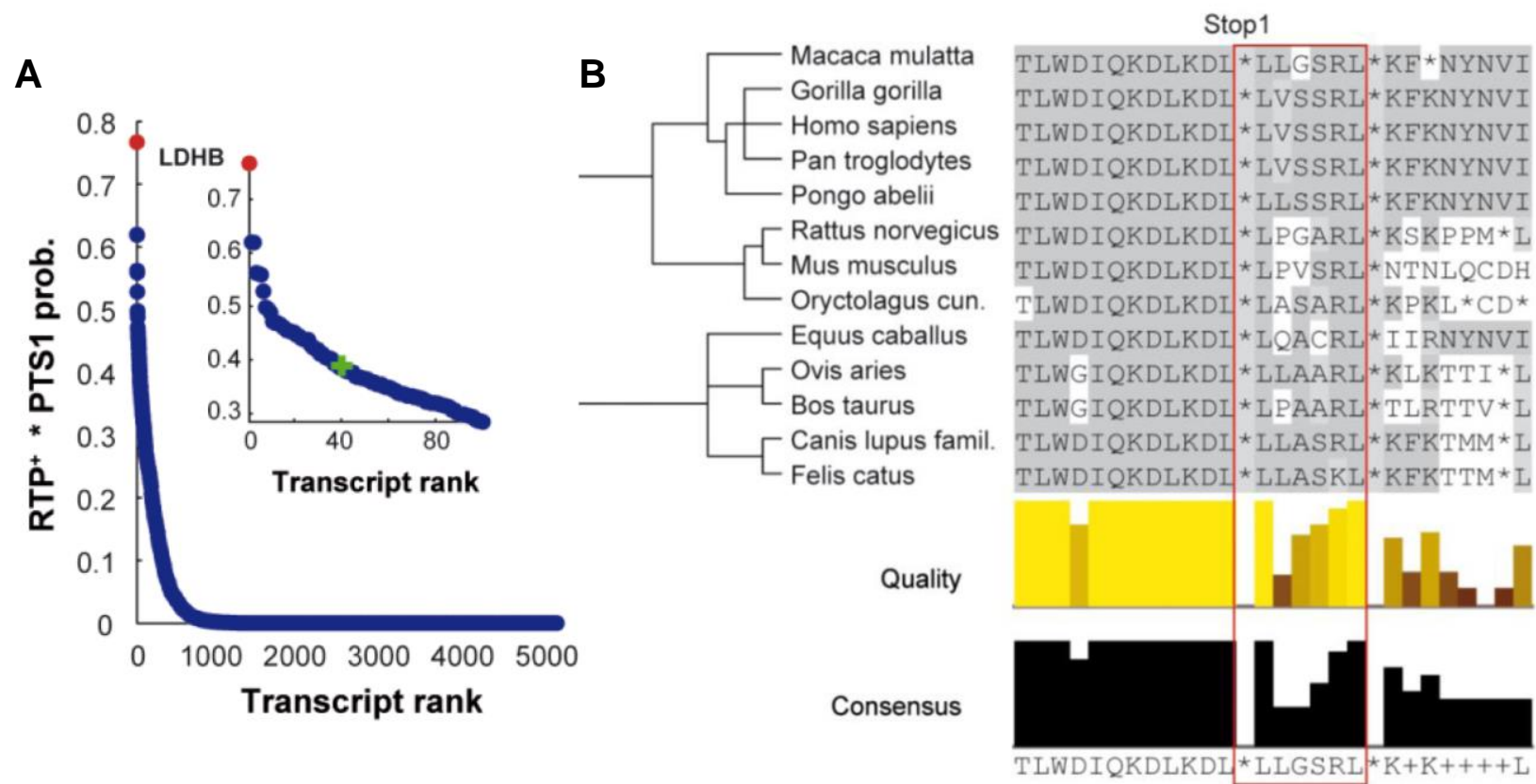

Figure 5: LDHB was identified to demonstrate high RT and peroxisome targeting probability. A) The RTP*PTS1 algorithm evaluated the stop codon and surrounding nucleotides for RT probability while the PTS1 algorithm scanned for potential peroxisomal targeting signal in the RT extension of the proteins. Based on the RTP and PTS1 scores the SCC of LDHB exhibited high probability of RT and the extension of LDHBx acquires a high possibility of getting targeted into the peroxisomes. B) Orthologue analysis of LDHBx showed that the stop codon (indicated by *) and the PTS1 sequence SRL or sequence variants) is highly conserved in all the mammals. The figure is taken from our publication (Schueren et al., 2014). 
Introduction

\subsection{Aim of the study}

The objectives of the study are:

- To validate the RTP algorithm by analysing the read-through potential of SCCs of predicted candidate genes in vivo by using a dual reporter vector.

- To generate stop codon mutants of LDHB and compare the efficiency of stop suppression.

- To establish a new assay for the detection of low abundance peroxisomal proteins.

- To examine the sub-cellular localization of LDHBx generated as a result of read-through by employing stop codon mutants and PTS1 mutants of LDHBx.

- To employ proteomics approach and characterize the role of LDHBx inside the peroxisomes. 


\section{Materials and Methods}

\subsection{Materials}

\subsubsection{Essential Equipment}

\begin{tabular}{|c|c|c|}
\hline Appliance & Description & Company \\
\hline $\begin{array}{l}\text { Agarose gel electrophoresis } \\
\text { chamber }\end{array}$ & Agarose gel tank & peQLab Biotechnologie $\mathrm{GmbH}$ \\
\hline BioDoc Analyse & Agarose gel imager & Biometra \\
\hline Centrifuges & Eppendorf 5424 \& 5417R & Eppendorf \\
\hline Gel electrophoresis chamber & Mini-PROTEAN® Tetra cell & Bio-Rad Laboratories \\
\hline Heating block & TB2 Thermoblock & Biometra \\
\hline Haemocytometer & Nueubar chamber $(0.1 \mathrm{~mm})$ & Marienfeld-Superior \\
\hline Incubator & $37^{\circ} \mathrm{C}, 5 \% \mathrm{CO}_{2}$ & Memmert \\
\hline Laminar- flow hoods & HERA safe & Thermo Fisher Scientific \\
\hline Luminescent image reader & LAS-4000 mini & Fujifilm \\
\hline Microplate reader & 96 well micro-plate reader & Biotek SynergyMx \\
\hline Microscope & $\begin{array}{c}\text { AxioimagerM1, Plan Neofluar } \\
\text { 100x/1.3 Oil lens }\end{array}$ & Carl-Zeiss \\
\hline Nanodrop & ND-1000 spectrophotometer & Thermo Fisher Scientific \\
\hline $\mathrm{pH}$ meter & Schott gerät CG 820 & Gemini BV \\
\hline Rocking platform & & Biometra \\
\hline Semi-dry blot & & Biometra \\
\hline Thermocycler & T3000, T3 & Biometra \\
\hline Thermomixer & Compact & Eppendorf \\
\hline TissueRuptor & $\begin{array}{c}\text { Handheld rotor-stator } \\
\text { homogenizer }\end{array}$ & Quiagen \\
\hline Vortex mixer & & Benden \&Hobein \\
\hline Water bath & & Memmert \\
\hline
\end{tabular}

\subsubsection{Consumables}

\begin{tabular}{|cl|}
\hline Description & Company \\
\hline $15 \mathrm{ml} \& 50 \mathrm{ml}$ tubes & BD Falcon \\
\hline 96 well micro-plates & Greiner Bio-One \\
\hline Blotting paper sheet & Sartorius Stedim \\
\hline CELLSTAR $\AA 10 \mathrm{~cm}$ tissue culture plates & Sarstedt AG \& Co \\
\hline CELLSTAR $\AA 12$-well cell culture plates & Sarstedt AG \& Co \\
\hline
\end{tabular}




\begin{tabular}{|c|c|}
\hline CELLSTAR® 24-well cell culture & Sarstedt AG \& Co \\
\hline CELLSTAR® 6-well cell culture plates & Sarstedt AG \& Co \\
\hline $\begin{array}{l}\text { CELLSTAR } \circledast \text { Filter Top cell culture flasks } \\
\qquad\left(25 \mathrm{~cm}^{2}, 75 \mathrm{~cm}^{2}, 125 \mathrm{~cm}^{3}\right)\end{array}$ & Sarstedt AG \& Co \\
\hline Disposable scalpel No.21 & Feather \\
\hline Insulin syringes & Braun AG \\
\hline Microscope Cover Glasses (12mm) & $\begin{array}{c}\text { Thermo Fisher Scientific (Menzel- } \\
\text { Gläser) }\end{array}$ \\
\hline Microscopic Slides & $\begin{array}{c}\text { Thermo Fisher Scientific (Menzel- } \\
\text { Gläser) }\end{array}$ \\
\hline Nitrocellulose blotting membrane & GE Healthcare \\
\hline Parafilm & Pechiney Plastic Packaging \\
\hline Pipette-tips, Tip One®, (Blue/Yellow/White) & Sarstedt AG \& Co \\
\hline Reaction tubes $(1.5 \mathrm{ml})$ & Sarstedt AG \& Co \\
\hline Reaction tubes (2 ml) & Sarstedt AG \& Co \\
\hline Round bottom Polystyrene tubes (14 ml) & Greiner Bio-One \\
\hline Serological pippetes $(5 \mathrm{ml}, 10 \mathrm{ml}, 25 \mathrm{ml})$ & Sarstedt AG \& Co \\
\hline
\end{tabular}

\subsubsection{Chemicals and Media}

\begin{tabular}{|cc|}
\hline Description & Company \\
\hline $20 \%$ SDS ultra-pure & Gibco \\
\hline $4^{\prime}$ 6-Diamidin-2-phenylindol (DAPI) & Sigma \\
\hline Acrylamide (Rotiphorese Gel 30, (37,5:1) & Roth \\
\hline Agarose & Bioline \\
\hline Albumin - Fraction V & Roth \\
\hline Ammonium persulfate (APS) & Serva \\
\hline Ampicillin & Roth \\
\hline Bovine serum albumin (BSA) & Sigma \\
\hline Bromophenol blue & Merck \\
\hline Diethyl pyro carbonate (DEPC) & Sigma \\
\hline Digitonin (5\%) & Invitrogen \\
\hline Dimethyl sulfoxide (DMSO), molecular biology grade & SERVA \\
\hline Dithiothreitol (DTT) & Serva \\
\hline dNTP-Set 'Long Range` & peQLab \\
\hline Dulbecco's Phosphate Buffered Saline \\
(PBS) without Ca2+/Mg2+ & Biochrome Gmbh \\
\hline $\begin{array}{c}\text { Dulbecco's Modified Eagle Medium } \\
\text { (DMEM) 1g/L D-glucose }\end{array}$ & Biochrome Gmbh \\
\hline
\end{tabular}




\begin{tabular}{|c|c|}
\hline Ethanol & Merck \\
\hline Ethylenediaminetetraacetic acid (EDTA) & Roth \\
\hline Fetal Bovine Serum & Merck \\
\hline Formaldehyde (37\%) & Roth \\
\hline Formamide, genetic analysis grade & Applied Biosystems \\
\hline GelRed Nucleic Acid Stain & Biotrend \\
\hline Gene Ruler DNA Ladder Mix & Fermentas \\
\hline Glycine & Roth \\
\hline Isopropanol & Merck \\
\hline Kanamycin & Roth \\
\hline Laminin & Sigma \\
\hline L-Glutamine (20mM) & GE Healthcare \\
\hline Lumi-Light Plus Western blot substrate & Roche \\
\hline Luria Agar & Sigma \\
\hline Luria Broth & Sigma \\
\hline Magnesium chloride $\left(\mathrm{MgCl}_{2}\right)$ & Roche \\
\hline Magnesium sulfate $\left(\mathrm{MgSO}_{4}\right)$ & Roth \\
\hline Methanol & J.T. Baker \\
\hline Milk powder & Roth \\
\hline Mowiol & Calbiochem \\
\hline $\mathrm{N}, \mathrm{N}, \mathrm{N}^{\prime}, \mathrm{N}^{\prime}$-Tetramethylethan-1,2-diamin (TEMED) & Roth \\
\hline Nonidet P40 Solution & Fluka \\
\hline Page Ruler Prestained Protein Ladder & Fermentas (Thermo-Scientific) \\
\hline Penicillin-Streptomycin $(10,000 \mu \mathrm{g} / \mathrm{ml})$ & Merck \\
\hline Phenylmethylsulfonyl fluoride (PMSF) & AppliChem \\
\hline Poly-L-Lysine & Sigma \\
\hline Ponceau S solution & Sigma \\
\hline Protease Inhibitor Cocktail Tablets (Complete) & Roche \\
\hline Protein A / G beads & Pierce \\
\hline Roti-Load, $4 \times$ concentrated & Roth \\
\hline Rotiphoresis Gel 30 & Roth \\
\hline Sodium Chloride $(\mathrm{NaCl})$ & Roth \\
\hline Sodium dodecyl sulfate (SDS) & Sigma \\
\hline Sodium hydroxide $(\mathrm{NaOH})$ & Roth \\
\hline Tris Base & Sigma \\
\hline Triton X-100 & Roth \\
\hline Trypan blue & Biochrom AG \\
\hline
\end{tabular}


Trypsin-EDTA (1:250)

Tween-20
GE Healthcare

Roth

\subsubsection{Commercial kits}

\begin{tabular}{|cc|}
\hline Description & Company \\
\hline BC Assay Protein quantitation kit & Uptima \\
\hline Big Dye Terminator v3.1 sequencing kit & Applied Biosystems \\
\hline Effectene transfection kit & Qiagen \\
\hline NucleoBond Xtra Midi Plus EF & Macherey-Nagel \\
\hline PCR clean-up \& NucleoSpinR Extract II & Macherey-Nagel \\
\hline QIAprep Spin Miniprep Kit (250) & Qiagen \\
\hline
\end{tabular}

\subsubsection{Enzymes \& Buffers}

\begin{tabular}{|cl|}
\hline Enzymes & Company \\
\hline BamHI & New England Bio labs \\
\hline Dpnl & New England Bio labs \\
\hline EcoRl & New England Bio labs \\
\hline Xbal & New England Bio labs \\
\hline Xho I & New England Bio labs \\
\hline Sacll & New England Bio labs \\
\hline Cutsmart buffer 10x & New England Bio labs \\
\hline KAPAHiFiTM DNA-Polymerase & peQLab \\
\hline GC buffer 5X & peQLab \\
\hline T4-DNA Ligase & Fermentas \\
\hline T4- DNA Ligase buffer 10x & Fermentas \\
\hline
\end{tabular}

\subsubsection{Media for bacteria}

\begin{tabular}{|cc|}
\hline Ingredients & Quantity/Volume \\
\hline Luria agar & $25 \mathrm{~g}$ \\
\hline Luria broth & $20 \mathrm{~g}$ \\
\hline Distilled water & Adjust to $1000 \mathrm{ml}$ \\
\hline
\end{tabular}

\subsubsection{Common buffers}

\subsubsection{Protein lysis buffer}




\begin{tabular}{|ccc|}
\hline Ingredients & Stock concentration & Final concentration \\
\hline Tris- $\mathrm{HCl} \mathrm{pH} 7.4$ & $1 \mathrm{M}$ & $20 \mathrm{mM}$ \\
\hline $\mathrm{NaCl}$ & $5 \mathrm{M}$ & $150 \mathrm{mM}$ \\
\hline EDTA & $0.5 \mathrm{M}$ & $2 \mathrm{mM}$ \\
\hline $\mathrm{NP}-40$ & $100 \%$ & $1 \%$ \\
\hline DTT & $1 \mathrm{M}$ & $1 \mathrm{mM}$ \\
\hline PMSF & $100 \mathrm{mM}$ & $0.1 \mathrm{mM}$ \\
\hline Complete & $25 \mathrm{x}$ & $1 \mathrm{x}$ \\
\hline
\end{tabular}

\subsubsection{Immunoprecipitaion buffer}

\begin{tabular}{|ccc|}
\hline Ingredients & Stock concentration & Final concentration \\
\hline Tris- $\mathrm{HCl} \mathrm{pH} \mathrm{7.4}$ & $1 \mathrm{M}$ & $20 \mathrm{mM}$ \\
\hline $\mathrm{NaCl}$ & $5 \mathrm{M}$ & $150 \mathrm{mM}$ \\
\hline EDTA & $0.5 \mathrm{M}$ & $2 \mathrm{mM}$ \\
\hline Triton X-100 & $100 \%$ & $1 \%$ \\
\hline PMSF & $100 \mathrm{mM}$ & $0.1 \mathrm{mM}$ \\
\hline Complete & $25 \mathrm{x}$ & $1 \mathrm{x}$ \\
\hline Glycerol & $100 \%$ & $10 \%$ \\
\hline
\end{tabular}

\subsubsection{SDS -PAGE buffers and pipetting scheme}

\begin{tabular}{|ccc|}
\hline Ingredients & $\mathbf{1 2 \%}$ separating gel & Loading gel \\
\hline Distilled water & $1.6 \mathrm{ml}$ & $1.4 \mathrm{ml}$ \\
\hline Rotiphorese Gel 30 & $2 \mathrm{ml}$ & $0.33 \mathrm{ml}$ \\
\hline $1 \mathrm{M}$ Tris pH (8.8) & $1.3 \mathrm{ml}$ & - \\
\hline $1 \mathrm{M}$ Tris pH (6.8) & - & $0.25 \mathrm{ml}$ \\
\hline $10 \%$ SDS & $0.05 \mathrm{ml}$ & $0.02 \mathrm{ml}$ \\
\hline $10 \%$ APS & $0.05 \mathrm{ml}$ & $0.02 \mathrm{ml}$ \\
\hline TEMED & $0.002 \mathrm{ml}$ & $0.002 \mathrm{ml}$ \\
\hline
\end{tabular}

\subsubsection{Coomassie staining and de-staining buffer}

\begin{tabular}{|ccc|}
\hline Ingredients & Staining solution & De-staining solution \\
\hline Coomassie brilliant blue & $1.35 \mathrm{~g}$ & - \\
\hline Acetic acid & $200 \mathrm{ml}$ & $200 \mathrm{ml}$ \\
\hline Ethanol & $400 \mathrm{ml}$ & $400 \mathrm{ml}$ \\
\hline Distilled water & $400 \mathrm{ml}$ & $400 \mathrm{ml}$ \\
\hline
\end{tabular}




\subsubsection{Running buffer}

\begin{tabular}{|cc|}
\hline Ingredients & Quantity/Volume \\
\hline Tris base & $30.3 \mathrm{~g}$ \\
\hline Glycine & $144 \mathrm{~g}$ \\
\hline SDS & $20 \%$ \\
\hline Distilled water & Adjust to $1000 \mathrm{ml}$ \\
\hline
\end{tabular}

\subsubsection{Transfer buffer}

\begin{tabular}{|cc|}
\hline Ingredients & Quantity/Volume \\
\hline Tris base & $3.03 \mathrm{~g}$ \\
\hline Glycine & $12.1 \mathrm{~g}$ \\
\hline Methanol (100\%) & $200 \mathrm{ml}$ \\
\hline SDS (20\%) & $200 \mathrm{ml}$ \\
\hline Distilled water & Adjust to $1000 \mathrm{ml}$ \\
\hline
\end{tabular}

\subsubsection{Phosphate buffered saline (PBS)}

\begin{tabular}{|cc|}
\hline Ingredients & Quantity/Volume \\
\hline $\mathrm{NaCl}$ & $80 \mathrm{~g}$ \\
\hline $\mathrm{KCl}$ & $2 \mathrm{~g}$ \\
\hline $\mathrm{Na}_{2} \mathrm{HPO}_{4} \cdot 12 \mathrm{H}_{2} \mathrm{O}$ & $28.9 \mathrm{~g}$ \\
\hline $\mathrm{KH}_{2} \mathrm{PO}_{4}$ & $2.4 \mathrm{~g}$ \\
\hline $\mathrm{NaOH}$ & Adjust $\mathrm{pH} 7.4$ \\
\hline Distilled water & Adjust to $1000 \mathrm{ml}$ \\
\hline
\end{tabular}

\subsubsection{Blocking and antibody solution}

\begin{tabular}{|ccc|}
\hline Ingredients & Blocking solution & Antibody solution \\
\hline 1X PBS & $10 \mathrm{ml}$ & $10 \mathrm{ml}$ \\
\hline Tween 20 & $0.05 \%$ & $0.05 \%$ \\
\hline Milk powder & $5 \%$ & $1 \%$ \\
\hline
\end{tabular}

\subsubsection{Buffer for immunofluorescence}

\begin{tabular}{|ccc|}
\hline Ingredients & Stock concentration & Final concentration \\
\hline PBS & $1 \mathrm{X}$ & $1 \mathrm{X}$ \\
\hline Digitonin & $5 \%(\mathrm{w} / \mathrm{v})$ & $0.02 \%$ \\
\hline Formaldehyde & $37 \%(\mathrm{w} / \mathrm{v})$ & $10 \%$ \\
\hline
\end{tabular}




\begin{tabular}{|ccc|}
\hline Glycine & $1 \mathrm{M}$ & $50 \mu \mathrm{M}$ \\
\hline Triton X-100 & $100 \%$ & $0.5 \%$ \\
\hline BSA powder & $100 \%$ & $10 \%$ and $1 \%$ \\
\hline Mounting Media & - & Mowiol containing DAPI \\
\hline
\end{tabular}

\subsubsection{Hank's buffered salt solution (HBSS)}

\subsection{HBSS stock solution}

\begin{tabular}{|c|c|c|}
\hline Stock & Ingredients & Quantity/Volume \\
\hline & $\mathrm{NaCl}$ & $8 \mathrm{~g}$ \\
\hline \multirow[t]{4}{*}{ Stock 1} & $\mathrm{KCl}$ & $0.4 \mathrm{~g}$ \\
\hline & Glucose & $1 \mathrm{~g}$ \\
\hline & Distilled water & $100 \mathrm{ml}$ \\
\hline & $\mathrm{Na}_{2} \mathrm{HPO}_{4}$ (anhydrous) & $0.358 \mathrm{~g}$ \\
\hline \multirow[t]{2}{*}{ Stock 2} & $\mathrm{KH}_{2} \mathrm{PO}_{4}$ & $0.60 \mathrm{~g}$ \\
\hline & Distilled water & $100 \mathrm{ml}$ \\
\hline \multirow[t]{2}{*}{ Stock3 } & $\mathrm{CaCl}_{2}$ & $0.72 \mathrm{~g}$ \\
\hline & Distilled water & $50 \mathrm{ml}$ \\
\hline \multirow[t]{2}{*}{ Stock 4} & $\mathrm{MgSO}_{4} \times 7 \mathrm{H}_{2} \mathrm{O}$ & $1.23 \mathrm{~g}$ \\
\hline & Distilled water & $50 \mathrm{ml}$ \\
\hline \multirow[t]{2}{*}{ Stock 5} & $\mathrm{NaHCO}_{3}$ & $0.35 \mathrm{~g}$ \\
\hline & Distilled water & $10 \mathrm{ml}$ \\
\hline
\end{tabular}

\subsection{HBSS Premix and full strength buffer}

\begin{tabular}{|cc|}
\hline Ingredients & Quantity/Volume \\
\hline Stock 1 & $10 \mathrm{ml}$ \\
\hline Stock 2 & $1 \mathrm{ml}$ \\
\hline Stock 3 & $1 \mathrm{ml}$ \\
\hline Stock 4 & $1 \mathrm{ml}$ \\
\hline Distilled water & $86 \mathrm{ml}$ \\
\hline & \\
\hline HBSS premix & $9.9 \mathrm{ml}$ \\
\hline
\end{tabular}




\subsubsection{Antibodies}

\begin{tabular}{|c|c|c|c|c|}
\hline Protein & $\begin{array}{l}\text { Molecular } \\
\text { weight }\end{array}$ & Host & Dilution & Company \\
\hline anti-GFP(JL-8) & $27 \mathrm{kDa}$ & mouse & $1: 1000$ & Living Colours, California (632381) \\
\hline anti-HA & $1 \mathrm{kDa}$ & rabbit & $1: 1000$ & Abcam, UK (ab9110) \\
\hline $\begin{array}{l}\text { anti-Myc } \\
(9 B 11)\end{array}$ & $1.2 \mathrm{kDa}$ & mouse & $1: 1000$ & Cell Signalling, UK (2276) \\
\hline Anti-Tubulin & $55 \mathrm{kDa}$ & mouse & $1: 1000$ & Sigma (T7451) \\
\hline anti-LDHB & $35 \mathrm{kDa}$ & mouse & $\begin{array}{l}1: 1000 \\
1: 200\end{array}$ & Abnova, Taiwan (H00003945-M01) \\
\hline anti-GAPDH & $37 \mathrm{kDa}$ & mouse & $\begin{array}{l}1: 1000 \\
1: 200\end{array}$ & Abcam Ab8245 \\
\hline anti-GAPDH & $37 \mathrm{kDa}$ & rabbit & & Sigma (G9545) \\
\hline anti-PEX 14 & $57 \mathrm{kDa}$ & rabbit & $1: 200$ & Proteintech, Chicago (10594-1-AP) \\
\hline anti-rabbit lgG & HRP conjugated & goat & $1: 5000$ & $\begin{array}{l}\text { Jackson Immuno Research (111-035- } \\
\text { 003) }\end{array}$ \\
\hline anti-mouse IgG & HRP conjugated & donkey & $1: 5000$ & $\begin{array}{l}\text { Jackson Immuno Research (715-035- } \\
151)\end{array}$ \\
\hline anti-mouse IgG & Alexa 488 & donkey & $1: 200$ & MoBitec (A1108) \\
\hline anti-rabbit lgG & Alexa 647 & donkey & $1: 200$ & $\begin{array}{l}\text { Jackson Immuno Research (711-605- } \\
152)\end{array}$ \\
\hline anti-rabbit lgG & Alexa 488 & goat & $1: 200$ & MoBitec (A21202) \\
\hline anti-rabbit $\lg G$ & Су3 & goat & $1: 200$ & $\begin{array}{l}\text { Jackson Immuno Research (111-165- } \\
144)\end{array}$ \\
\hline
\end{tabular}

\subsubsection{Primer used for plasmid cloning}

\begin{tabular}{|c|c|c|}
\hline Oligo & Name & Sequence $5^{\prime}-3^{\prime}$ \\
\hline 801 & PTS1 (ACOX3) for & CACCCCTGTCATAGGAAGTCTGAAATCGAAGCTCTAG \\
\hline 802 & PTS1 (ACOX3) rev & CTAGAGCTTCGATTTCAGACTTCCTATGACAGGGGTG \\
\hline 963 & DR MCS for & TCGAGCGGTCACCATCGATTCCGGACCGTACGG \\
\hline 964 & DR MCS rev & TCGACCGTACGGTCCGGAATCGATGGTGACCGC \\
\hline 1053 & LDHB for & GCGCGAATTCTATGGCAACTCTTAAGGAAAAAC \\
\hline 1054 & LDHB rev & GCGCTCTAGACTACAGCCTAGAGCTCAC \\
\hline
\end{tabular}




\begin{tabular}{|c|c|c|}
\hline 1055 & LDHB (TGG) rev & $\begin{array}{l}\text { GCGCTCTAGACTACAGCCTAGAGCTCACTAGCCACAGGTCT } \\
\text { TTTAGG }\end{array}$ \\
\hline 1083 & DR-LDHB for & GTCACCAAAAAGACCTGTGACTAGTGAGCTT \\
\hline 1084 & DR-LDHB rev & CCGGAAGCTCACTAGTCACAGGTCTTTTTG \\
\hline 1123 & DR-LDHB (TGG) for & GTCACCAAAAAGACCTGTGGCTAGTGAGCTT \\
\hline 1124 & DR-LDHB (TGG) rev & CCGGAAGCTCACTAGCCACAGGTCTTTTTG \\
\hline 1125 & $\operatorname{LDHB}(\Delta \mathrm{L})$ rev & GCGCTCTAGACTACCTAGAGCTCACTAGTCAC \\
\hline 1126 & LDHB [SSI) rev & GCGCTCTAGACTATATACTAGAGCTCACTAGTC \\
\hline 1127 & LDHB (TAA) rev & $\begin{array}{l}\text { GCGCTCTAGACTACAGCCTAGAGCTCACTAGTTACAGGTCT } \\
\text { TTTAGG }\end{array}$ \\
\hline 1128 & LDHB (TAAT) rev & $\begin{array}{l}\text { GCGCTCTAGACTACAGCCTAGAGCTCACTAATTACAGGTCT } \\
\text { TTTAGG }\end{array}$ \\
\hline 1129 & LDHB (TGAT) rev & $\begin{array}{l}\text { GCGCTCTAGACTACAGCCTAGAGCTCACTAATCACAGGTCT } \\
\text { TTTAGG }\end{array}$ \\
\hline 1130 & LDHA for & GCGCGAATTCTATGGGTGAACCCTCAGGA \\
\hline 1131 & LDHA rev & GCGCTCTAGATTAAAATTGCAGCTCCTTTTGG \\
\hline 1132 & LDHB seq 1 & TGAAGTCTTCCTGAGCCTTC \\
\hline 1133 & LDHB seq 2 & GGC TGT GTG GAG TGG TG \\
\hline 1134 & LDHA seq & CAGCCCGATTCCGTTAC \\
\hline 1144 & DR-LENG1 for & GTCACCGCCTTACTCACTGACTCCTGAGGGT \\
\hline 1145 & DR-LENG1 rev & CCGGACCCTCAGGAGTCAGTGAGTAAGGCG \\
\hline 1146 & DR-ZNF 574 for & GTC ACC GGA TCA GTG GCT GAC TCT GCC CGA T \\
\hline 1147 & DR-ZNF574 rev & CCG GAT CGG GCA GAG TCA GCC ACT GAT CCG \\
\hline 1148 & DR-PRDM10 for & GTCACCGCACCAAACCATGACTTCCACCCTT \\
\hline 1149 & DR-PRDM10 rev & CCGGAAGGGTGGAAGTCATGGTTTGGTGCG \\
\hline 1150 & DR-FBXL20 for & GTCACCGCATCATCCTATGACAATGGAGGTT \\
\hline 1151 & DR-FBXL20 rev & CCGGAACCTCCATTGTCATAGGATGATGCG \\
\hline 1152 & DR-THG1L for & GTCACCGAGCCAGGCTTTGACGGAAGAGTCT \\
\hline 1153 & DR-THG1L rev & CCGGAGACTCTTCCGTCAAAGCCTGGCTCG \\
\hline 1154 & DR-EDEM3 for & GTCACCGGGATGAGCTATGACTTGCTAAACT \\
\hline 1155 & DR-EDEM3 rev & CCGGAGTTTAGCAAGTCATAGCTCATCCCG \\
\hline 1156 & DR-EDN1 for & GTCACCGAGCACATTGGTGACAGACCTTCGT \\
\hline 1157 & DR-EDN1 rev & CCGGACGAAGGTCTGTCACCAATGTGCTCG \\
\hline 1158 & DR-LEPRE1 for & GTCACCGGGATGAGCTATGACAGCGTCCAGT \\
\hline 1159 & DR-LEPRE1 rev & CCGGACTGGACGCTGTCATAGCTCATCCCG \\
\hline 1160 & DR-UBQLN1 for & GTCACCGCCAGCCATCATAGCAGCATTTCTT \\
\hline 1161 & DR-UBQLN1 rev & CCGGAAGAAATGCTGCTATGATGGCTGGCG \\
\hline
\end{tabular}




\begin{tabular}{|cll|}
\hline 1162 & DR-IRAK3 for & GTCACCGCAAAAAAGAATAAATTCTACCAGT \\
\hline 1163 & DR-IRAK3 rev & CCGGACTGGTAGAATTTATTCTTTTTTGCG \\
\hline 1164 & DR-SLC3A1 for & GTCACCGTACCTCGTGTTAGGCACCTTTATT \\
\hline 1165 & DR-SLC3A1 rev & CCGGAATAAAGGTGCCTAACACGAGGTACG \\
\hline 1202 & HA-LDHB-Myc for & $\begin{array}{l}\text { GCGCGCTAGCATGTACCCATACGATGTTCCAGATTACGCTG } \\
\text { CAACTCTTAAGGAAAAACTC }\end{array}$ \\
\hline 1203 & HA-LDHB-Myc rev & GCGCGGATCCCAGCCTAGAGCTCACTAG \\
\hline 1263 & LDHB TGG $(\Delta \mathrm{L})$ rev & GCGCTCTAGACTACCTAGAGCTCACTAGCCAC \\
\hline 1264 & LDHB TGG $(\mathrm{SSI})$ rev & GCGCTCTAGACTATATACTAGAGCTCACTAGCCA \\
\hline 1482 & GAPDH for & GCGCGAATTCTATGGGGAAGTGAAGGTC \\
\hline 1483 & GAPDH rev & GCGCGGATCCTTACTCCTTGGAGGCCATG \\
\hline 1484 & GAPDH seq & GCTCTCCAGAACATCATCC \\
\hline
\end{tabular}

\subsubsection{Plasmid DNA}

\begin{tabular}{|clc|}
\hline Plasmid & \multicolumn{1}{c|}{ Name } & Source \\
\hline & pENTR-TOPO-D & Invitrogen \\
\hline 1327 & pEXP-N-Venus & Ania Muntau lab \\
\hline 1019 & pCDNA3.1 myc-His (-) A & Invitrogen \\
\hline 1209 & pENTR-TOPO-D-PTS1 (ACOX3) & Thoms Lab \\
\hline 1226 & pEXP-N-Venus-PTS1 (ACOX3) & Thoms Lab \\
\hline 1360 & pEXP Venus-hRluc with MCS & Thoms Lab \\
\hline 1365 & pOTB7-LDHB (clone HsCD00334443) & plasmID \\
\hline 1378 & pEYFP-C1 & Clontech \\
\hline 1382 & pECFP-C1 & Clontech \\
\hline 1385 & pDRVL-LDHB & Thoms Lab \\
\hline 1388 & pEYFP-C1-LDHBwt & Thoms Lab \\
\hline 1389 & pEYFP-C1-LDHB (TGG) & Thoms Lab \\
\hline 1407 & pEYFP-C1-LDHB (AL) & Thoms Lab \\
\hline 1408 & pEYFP-C1-LDHB (SSI) & Thoms Lab \\
\hline 1409 & pEYFP-C1-LDHB (TGAT) & Thoms Lab \\
\hline 1410 & pEYFP-C1-LDHB (TAA) & Thoms Lab \\
\hline 1411 & pEYFP-C1-LDHB (TAAT) & Thoms Lab \\
\hline 1418 & pDRVL-LENG1 & Thoms Lab \\
\hline 1419 & pDRVL-PRDM10 & Thoms Lab \\
\hline 1420 & pDRVL-FBXL20 & Thoms Lab \\
\hline 1421 & pDRVL-THG1L & Thoms Lab \\
\hline & & \\
\hline
\end{tabular}




\begin{tabular}{|lll|}
\hline 1422 & pDRVL-EDEM3 & Thoms Lab \\
\hline 1423 & pDRVL-EDN1 & Thoms Lab \\
\hline 1424 & pDRVL-UBQLN1 & Thoms Lab \\
\hline 1425 & pDRVL-IRAK3 & Thoms Lab \\
\hline 1426 & pDRVL-SLC3A1 & Thoms Lab \\
\hline 1430 & pDRVL-LEPRE1 & Thoms Lab \\
\hline 1434 & pEYFP-C1-LDHA & Thoms Lab \\
\hline 1437 & pDRVL-VASN & Thoms Lab \\
\hline 1440 & pECFP-C1-LDHB (TGG) & Thoms Lab \\
\hline 1441 & pcDNA3.1-HA-LDHBx-myc & Thoms Lab \\
\hline 1442 & pcDNA3.1-HA-LDHB (TGG)-myc & Thoms Lab \\
\hline 1456 & pcDNA3.1-HA-LDHB (TGA T)-myc & Thoms Lab \\
\hline 1457 & pcDNA3.1-HA-LDHB (TAA)-myc & Thoms Lab \\
\hline 1458 & pcDNA3.1-HA-LDHB (TAA T)-myc & Thoms Lab \\
\hline 1491 & pEYFP-C1-GAPDH & Thoms Lab \\
\hline 1512 & pECFP-C1-LDHB (AL) & Thoms Lab \\
\hline 1513 & pECFP-C1-LDHB (SSI) & Thoms Lab \\
\hline
\end{tabular}

\subsection{Methods}

\subsubsection{Cell culture}

HeLa cells were maintained in low glucose Dulbecco's minimal essential medium (DMEM), while human brain glioma cell line U118, fibroblast Otto cells and monkey kidney cells COS were maintained in high glucose DMEM (1g/L) and supplemented with $1 \%(\mathrm{w} / \mathrm{v})$ glutamine, 5\%-10\% (v/v) heat inactivated foetal calf serum (FCS), $100 \mathrm{U} / \mathrm{ml}$ penicillin and $100 \mu \mathrm{g} / \mathrm{ml}$ streptomycin at $37^{\circ} \mathrm{C}$ in a humidified incubator containing $5 \%$ CO2. U118 cells needed $1 \%$ non-essential amino acids and $1 \%$ pyruvate in addition to above mentioned components. Every third day cells were passaged (1:5) using $1 \mathrm{ml}$ trypsin after being washed with PBS. Cells were transfected using Effectene transfection reagent (Qiagen). Plasmids were diluted in Buffer EC and Enhancer and incubated for $5 \mathrm{~min}$ at room temperature. Effectene was added and incubated for $10 \mathrm{~min}$ at room temperature. Pre-warmed medium was added to the culture cells and to the transfection mixture which was then added to cells and incubated at $37^{\circ} \mathrm{C}$ in a humidified 5\% CO2 incubator for $24 \mathrm{hr}$. Six hours after transfection, transfection reagent was removed, and where indicated, $100 \mu \mathrm{g} / \mathrm{ml}$ geneticin (G418) was added. 


\subsubsection{Cloning}

The dual reporter vector with the reporter genes Venus and luciferase, pDRVL (PST1360) was created from the pEXP-Venus-hRluc vector which was kindly provided by the Ania Muntau working group. A 33 base pair long MCS containing the restriction enzymes, BstEII, Clal, BspEI, and BsiWI was inserted between the Xhol restriction site using site directed mutagenesis. The dual reporter vector containing the MCS will be refereed as the PDRVL vector or PST1360. For measuring RT, the pre-annealed oligonucleotides OST 1144-1165 and 1123-1124 containing the stop codon contexts of the test genes LENG1, ZNF-574, PRDM10, FBXL20, THG1L, EDEM3, EDN1, LEPRE1, UBQLN1, IRAK3, SLC3A1, PPP13RF, VASN and LDHB were cloned into BspEl and BstEII of pDRVL vector. The plasmid DNA generated as a result were called pDRVL-LENG1, pDRVL-ZNF-574, pDRVL-PRDM10, pDRVL- LDHB, pDRVL-FBXL20, pDRVL-THG1L, pDRVLEDEM3, pDRVL-EDN1, pDRVL-LEPRE1, pDRVL-UBQLN1, pDRVL- IRAK3, pDRVL- SLC3A1, pDRVL-PPP13RF and pDRVL-VASN.

The co-localisation study which demonstrated peroxisomal localization of LDHB used enhanced yellow ( $p E Y F P$ ) or cyan fluorescent ( $p E C F P$ )tags. The peroxisome targeting signal of ACOX3 was created by gateway cloning. The annealed oligonucleotides OST801 \& 802 was inserted into the entry vector $\mathrm{pENTR}$-TOPO-D by BP reaction and then into the destination vector $\mathrm{pEXP-N-Venus}$ by LR clonase II reaction. The cloning of GAPDH, LDHA or LDHB (including 21 nucleotides 3' extension) was done differently. Human cDNA fibroblasts or human clone HsCD00334443 (Gene ID 3945 LDHB) were PCR amplified using the primer pairs OST 1482 \& 1483, OST1053 \& 1054 or OST1130 \& OST1131 respectively. The stop mutants of LDHB i.e. pEYFP-LDHB (TGG), pECFP-LDHB (TGG), pEYFP- LDHB (TAA), pEYFP-LDHB (TAAT), pEYFP-LDHB (TGAT), the peroxisome targeting signal deletion mutant pEYFP-LDHB $(\Delta \mathrm{L})$, pECFP-LDHB $(\Delta \mathrm{L})$ and substitution mutant pEYFP-LDHB (SSI), pECFP-LDHB (SSI) were generated using the forward primer OST1053 and the following reverse primers OST1055, 1127, 1128,1129,1125, 1263, 1126, and 1264 respectively. These PCR fragments were introduced into the EcoRI and Xbal sites of pEYFP-C10 pECFP-C1 vectors which was then chemically transformed competent (BIOBlue 10^9; BIO-85037) cells from Bioline. These transformed cells were streaked on Kanamycin containing LB Agar medium and incubated overnight at $37^{\circ} \mathrm{C}$. Isolated colonies were analysed on agarose gel by restriction digestion and positive clones were selected after DNA sequencing.

For the analysis of full length LDHB and its stop variants by western blot the entire sequence of LDHB including its extension were amplified using the primer pairs OST1202 and 1203 . The 
following plasmids pEYFP-LDHB (TGG), pEYFP-LDHB (TGAT), pEYFP-LDHB (TAA), and pEYFP-LDHB (TAAT) were used as the template. The resulting PCR fragments were digested with Nhel and BamHI restriction enzymes and were ligated with the pcDNA3.1/Myc-His (-) A vector to generate HA and Myc tagged vectors. TOP 10 bacteria were transformed and the bacteria were streaked on Ampicillin LB Agar plates and incubated overnight at $37^{\circ} \mathrm{C}$. individual colonies were checked on agarose gel by restriction digestion and positive clones were selected upon confirmation by DNA sequencing. The plasmids were all verified by the sequencing facility of the department using the BigDye® Terminator v1.1 Cycle Sequencing Kit (Applied Biosystems, Carlsbad, California) according to manufacturer's instructions. The forward and reverse primers, oligonucleotides for annealing and the sequencing primers used in this study are mentioned in the section 2.1.9 and section 2.1.10.

\subsubsection{Dual reporter assays and read-through calculation}

For the read-through assay, $1 \times 10^{5}$ cells were seeded in each of the wells of a 12-well plate at least 18-20 hours before transfection. These cells were transfected with necessary plasmid DNA using the Effectene transfection kit from Qiagen. Transfected cells were maintained in culture for 24 hours or treated with read-through inducing drug geneticin 6 hours post transfection. Venus fluorescence and Renilla luminescence of transfected cells is measured after they are lysed. So the cells in culture were washed with PBS, trypsinized and the cell pellet is lysed in $30 \mu \mathrm{l}$ of ice cold Renilla Luciferase Assay Lysis Buffer followed by centrifugation at 14000rp for 2 min at $4^{\circ} \mathrm{C}$. The supernatants were either used directly for measurement or stored at $-80^{\circ} \mathrm{C}$. the proteins lysates thus obtained were diluted (1:25) in PBS before the fluorescence measurement at $485 \mathrm{~nm}$ excitation, $530 \mathrm{~nm}$ emission. The blank control was PBS. the luminescence was measured with $20 \mu \mathrm{l}$ of undiluted lysates that were mixed with $100 \mu \mathrm{l}$ Renilla Luciferase Assay Reagent (Promega) and the blank control for luminescence measurement was Renilla Luciferase Assay Reagent. Ratio of luminescence / fluorescence was calculated to obtain the read-through and the measurement of pDRVL was the positive control against which all other measurements were normalized. All fluorescence and luminescence were measured according to the manufacturer's manual using the Synergy Mx plate reader (Biotek).

\subsubsection{Western blot}

Organ tissues or cultured cells after lysing in 30-200 $\mu \mathrm{l}$ of protein lysis buffer (2.1.7.1) were

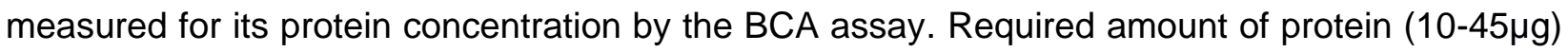
were mixed with $10 \mu \mathrm{l}$ of the $4 \mathrm{X}$ Sample buffer, denatured at $95^{\circ} \mathrm{C}$ for 5 minutes and then 
centrifuged briefly before loading them on the gel. Proteins were separated on a $12 \%$ SDS-PAGE (2.2.7.3), initially at $10 \mathrm{~mA}$ and then at $20 \mathrm{~mA}$ in approximately $800 \mathrm{ml} 1 \mathrm{X}$ running buffer (2.1.7.5). By semi-dry blotting proteins were transferred onto nitrocellulose membrane. For the blotting the gel, nitrocellulose membrane and Whatman filter papers were pre-soaked in transfer buffer (2.1.7.6). Blotting or transfer of proteins was done at a constant $65 \mathrm{~mA}$ for 1 hour by sandwiching the gel and the membrane between Whatman filter papers. Membrane was stained with Ponceau $S$ to observe for proper transfer and after de-staining with PBST (2.1.7.7) blocked with $10 \mathrm{ml}$ blocking solution (5\% milk in PBST, 2.1.7.8) for 30 minutes. The blocking buffer was removed and replaced with appropriate primary antibody solution (prepared in 1\% milk in PBST) and incubated overnight at $4^{\circ} \mathrm{C}$. this is followed by HRP labelled secondary antibody incubation for 1 hour at room temperature. In between the incubations the membrane was washed thrice with PSBT (10 minutes each) and then incubated with ECL solutions for 1 minute, prior to developing in the Luminescent image analyser LAS 4000 (Fuji).

\subsubsection{Immunoprecipitation}

Tissues of rat heart, brain, kidney and muscle were homogenized and lysed in immunoprecipitation buffer (2.1.7.2) containing $1 \%$ Triton X-100 for 30 min on ice. After centrifugation, the pellet was discarded and the supernatant were measured for its protein concentration. $1 \mu \mathrm{l}$ of IP antibody was added to the $500 \mu \mathrm{g}$ of protein lysate and this mixture was incubated for 2-24 hours at $4^{\circ} \mathrm{C}$ on a rotating wheel. Protein $A$ or $G$ beads (Thermo Scientific) were prepared by spinning at 5,500 rpm for 2 minutes. The supernatant was discarded and the beads were washed 3-5 times with $500 \mu \mathrm{l}$ PBS and one time with immunoprecipitation buffer. Washed beads were incubated with the lysate-antibody mix overnight at $4^{\circ} \mathrm{C}$. as the negative control, tissue lysate without antibody was incubated with bead. Bound proteins were eluted from the beads with $4 x$ Roti-Load2 after heat denaturing for 10 minutes at $70^{\circ} \mathrm{C}$. samples were briefly centrifuged at 11,000 rpm and transferred to new tubes before analysing them on the western blot.

\subsubsection{Immunofluorescence}

$0.5 \times 10^{5}-1 \times 10^{5}$ cells were seeded on $12 \mathrm{~mm}-14 \mathrm{~mm}$ cover slides inside a 24 well or 12 well plate $18-20$ hours before transfection. The cells were maintained at $37^{\circ} \mathrm{C}$ until they were taken out for fixation of proteins. For better adhesion of U118 cells and COS cells, the cover slides were coated with laminin at least 2 hours prior to seeding. The cells were transfected with appropriate fluorescent tagged plasmid DNA with Effectene transfection reagent and 6hr post transfection the 
media was exchanged. 24 hours later cells were taken out of the incubator, washed with PBS and were prepared for digitonin permeabilization at room temperature. Removal of cytosolic fluorescence was achieved with $0.02 \%(\mathrm{w} / \mathrm{v})$ digitonin incubation for $5 \mathrm{~min}$. This was followed by fixation of proteins for 20 min with $10 \%(\mathrm{w} / \mathrm{v})$ formaldehyde and permeabilization for 5 min with $0.5 \%$ Triton X-100. Blocking buffer used contained 10\% BSA and the cells were incubated for 20 $\min$ at $37^{\circ} \mathrm{C}$. this was followed by 1 -hour incubation each with primary antibodies and secondary antibodies at $37^{\circ} \mathrm{C}$. the cells on the coverslips were mounted with Mowiol with/without DAPI. It should be noted that between each step the cells were washed three times with PBS carefully and gently. 1:200 dilutions of primary and secondary antibodies in blocking buffer were used. Images were acquired using the 100x oil objective (1.3 NA) of Zeiss Imager M1 fluorescence wide field microscope, equipped with the Zeiss Axiocam HRm Camera and Zeiss Axiovision 4.8 acquisition software. Z-Stacks with 10-20 images and 0.4-0.2 $\mu \mathrm{m}$ spacing were logged and subjected to deconvolution and a linear contrast enhancement was applied to images.

\subsubsection{Fluorescence loss in photo-bleaching (FLIP)}

HeLa cells in culture were seeded in ibidiTreat $\mu$-Dish ${ }^{35 m m h i g h ~} 18-20$ hours before the transfection. Respective ECFP and EYFP tagged plasmid DNA were transfected using Effectene reagent and 24 hours later using confocal laser scanning microscope live cell images were acquired. A laser beam focusses on a small area called region of interest $(\mathrm{ROI})$ of the fluorescent cell. The intensity of the laser beam is enhanced to bleach the dye in the ROI multiple times. This reduces the fluorescence signal and the recovery time in between multiple bleaching diffuses unbleached fluorescent molecules into the ROI from the adjacent areas. The ROI gradually becomes dimmer while the remaining unbleached area of the cell remains bright. FLIP thus reveals that the residual unaltered fluorescence from proteins that were protected by the peroxisomal membrane. 


\section{Results}

\subsection{Experimental validation of read-through algorithm}

Stop codon RT is a recoding event known to occur in viruses and fungi to generate C-terminally extended proteins with specific functions (Namy et al., 2003). In humans, the regulation of RT is poorly understood and therefore, in our published work we developed an iterative computational algorithm based on RT frequencies of the three stop codons and their neighbouring nucleotides (Schueren et al., 2014). For a brief description of the algorithm please see section 1.4 and figure 4 in the introduction. To evaluate the RT prediction algorithm, we selected SCCs of candidates (listed in table 1) with high, intermediate and low RTP scores from the LIN regression model. The SCCs were cloned into a dual reporter vector which contained a fluorescent tag, Venus at the $\mathrm{N}$ terminus and a luciferase tag at the C-terminus. The SCCs were inserted into the multiple cloning site (MCS) of the reporter vector using the restriction enzymes BstEll and BspEI. When stop signal was suppressed a longer protein variant containing both fluorescent and luminescent tags was generated while a shorter variant containing only a fluorescent tag was generated when stop codon signalled translational halt (figure 6A). RT was calculated as ratio of luciferase signal over Venus fluorescence and expressed as percentage of the positive control. The reporter vector expressing Venus-luciferase fusion protein containing no stop codon was used as the positive control which was set at $100 \%$ and the measurement of all listed candidates were normalized as percentage relative to positive control.

Based on the RTP score the SCCs of selected candidates were categorized as high, intermediate and low RT genes. ZNF-574, LDHB, PRDM10, MDH1 and THG1L with RTP scores above 0.2 were considered as high RT, EDN1, EDEM3, IRAK3, LENG1, FBXL20, LEPRE1 of RTP scores between 0.2 and 0.05 were intermediate RT while UBQLN1, SLC3A1, PPP13RF with RTP scores below 0.05 were labelled as low RT. Dual reporter assay of these candidates recorded basal RT between $0.3 \%-8.8 \%$ for high RT group with $M D H 1$ (8.8\%) and LDHB (7.8\%). Intermediate RT group demonstrated 0.3\%-6.7\% with LEPRE1 (6.7\%), EDEM3 (1.9\%) and LENG1 (1.4\%) while low RT group showed basal RT in the range of $0.3 \%-0.7 \%$ and the candidate PPP13RF showed an RT of $0.7 \%$ despite its poor RTP score (figure $6 \mathrm{~B}$, basal RT).

SCCs of the candidates were also verified in the presence of aminoglycoside drug, geneticin (G418) to test if the stop codons genuinely express RT. It is known that translational fidelity of stop codons is reduced not only by the suppressor tRNAs but also in the presence RT aminoglycoside antibiotics (Mohamed et al., 2015). Evaluation of SCCs from high RT group showed an increase 
in read-through to levels between 30-37\%, intermediate RT group demonstrated 7\%-46\% and low RT group showed between 3\%-13\%. A significant increase in RT for most of the candidates also illustrated a successful induction of RT by the chosen compound thus validating true RT (figure 6B, induced RT). Absence of RNA structural elements that may modulate RT and exclusion of splicing sites ensured that the reporter assay strictly measured RT as a consequence of the SCCs (Schueren et al., 2014). From this study, it was concluded that the LIN model which predicted RTP score for human genes needs further optimization as the experimental RT values does not correlate entirely with the predicted RTP score. Additional candidates had to be included in the study to test the prediction tool and several repetitions had to be conducted in additional cell lines to evaluate regulation of $\mathrm{RT}$ in different tissues.

\begin{tabular}{|ccccc|}
\hline Gene & RTP score & \multicolumn{3}{c|}{ Stop codon context (SCC) } \\
\hline$Z N F 574$ & 0.27 & G ATC AGT GGC & TGA & CTC TGC CCG A \\
\hline LDHB & 0.27 & A AAA GAC CTG & TGA & CTA GTG AGC T \\
\hline$P R D M 10$ & 0.24 & C ACC AAA CCA & TGA & CTT CCA CCC T \\
\hline MDH1 & 0.23 & T TCC TCT GCC & TGA & CTA GAC AAT G \\
\hline THG1L & 0.22 & A GCC AGG CTT & TGA & CGG AAG AGT C \\
\hline EDN1 & 0.17 & A GCA CAT TGG & TGA & CAG ACC TTC G \\
\hline EDEM3 & 0.15 & G GAT GAG CTA & TGA & CTT GCT AAA C \\
\hline IRAK3 & 0.14 & T ATG GAG ACG & TGA & TTT CTG CAA C \\
\hline LENG1 & 0.10 & G CCT CTC CTG & TGA & AAC CTG GGA G \\
\hline FBXL20 & 0.10 & A ATG GCT ACA & TAA & CTC TCC AAC T \\
\hline LEPRE1 & 0.08 & G GAT GAG CTA & TGA & CAG CGT CCA G \\
\hline UBQLN1 & 0.02 & C CAG CCA TCA & TAG & CAG CAT TTC T \\
\hline SLC3A1 & 0.02 & T ATT GTA AGT & TGA & ATA CAA CTT G \\
\hline PPP13RF & -0.21 & T TGG TTC TCA & TAG & GCT CTG CTT G \\
\hline VASN & 0.01 & G CCC TAC ATC & TAA & GCC AGA GAG A \\
\hline
\end{tabular}

Table 1: A list of selected genes obtained from the LIN in silico regression model which calculated the read-through probability (RTP) of all human transcripts. A list of remaining human transcripts with their RTP scores is available in Dataset 1 (Schueren et al., 2014). The table shows the names of genes, their predicted score indicated by RTP score and their stop codon context (SCC) consisting of the stop codon (highlighted in red) and 10 nucleotides upstream and downstream of the stop codon. RTP scores of 0.2 and above were predicted to exhibit high read-through, scores between 0.2 and 0.05 as candidates with intermediate to high read-through while those with a score below 0.05 were predicted with low or no probability of read-through. 
A
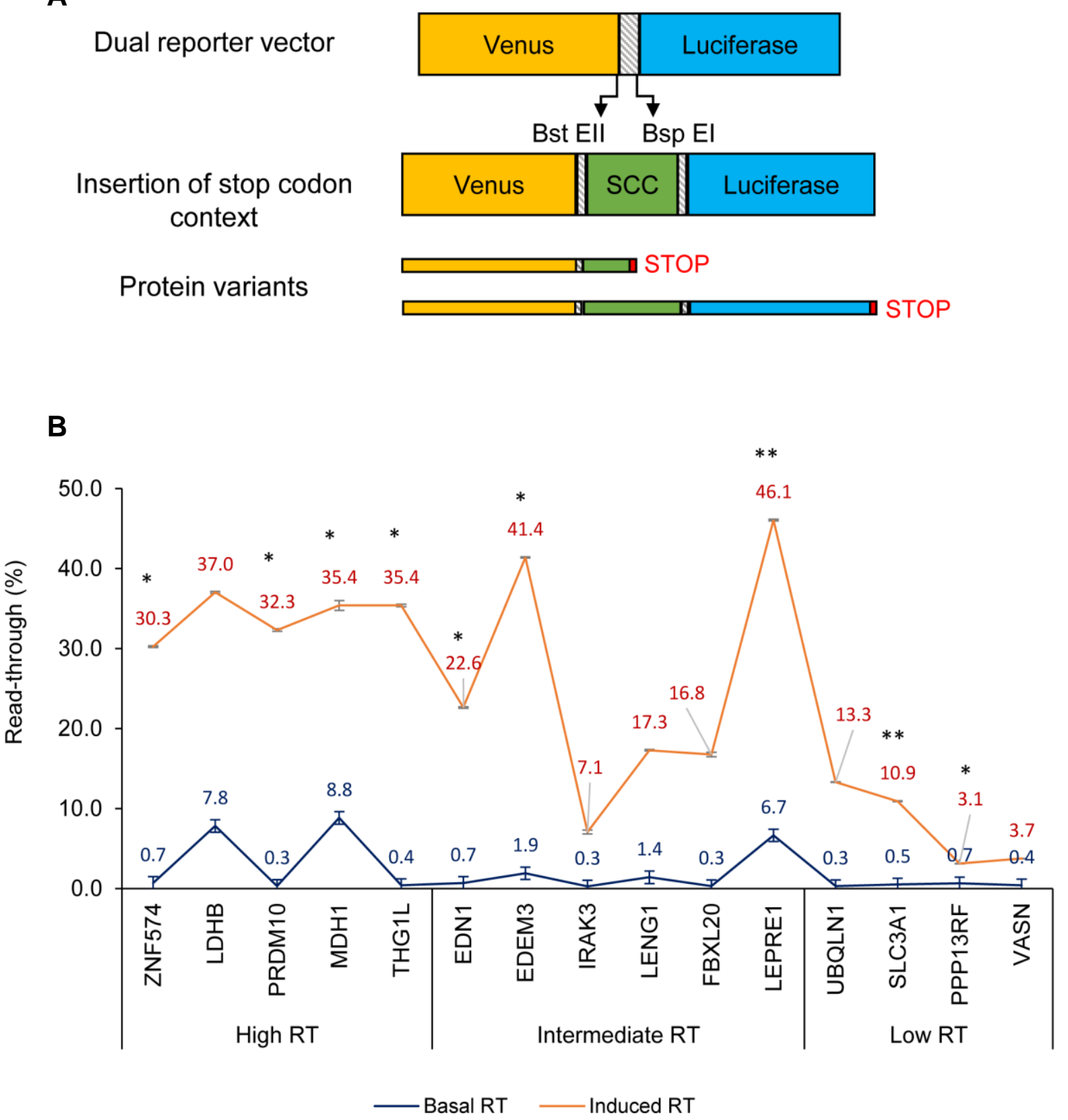

Figure 6: Dual reporter assay to test translational read-through selected gene candidates. A) Schematic representation of dual reporter vector which contain $\mathrm{N}$-terminal Venus (yellow) and C-terminal luciferase (blue) tags. The stop codon contexts (SCCs) of test genes were inserted by digesting the multiple cloning site of the reporter vector using the restriction enzymes BstEll and BspEl to generate a tagged fusion protein. Depending on the read-through (RT) of the stop codon (red) two types of protein variants can be generated. A short protein variant with a Venus tag suggest no RT while a long variant consisting of Venus and luciferase tags suggests RT of the stop codon. B) Evaluation of RT percentage of the selected SCCs is shown here. The candidates were categorised into high read-through (RT), intermediate RT and low RT. Basal read-through (blue line) for high RT candidates were recorded between $0.3 \%-8.8 \%$ which 
Results

upon drug G418 treatment (orange line) increase between 30\%-37\%. The intermediate RT candidates demonstrated basal read-through between $0.3 \%-1.9 \%$ and in the presence of G418 between $7.1 \%-46.1 \%$. The low RT candidates showed basal read-through percentage between $0.3 \%-0.7 \%$ and after G418 induction read-through increased between $3.1 \%-13.3 \%$. Mean $\pm S D, n=3$. P-value ${ }^{*} \leq 0.05,{ }^{* *} \leq 0.005$.

\subsection{Investigation of read-through protein extension for functional domain}

The extensions of the RT proteins were screened for presence of trans membrane domains, prenylation sites, endoplasmic reticulum retention signals and glycosylation sites to track the behaviour of RT proteins. However, we choose to mainly search for peroxisome targeting signals in the RT extensions because of the following three reasons. First, we had the advantage of employing a PTS1 algorithm originally developed for plants that was adapted for scanning human PTS1 which assigned a PTS1 posterior probability score similar to RTP score. So proteins that acquired a combined high RTP and PTS1 score indicated they were more likely to get targeted to the peroxisomes due to stop codon RT (Lingner et al., 2011; Schueren et al., 2014). Secondly, translational RT of certain glycolytic proteins in fungi generated protein variants with functional peroxisome targeting signals suggesting a role redox homeostasis (Freitag et al., 2012). Thirdly, results of our previous experiments (figure 6B) showed SCCs of two metabolic enzymes LDHB and $\mathrm{MDH} 1$ to undergo high basal RT (relative to positive control). We therefore, wanted to screen for a yet unknown cryptic PTS1 in the C-terminal extension of RT proteins (Schueren et al., 2014).

Based on the combined RTP and PTS1 scores, we identified LDHB as the number one candidate with a cryptic PTS1 in its C-terminal extension. Also, sequence analysis of RT extension of LDHB showed that the stop as well as PTS1 in its C-terminal extension was highly conserved in mammals (figure 5, introduction) leading us to examine RT dependent localization of LDHB inside peroxisomes (Schueren et al., 2014). We initiated the study by evaluating the RT of SCCs consisting of wild type stop, TGA and its mutations: TAA (ochre stop) and TGG (encoding tryptophan) by the dual reporter assay. A table showing the SCCs of LDHB stop mutants is shown in figure 7A. LDHB (TGG) served as the positive control and hence set to $100 \%$. Evaluation of RT by dual reporter assay demonstrated TGA stop with $4 \%$ basal RT while the TAA stop showed $1 \%$ (figure 7B, blue bar). However, when induced with G418, there was a significant increase in RT of the stop TGA (54\%) and for TAA stop (16\%) (figure 7B, orange bar). RT of LDHB stop mutants were also confirmed on protein level by analysing LDHB SCCs in the presence and absence of RT inducing drug, G418. Expression of GFP band served as an internal control for translation initiation which was shown by the stops TGG, TGA and TAA both in the treated and untreated conditions. Only when RT happens luciferase band is expressed. So the stops TGG and TGA show a band while TAA shows luciferase only induced with G418 (figure 7C). 
A

\begin{tabular}{|c|c|}
\hline LDHB mutants & Stop codon context \\
\hline LDHB TGG & AAAA GAC CTG TGG CTA GTG AGC T \\
\hline LDHB TGA & AAAA GAC CTG TGA CTA GTG AGC T \\
\hline LDHB TAA & AAAA GAC CTG TAA CTA GTG AGC T \\
\hline
\end{tabular}

B

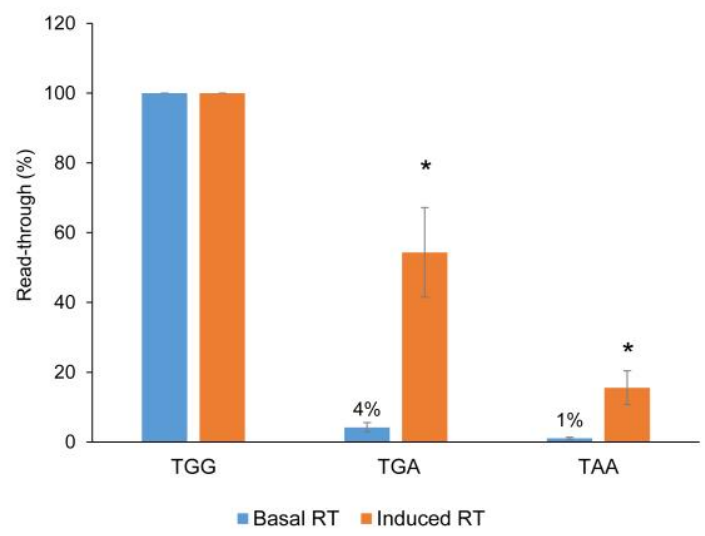

C

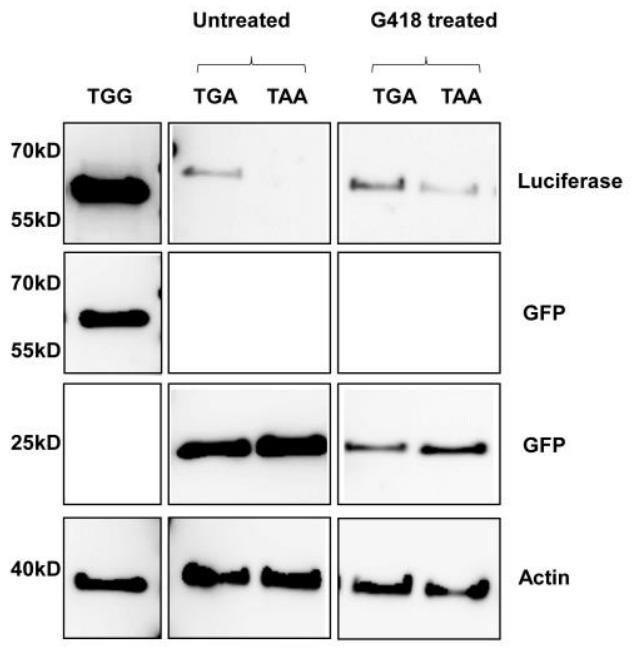

Figure 7. Read-through analysis of LDHB stop codon context. RT was evaluated for LDHB stop variants using dual reporter vector and RT proteins were analysed on western blot. A) The SCCs of LDHB with a tryptophan encoding TGG, wild type TGA and a better stop TAA is shown. The stop codons are highlighted in red. B) RT was calculated as the ratio of test construct luciferase activity to fluorescence signal and expressed in percentage. Basal (blue bar) and G418 induced (orange bar) RT evaluation is shown where TGG (basal and induced) was the positive control set to $100 \%$ against which basal and induced RT of TGA and TAA values were normalised. TGA showed a basal RT of $4 \%$ and an increased RT of $54 \%$. TAA showed basal RT of $1 \%$ and induced RT of $16 \%$ and significant increase is highlighted by $\left({ }^{*}\right)$ on the bars. C) Dual reporter vector consisting of LDHB SCCs were expressed in HeLa and were treated with or without $100 \mu \mathrm{g} / \mu \mathrm{l}$ of G418 to induce RT. All three stop codons TGG, TGA and TAA showed a GFP band indicating expression of SCCs in both untreated and treated samples. Untreated TGA showed a luciferase band indicating RT while TAA showed no luciferase band. However, when induced with G418 both TGA and TAA showed luciferase band. TGG was the positive control as the stop TGA was mutated to encode tryptophan ensuring condition similar to $100 \%$ RT and actin band shows equal amount of proteins were loaded on the SDS gel. Mean $\pm S D, n=3$. P-value * $\leq 0.05$

\subsection{Read-through extended LDHB has functional PTS1}

We next wanted to detect RT extended LDHB (henceforth LDHBx) on western blot and for this open reading frame of LDHB, its stop codon TGA and 18 nucleotides beyond the stop until the next in-frame stop TAG (figure $\mathbf{8 A}$ ) was inserted into a dual reporter vector. Using the restriction 
Results

enzymes Nhel and BamHI the LDHBx was cloned into the MCS of vector that contained HA tag at its N-terminal and Myc-tag at its C-terminal (figure 8B). LDHBx stop mutants: TGG (encoding

A

\section{$\underline{\text { LDHBx nucleotide sequence }}$}

Start

ATGGCAACTCTTAAGGAAAAACTCATTGCACCAGTTGCGGAAGAAGAGGCAACAGTTCCA AACAATAAGATCACTGTAGTGGGTGTTGGACAAGTTGGTATGGCGTGTGCTATCAGCATTC TGGGAAAGTCTCTGGCTGATGAACTTGCTCTTGTGGATGTTTTGGAAGATAAGCTTAAAGG AGAAATGATGGATCTGCAGCATGGGAGTTATTTCTTCAGACACCTAAAATTGTGGCAGATA AAGATTATTCTGTGACTGCCAATTCTAAGATTGTAGTGGTAACTGCAGGAGTCCGTCAGCA AGAAGGGGAGAGTCGGCTCAATCTGGTGCAGAGAAATGTTAATGTCTCAAATTCATTATTC CTCAGATCGTCAAGTACAGTCCTGATTGCATCATAATTGTGGTTTCCAACCCAGTGGACAT TCTTACGTATGTTACCTGGAAACTAAGTGGATTACCCAAACACCGCGTGATTGGAAGTGGA TGTAATCTGGATTCTGCTAGATTTCGCTACCTTATGGCTGAAAAACTTGGCATTCATCCCA GCAGCTGCCATGGATGGATTTTGGGGGAACATGGCGACTCAAGTGTGGCTGTGTGGAGT GGTGTGAATGTGGCAGGTGTTTCTCTCCAGGAATTGAATCCAGAAATGGGAACTGACAAT GATAGTGAAAATTGGAAGGAAGTGCATAAGATGGTGGTTGAAAGTGCCTATGAAGTCATCA AGCTAAAAGGATATACCAACTGGGCTATTGGATTAAGTGTGGCTGATCTTATTGAATCCAT GTTGAAAAATCTATCCAGGATTCATCCCGTGTCAACAATGGTAAAGGGGATGTATGGCATT GAGAATGAAGTCTTCCTGAGCCTTCCATGTATCCTCAATGCCCGGGGATTAACCAGCGTT ATCAACCAGAAGCTAAAGGATGATGAGGTTGCTCAGCTCAAGAAAAGTGCAGATACCCTG TGGGACATCCAGAAGGACCTAAAAGACCTGTGACTAGTGAGCTCTAGGCTGTAG

\section{Stop1 RT extension Stop2}

B

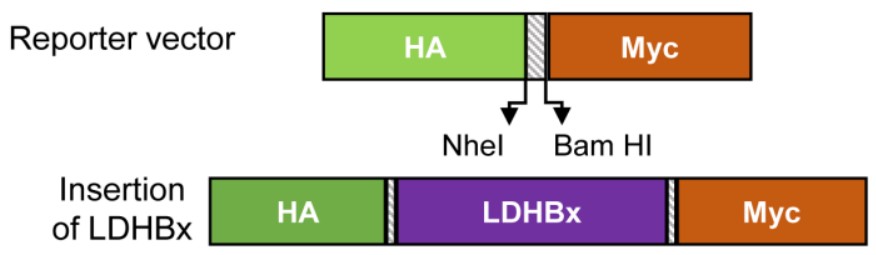

C

\begin{tabular}{|c|c|}
\hline $\begin{array}{c}\text { LDHBx } \\
\text { mutants }\end{array}$ & 3' extension nucleotide sequence \\
\hline TGA & A AAA GAC CTG TGA CTA GTG AGC TCT AGG CTG TAG \\
\hline TGA T & A AAA GAC CTG TGA TTA GTG AGC TCT AGG CTG TAG \\
\hline TAA & A AAA GAC CTG TAA CTA GTG AGC TCT AGG CTG TAG \\
\hline TAA T & A AAA GAC CTG TAA TTA GTG AGC TCT AGG CTG TAG \\
\hline TGG & A AAA GAC CTG TGG CTA GTG AGC TCT AGG CTG TAG \\
\hline
\end{tabular}

D

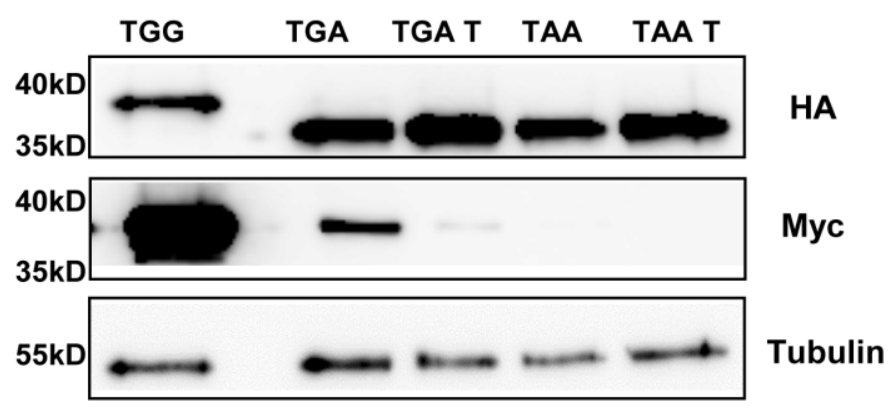


Results

Figure 8. Read-through analysis of LDHBx. RT was evaluated for full length LDHBx and its 3'context variants using dual reporter vector and RT proteins were analysed on western blot. A) The nucleotide sequence of LDHB is shown here. The start codon ATG is highlighted in green, the stop 1 (TGA) and stop 2 (TAG) in red followed by 18 nucleotide RT extension highlighted in blue. B) The dual reporter vector consisting of an HA and Myc tag is shown here into the MCS of which the LDHBx was inserted using the restriction enzymes Nhel and BamHI. C) A table showing the nucleotide sequence of wild type stop TGA of LDHBx and its variants: tryptophan encoding TGG variant, ochre stop variant TAA and the 3' context nucleotide variants TGA T and TAA T which were cloned into the HA-Myc dual reporter vector. D) Western blot shows HA band for all LDHBx stop variants suggesting expression of the proteins. However, only LDHBx TGG and TGA shows a Myc band indicating RT protein. While other variants failed to show a detectable RT protein.

tryptophan to mimic $100 \%$ RT), tighter stop TAA, point mutation of 3'context nucleotide (TGA T and TAA T) where cytosine $(\mathrm{C})$ to $(\mathrm{T})$ thymine were also included to analyse RT (figure $\mathbf{8 C}$ ). These reporter vectors were expressed in HeLa cells and were analysed with anti-HA and anti-Myc antibodies on western blot. The HA band indicated expression of LDHBx protein while expression of Myc band indicated RT of full length LDHBx. It was observed that except TGG and TGA none of the remaining context variants showed a Myc band suggesting absence of detectable readthrough (figure 8D). These experimental results demonstrate that the wild type stop TGA is more amenable to RT compared to TAA stop and mutation of 3' context seems to negatively affect RT.

We then investigated localization of LDHBx by microscopy which necessitated tagging of LDHBx with an enhanced yellow fluorescent protein (EYFP). It should be noted that percentage of RT proteins generated is lower compared to non-RT LDHB and therefore, the punctate fluorescence signal from the RT LDHBx cannot not be seen. In order to remove this strong background fluorescence, we developed a technique that enabled detection of fluorescence signal from the peroxisomes. We used a low concentration $(0.02 \%)$ of detergent digitonin which binds cholesterol and other $\beta$-hydroxysterols of the plasma membrane to create pores. As a result, the cellular content was leaked out which also reduced excessive fluorescence from the cytosol without any severe effects on the membranes of cellular organelles (Baghirova et al., 2015; Schulz, 1990). To observe fluorescently tagged proteins immunofluorescence (IF) was carried out which was modified by incorporating digitonin mediated cytosol removal (henceforth digitonin washed) step and to check if usage of digitonin affected sample preparation for microscopy the usual IF (henceforth unwashed) was always done in parallel. Digitonin amount required for microscopic analysis was optimised by expressing EYFP fused to the PTS1 of ACOX 3, a peroxisomal matrix protein (EYFP-PTS1) in HeLa cells. As negative control EYFP alone was expressed. 
Results

Unwashed and digitonin washed cells expressing EYFP-PTS1 showed punctate distribution of this fusion protein and upon labelling with peroxisomal matrix protein (PEX14) demonstrated peroxisome localization (figure 9B). On the other hand, EYFP in unwashed cells showed fluorescence signal in the cytosol (figure 9A, unwashed) but when subjected to digitonin treatment a complete removal of fluorescence signal was observed (figure 9A, digitonin washed). This technique was then extended to test localization of LDHBx in HeLa cells. A cytosolic distribution of fluorescence signal was observed in unwashed cells but when digitonin washed cells were analysed a punctate distribution of fusion proteins was observed very much similar to EYFP-PTS1. Further, when these puncta were co-localised with PEX 14, most of fluorescence signal from this fusion protein showed an overlap with signal from PEX14 (figure 10).

We next studied if localization of LDHBx was affected when the natural stop TGA was exchanged with a better stop TAA. For this study, we generated a stop codon mutant (LDHBx-TAAmt). As a control we also included another stop mutant (LDHBx-TGGmt) by exchanging the wild type stop codon TGA with tryptophan encoding TGG mutation and it was done to obtain $100 \%$ RT control. Unwashed cells expressing LDHBx-TAAmt demonstrated a cytosolic distribution of LDHBx and the digitonin washed cells showed removal of LDHBx proteins from the cytosol (figure 11B). However, LDHBX-TGGmt showed a punctate distribution of fluorescent signal similar to EYFPPTS1 and they also co-localised with PEX 14 suggesting peroxisome localization of LDHBxTGGmt (figure 11A). From this study we concluded that RT of LDHB is more favourable with TGA stop and that the RT extended LDHBx co-localizes with peroxisome marker protein PEX14.

To obtain more evidence that LDHBx localizes inside peroxisomes the PTS1 sequence (SRL) in its RT extension (figure $5 \mathrm{~B}$ ) was mutated to generate a deletion mutant (LDHBx- $\Delta \mathrm{Lmt}$ ) by deleting amino acid leucine (L) and a substitution mutant (LDHBx-SSImt) by exchanging arginine (R), leucine (L) with serine (S) and isoleucine (I) respectively. The stop codon TGA of LDHBx in these PTS1 mutants were changed to tryptophan encoding TGG codon to ensure that localization of LDHBx is not affected by the intervening stop codon. Analysis of HeLa cells expressing LDHBx$\Delta \mathrm{Lmt}$ and LDHBx-SSImt in unwashed cells showed cytosolic distribution of LDHBx protein while the digitonin washed cells showed no fluorescence signal at all as they were completely leaked out (figure 12).

In essence, we were successful in optimising the IF protocol that enabled us to examine RT extended LDHBx inside peroxisomal sub-compartment. Secondly, we observed that the exchange of leaky stop codon TGA with TAA or TGG affected localisation of LDHBx and finally, when amino acids in the PTS1 targeting signal altered (either deleted or substituted) it affected the targeting 
efficiency of LDHBx. We then analysed localization of RT LDHB by direct immunofluorescence in monkey kidney fibroblast line, COS-7 cells (figure 13A) and human glioblastoma cell line U118 (figure 13B) HeLa cells (figure 14A), human skin fibroblasts (figure 14B), using anti-LDHB and anti-PEX 14 antibodies.

A
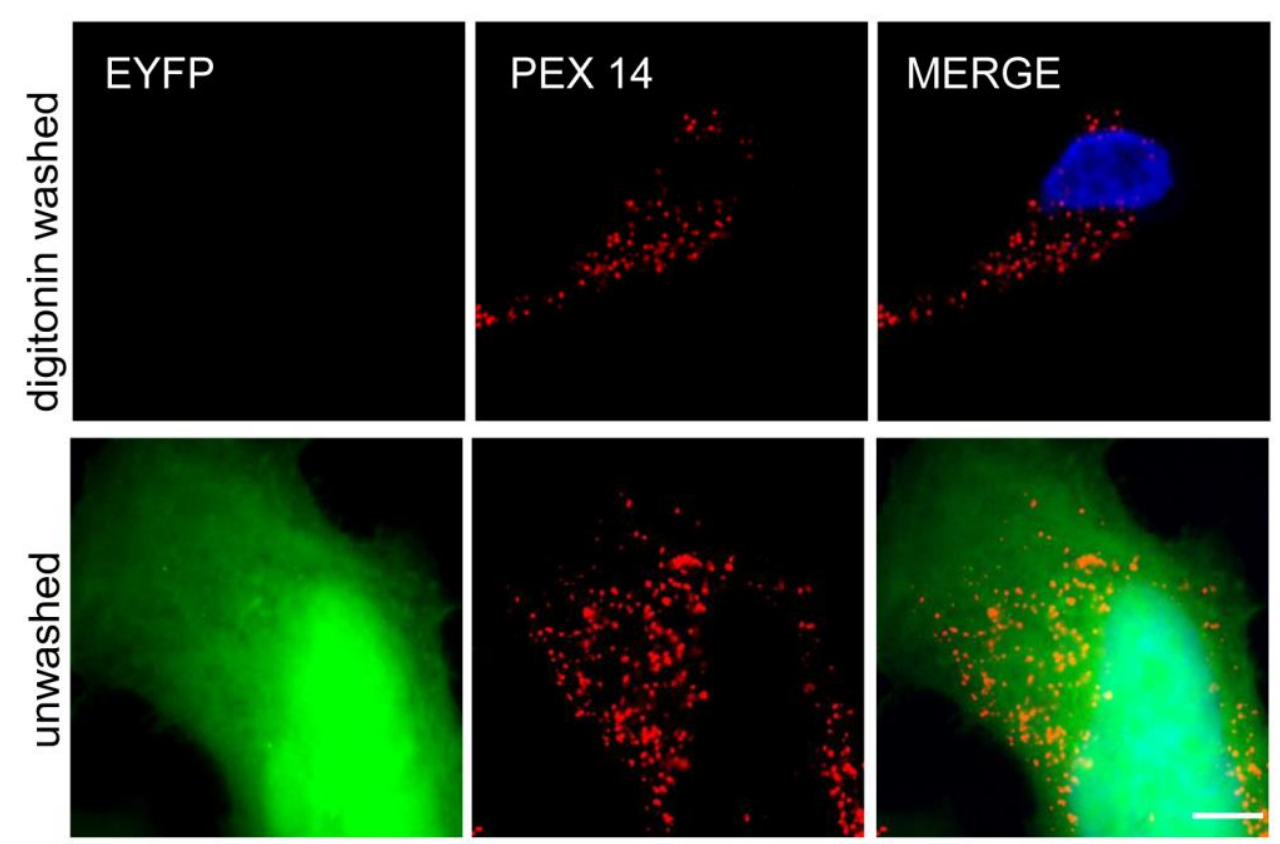

B
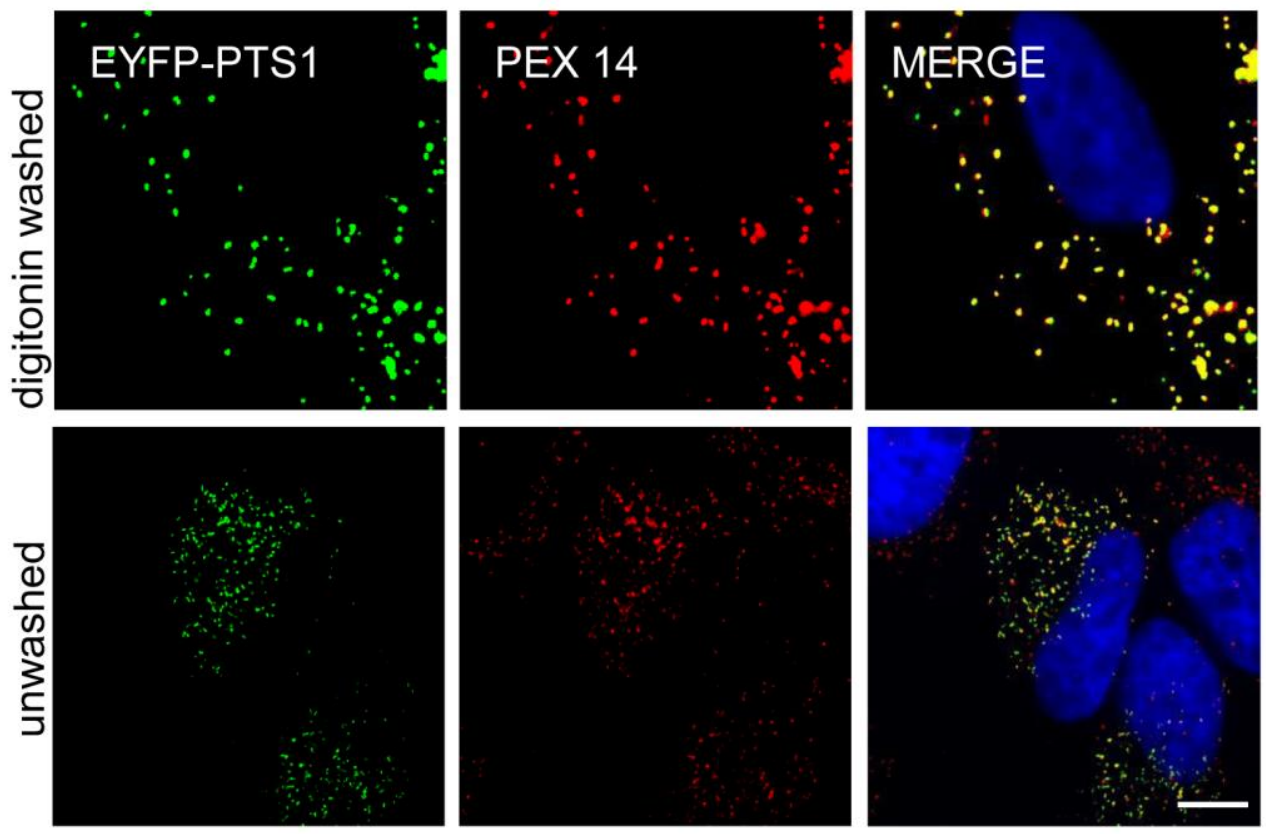

Figure 9: Optimization of immunofluorescence protocol. To observe fluorescence signal from the peroxisome sub-compartment the immunofluorescence (IF) protocol was modified slightly involving 
Results

detergent washout step before fixation of proteins. A) EYFP expressing HeLa cell shows a cytosolic distribution of fluorescence signal in the unwashed cells and absence of signal in digitonin washed cell. B) EYFP fusion protein consisting of ACOX3 PTS1 (EYFP-PTS1) shows a punctate distribution of fluorescence signal in both washed and unwashed cell. Also overlap of this signal with peroxisome membrane protein PEX 14 shows co-localization suggesting peroxisome localization. Pearson coefficient for digitonin washed cells was calculated using ImageJ plugin, JACOP. EYFP, $r=0.06$ and EYFP-PTS1, $r=0.69$. Scale $10 \mu \mathrm{m}$

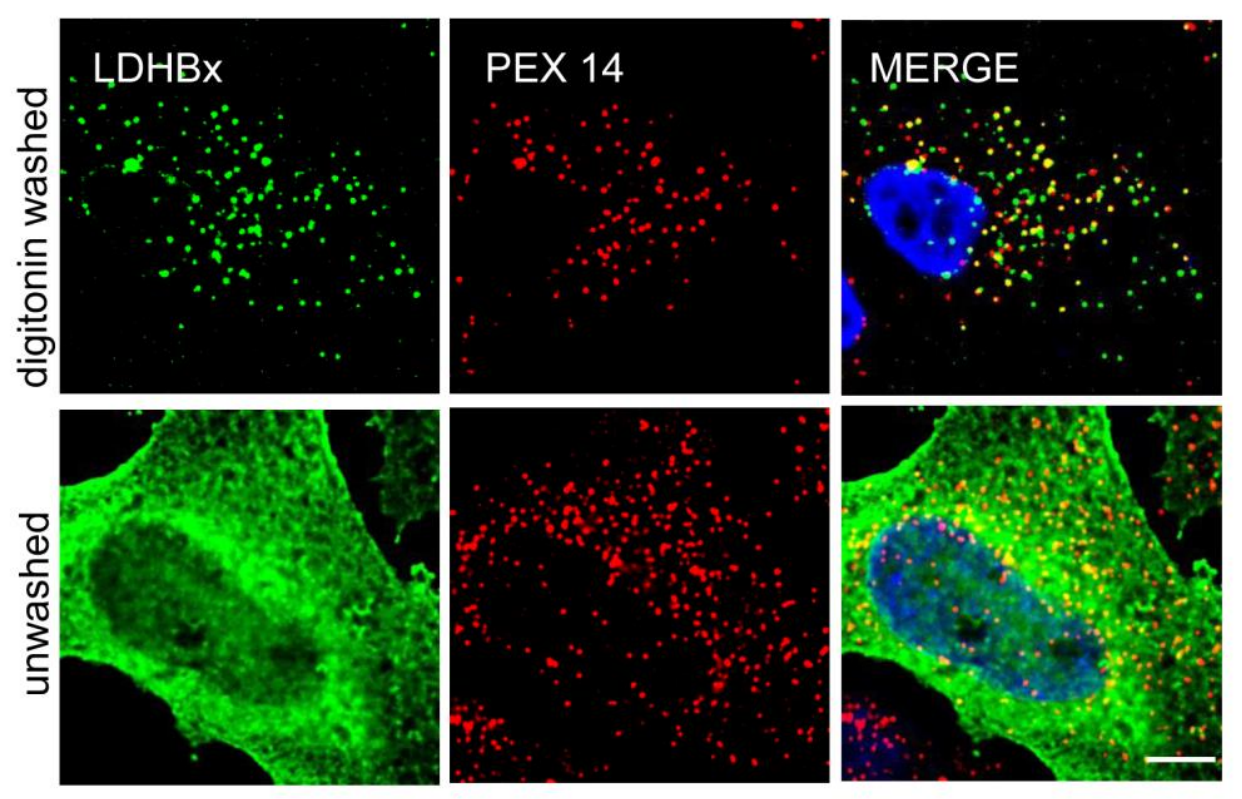

Figure 10: Immunofluorescence show peroxisomal isoform of LDHB. HeLa cells were expressed with LDHBx protein containing an EYFP tag. Analysis of LDHBx using normal Immunofluorescence (IF) procedure shows a cytosolic distribution of proteins (unwashed). However, when modified IF procedure was adopted where the cells were treated with digitonin the non-RT cytosolic LDHB was washed out (digitonin washed) while the RT LDHBx localised inside peroxisomes as indicated by overlap with peroxisomal marker protein, PEX 14. Pearson coefficient for digitonin washed cell was calculated using ImageJ plugin, JACOP. LDHBX, $r=0.3$. Scale $10 \mu \mathrm{m}$. 
A
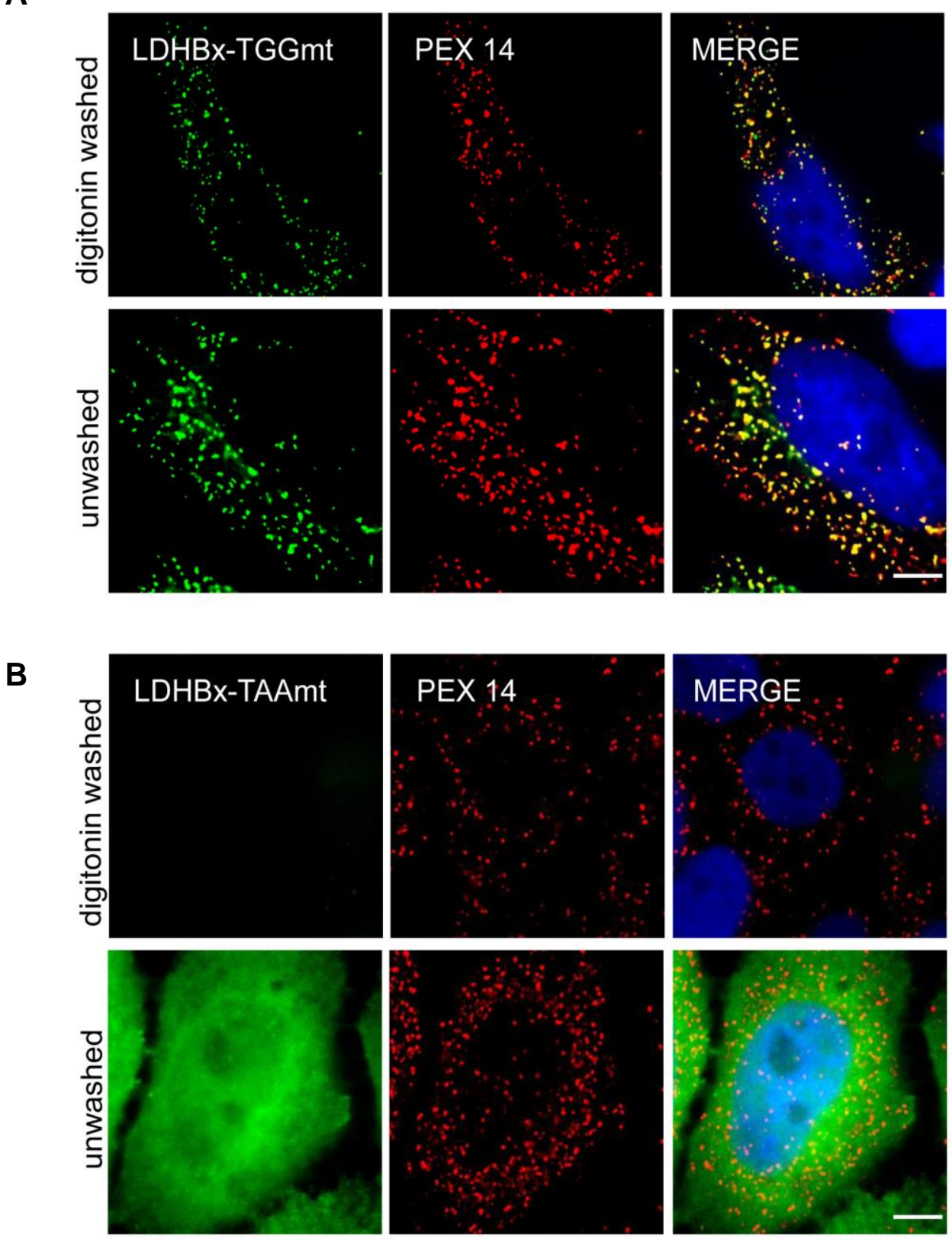

Figure 11: Exchange of stop codon affects LDHBx localization inside peroxisomes. A) LDHBxTGGmt is EYFP fusion protein consisting of stop codon mutant where the wild type TGA is mutated to TGG encoding tryptophan. When it was expressed in HeLa cells, both in unwashed and digitonin washed cells LDHBx showed a punctate distribution of fluorescence signal which co-localised with peroxisomal marker protein, PEX 14. B) LDHBX-TAAmt is EYFP fusion protein consisting of stop codon mutant where the wild type TGA is mutated to better stop TAA. Unwashed cell shows cytosolic distribution while the digitonin washed cell show absence of fluorescence signal and no co-localisation with PEX 14. Pearson coefficient was calculated for digitonin washed cells using ImageJ plugin, JACOP. LDHBX-TGGmt, $r=0.5$ and LDHBX-TAAmt, $r=0.001$. Scale $10 \mu \mathrm{m}$. 
A
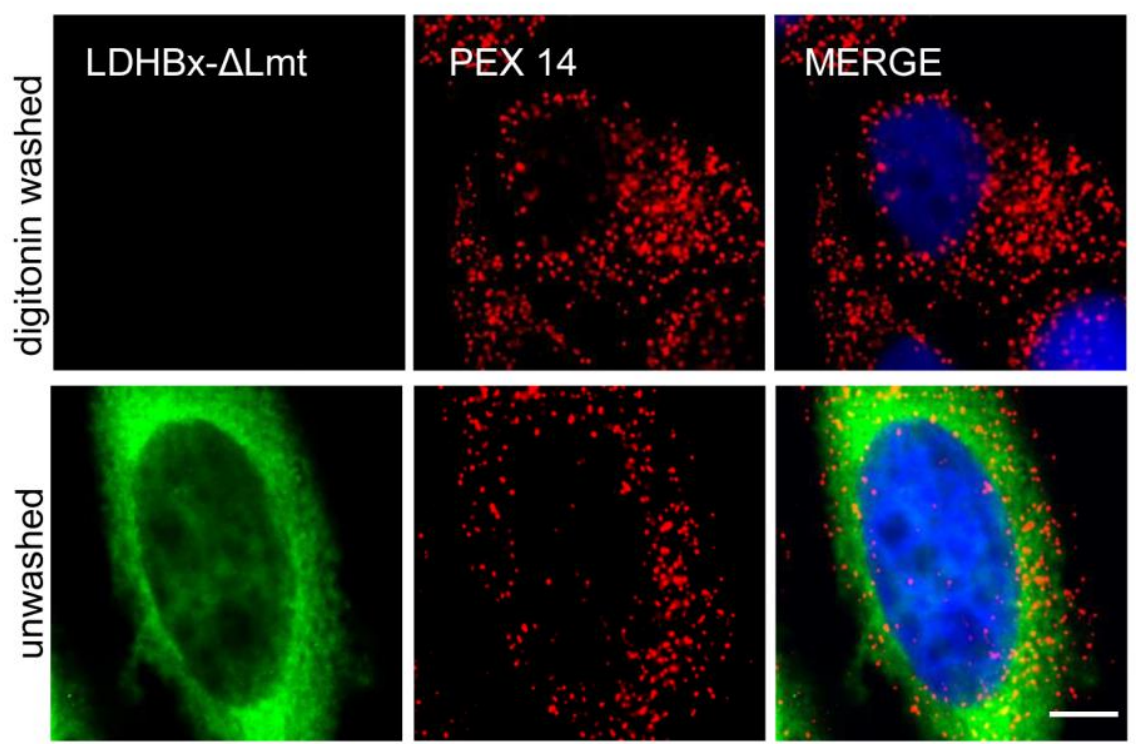

B
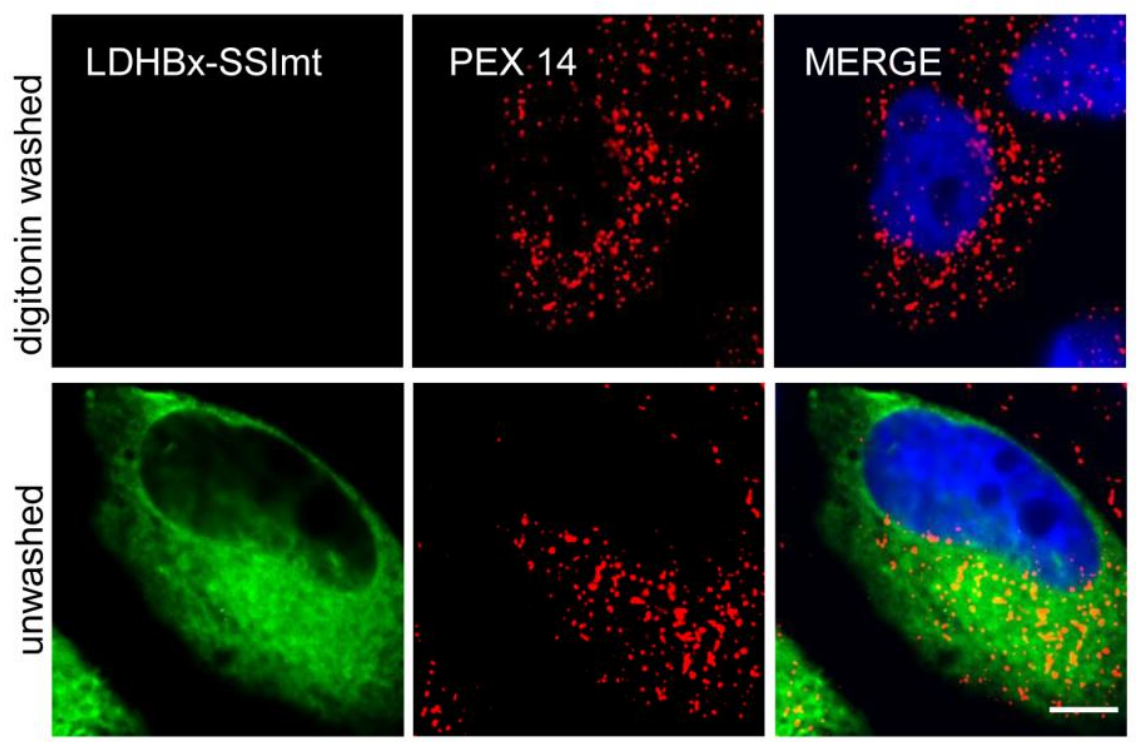

Figure 12: LDHBx localization inside peroxisomes is dependent on functional PTS1 in the RT extended protein. Stop suppression exposes the PTS1 sequence in the extension of LDHB protein and for localization of LDHBx intact targeting signal is essential. A) When HeLa cells were expressed with PTS1 deletion mutant of LDHBx, LDHBx- $\Delta \mathrm{Lmt}$ unwashed cells showed cytosolic distribution of LDHB while digitonin washed cell showed complete removal of EYFP signal. B) Similar observation was made when the PTS1 substitution mutant, LDHBx-SSImt was analysed. Unwashed cell showed cytosolic localization of LDHBx. Cells transfected with PTS1 mutants did show any co-localisation with PEX 14. Pearson coefficient was calculated for digitonin washed cells using ImageJ plugin, JACOP. LDHBX- $\Delta$ Lmt, $r=0.009$ and LDHBXSSImt, $r=0.003$. Scale $10 \mu \mathrm{m}$. 

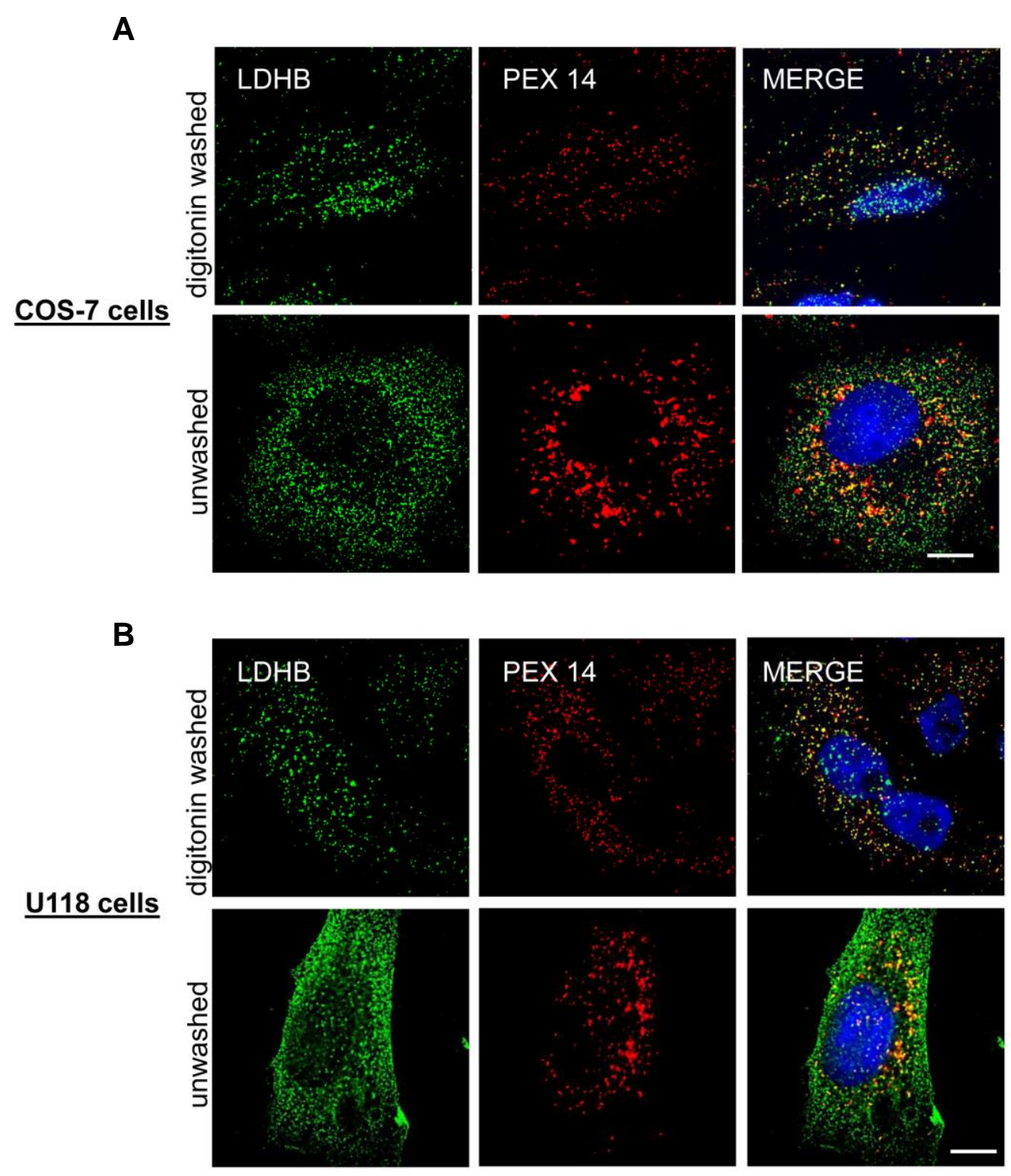

Figure 13: Peroxisomal localisation of read-through extended LDHB in different cell lines. Peroxisomal localisation of RT extended LDHB was examined in untransfected cell lines using anti-LDHB antibody and its localisation inside peroxisomes were checked with anti-PEX 14 antibody. Digitonin washed cells showed clear co-localisation of LDHB with PEX14 compared to the unwashed cells. A) COS-7 cells. B) human glioma cell lines, U118. Pearson coefficient was calculated for digitonin washed cells using Image J plugin, JACOP. COS-7, $r=0.7$. U118, $r=0.8$. Scale $10 \mu \mathrm{m}$. 


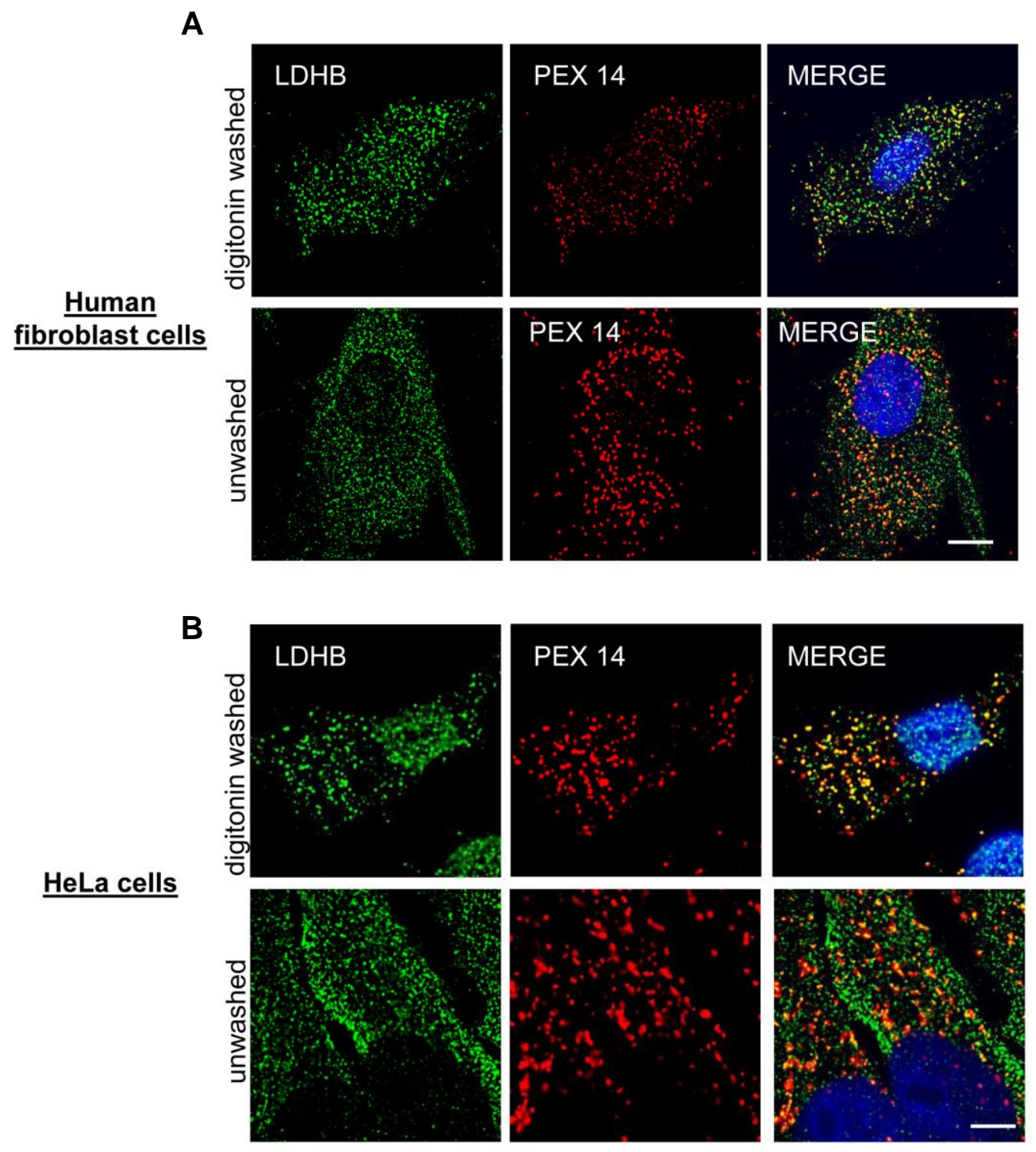

Figure 14: Peroxisomal localisation of read-through extended LDHB in different cell lines. Peroxisomal localisation of RT extended LDHB was examined in untransfected cell lines using anti-LDHB antibody and its localisation inside peroxisomes were checked with anti-PEX 14 antibody. Digitonin washed cells showed clear co-localisation of LDHB with PEX14 compared to the unwashed cells. A) human fibroblast cells. B) HeLa cells. Pearson coefficient was calculated for digitonin washed cells using ImageJ plugin, JACOP. Human skin fibroblast, $r=0.71$, HeLa, $r=0.8$. Scale $10 \mu \mathrm{m}$. 
Results

\subsection{Read-through LDHBx piggy-backs LDHA inside peroxisomes}

Lactate dehydrogenase is a highly conserved enzyme present in eukaryotes, Eubacteria and Archaea. A single gene underwent duplication event in vertebrates which resulted in two paralogous genes $L D H A$ and $L D H B$ ( $\mathrm{Li}$ et al., 2002) encoding LDHA and LDHB subunits respectively (Kopperschlager and Kirchberger, 1996). LDHA also known as the muscle (M) subunit is expressed mainly in the skeletal muscles whereas LDHB, the heart $(\mathrm{H})$ subunit is predominant in the cardiac muscles. They give rise to a mixture of tetrameric isoenzymes namely, LDH-1 or $\mathrm{H}_{4}$; LDH-2 or $\mathrm{H}_{3} \mathrm{M}$; LDH-3 or $\mathrm{H}_{2} \mathrm{M}_{2}$; LDH-4 or $\mathrm{HM}_{3}$ and LDH-5 or $\mathrm{M}_{4}$ with certain distribution patterns in human tissues (Boyer et al., 1963; Drent et al., 1996; Markert, 1963; Mohamed et al., 2015; Pesce et al., 1964). We have demonstrated in our previous experiments that $\mathrm{LDHB}$ can be extended by stop codon RT to generate LDHBx which is a slightly longer protein variant (extra seven amino acids) that localizes inside the peroxisomes. LDH-5 and LDH-4 HM isoforms were found in peroxisomal fractions of rat liver cells (Baumgart et al., 1996). We hypothesized that LDHA which does not contain any PTS may have associated with LDHBx and perhaps were co-imported to the peroxisomes together. Therefore, to investigate the role of LDHBx in transporting LDHA inside peroxisomes we carried a two-hybrid assay that involved LDHBX-TGGmt and LDHA.

LDHA was tagged with EYFP and LDHBx-TGGmt with ECFP fluorescent tags. They were coexpressed in HeLa cells and the expressed proteins were analysed microscopically for their localization inside peroxisomes. It was observed that when LDHA was expressed in the absence of LDHBx-TGGmt cells showed cytosolic distribution of the fluorescence signal (figure 15A, unwashed) and when cytosol was removed by detergent there was complete removal of LDHA (figure 15A, digitonin washed). However, when LDHA was co-expressed with LDHBx-TGGmt a punctate distribution of LDHA and LDHBX-TGGmt was observed that also co-localised with PEX14 (figure 15B). This suggested LDHA can oligomerize with RT extended LDHB which can then be targeted to the peroxisomes. In order to confirm that peroxisomal localisation of LDHA is dependent on the PTS1 of RT extended LDHB we tested the co-localisation of LDHA with PEX 14 in the presence of targeting signal mutants.

Two conditions were essential for LDHBx to localize inside peroxisomes - stop codon RT and non-mutated PTS1 sequence. Results from our previous two-hybrid assay indicate that RT extended LDHB associates with LDHA and to show that localisation is entirely dependent on PTS1 of RT extended LDHB we co-expressed PTS1 substitution and deletion mutants. Analysis of cells 
A

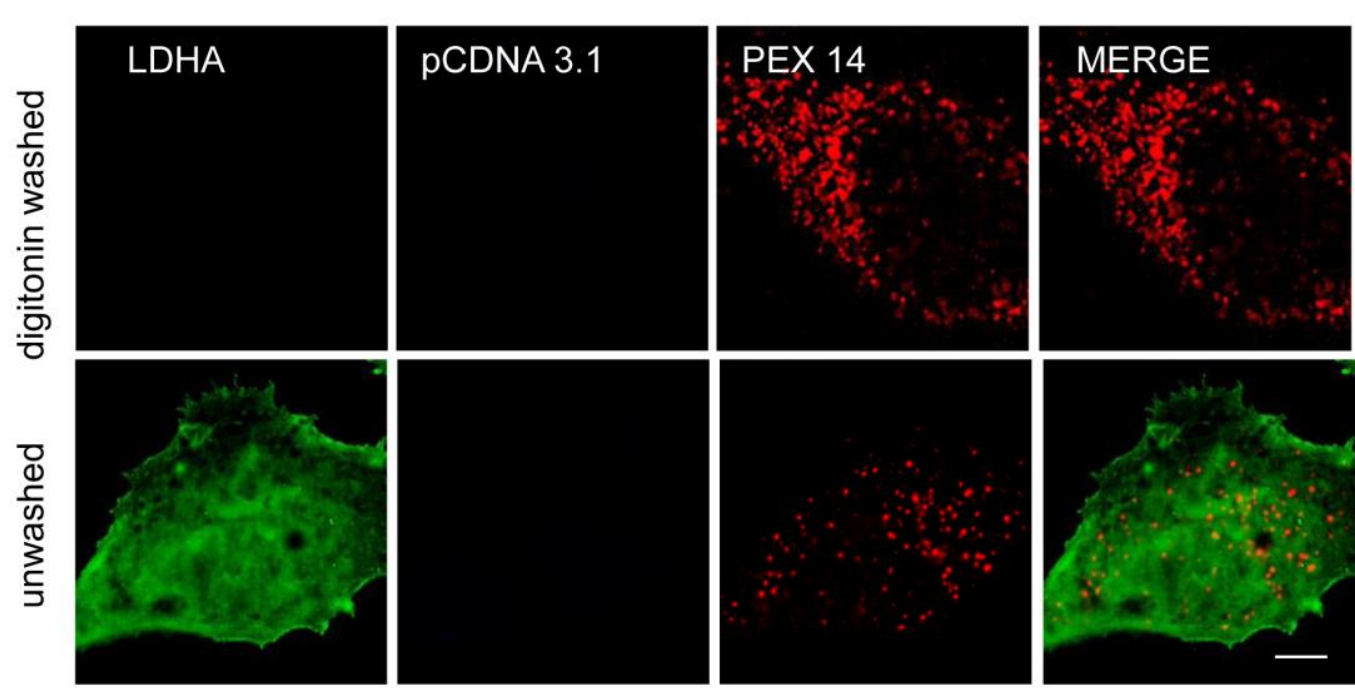

B

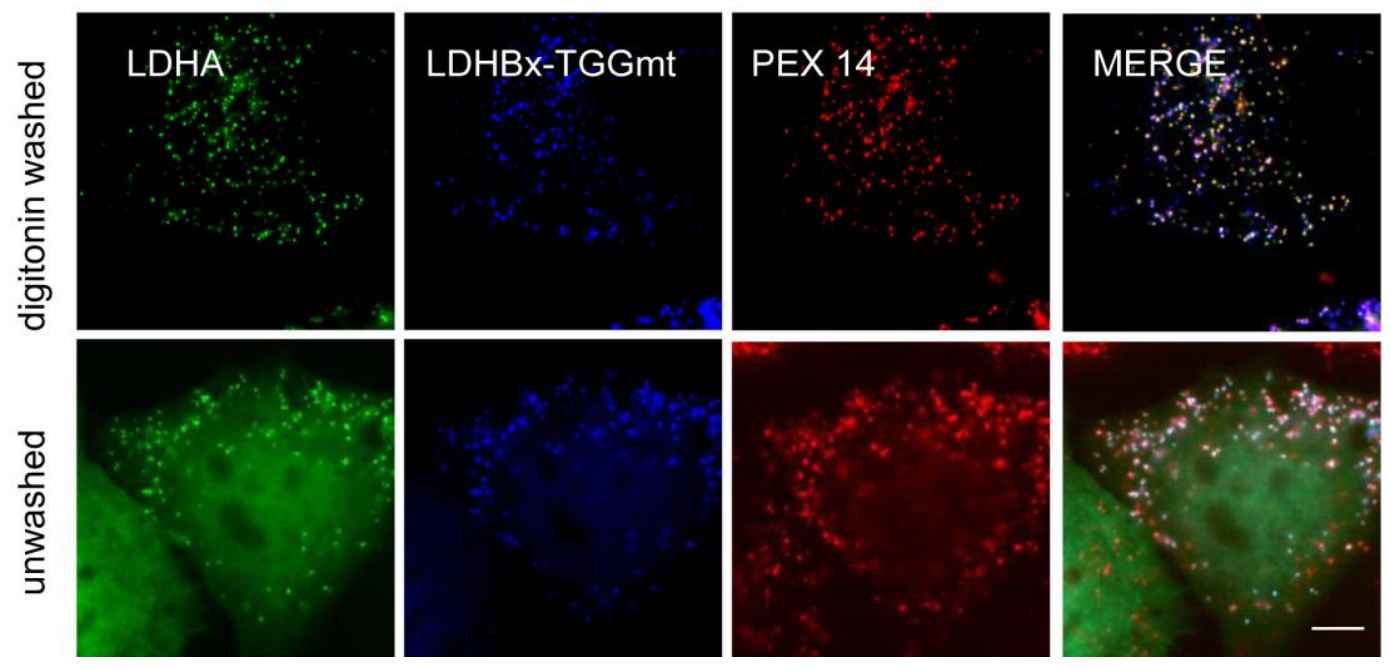

Figure 15: LDHA associates with LDHBx and localises inside peroxisomes. A) HeLa cells were transfected with pCDNA3.1 vector containing no fluorescent tag. When cells expressed LDHA (green) it showed a cytosolic localisation of the expressed protein (washed). Upon digitonin treatment the fluorescence signal was washed out of the cell (digitonin washed) and hence no peroxisome localisation. B) ECFP tagged LDHBX-TGGmt (blue) when co-expressed with EYFP tagged LDHA (green), a punctate distribution of both proteins were observed in digitonin washed cells and few proteins showed punctate pattern in unwashed cells too. Also when these proteins were overlapped with PEX 14 (red) signal both proteins demonstrated co-localisation. Scale $10 \mu \mathrm{m}$. 
A
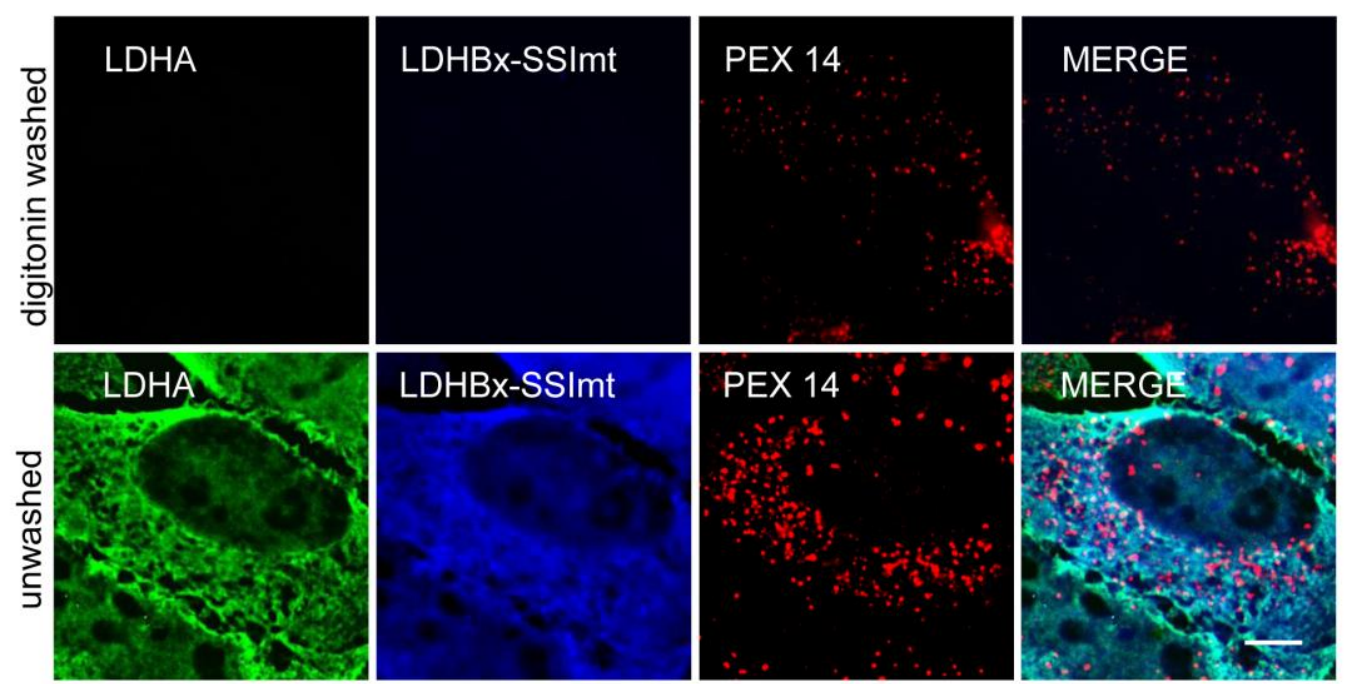

B
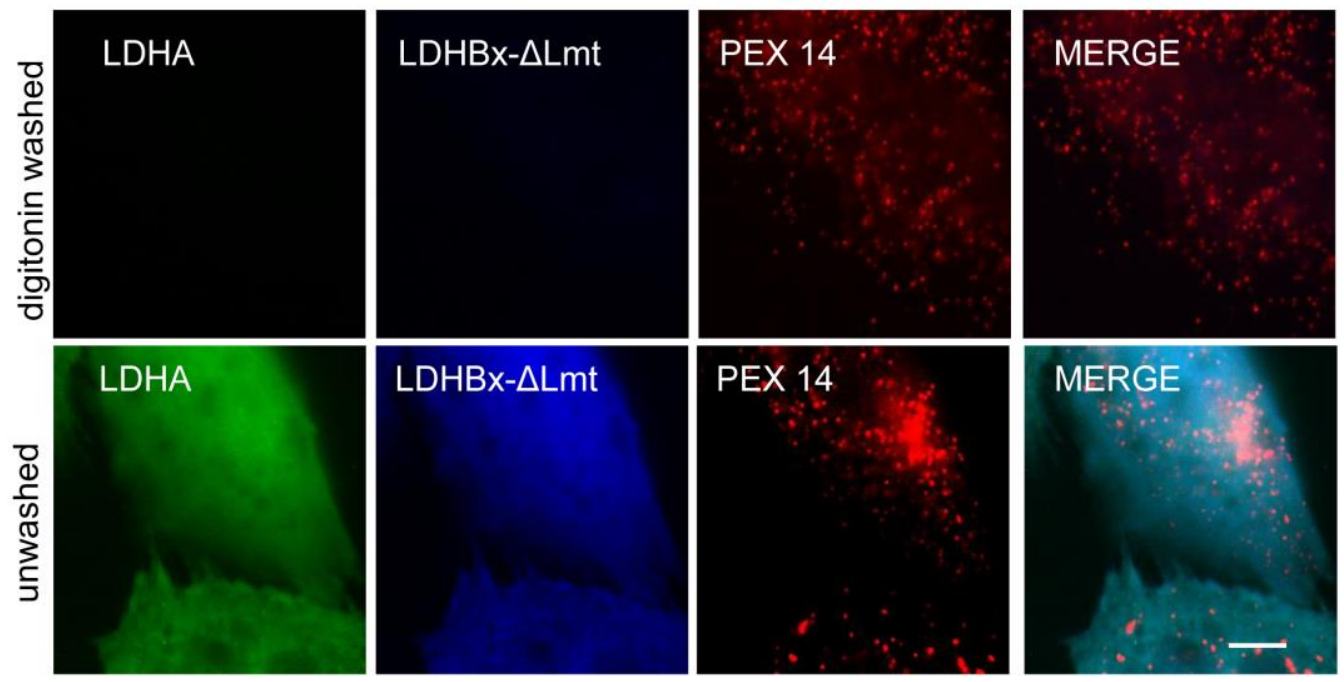

Figure 16: LDHA co-import inside peroxisomes is dependent on the peroxisome targeting signal of the read-through LDHB. A) EYFP tagged LDHA (green) was co-expressed with ECFP tagged LDHBxSSImt (blue). Unwashed cells showed cytosolic distribution of both LDHA and LDHBX-SSmt while digitonin washed cells demonstrated absence of any fluorescence signal. B) EYFP tagged LDHA (green) was coexpressed with ECFP tagged LDHBx- $\Delta$ Lmt (blue). and co-localisation of these proteins with PEX 14 was analysed by microscopy. Cytosolic distribution of both LDHA and LDHBx- $\Delta \mathrm{Lmt}$ was observed in unwashed cells and digitonin treated cells demonstrated wash out of all fluorescence signal. Also, neither the PTS1 mutants LDHBx- $\Delta$ Lmt/LDHBx-SSmt nor LDHA co-localise with PEX14 indicating absence of peroxisome localisation. Scale $10 \mu \mathrm{m}$. 
expressing LDHA and LDHBx-SSImt (figure 16A) and LDHBx- $\triangle$ Lmt (figure 16B) respectively demonstrated no LDHA co-localization with PEX 14 which confirmed PTS1 mediated localization of LDHA. This co-import inside peroxisomal matrix can be considered as an example to demonstrate peroxisome's unique ability to allow import of oligomeric proteins. Here, a non-PTS1 LDHA associates with a PTS1 containing LDHBx subunit to form an import complex that manages to cross the peroxisomal membrane (Lanyon-Hogg et al., 2010; McNew and Goodman, 1996; Schueren et al., 2014).

As this interaction between RT extended LDHBx and LDHA could not be demonstrated by coimmunoprecipitation, we performed a fluorescence loss in photo-bleaching (FLIP) experiment to support the conclusion of the co-import experiments. Briefly, FLIP is used to analyse movement of molecules inside cells and in the membranes and provides information about protein dynamics in different cellular regions. A small region inside the cell (region of interest, $\mathrm{ROI}$ ) is bleached several times using the laser beam of a confocal laser scanning microscope and images are taken between programmed bleaching of $\mathrm{ROI}$ with reduced laser power with a time lag (figure 17A). Since unbleached fluorophores are constantly exchanged for bleached fluorophores inside the cells multiple bleaching iterations ensure destruction of all fluorophores in the cell. This loss of fluorescence from other areas in the cell due to repeated photo-bleaching of $\mathrm{ROI}$ manifest the level of continuity and communication between subcellular compartments (Goodwin and Kenworthy, 2005).

For the FLIP study, LDHBx-TGGmt tagged with ECFP and EYFP tagged LDHA were coexpressed as demonstrated by the pre-bleach image (figure 17B). ROI was selected in the cell shown by a small white box (in the post-bleach image) that selectively photo-bleached the EYFP molecules. ECFP molecules in the same region were not affected as shown by the pre and postbleach images (figure 17B, left panel). With time the intensity of EYFP fluorescence signal diminished in the ROI which reduced the background signal significantly and displayed the punctate structures similar to LDHBx-TGGmt. This indicated LDHA and LDHBx-TGGmt colocalised while the co-expression of LDHA with LDHBx- $\Delta \mathrm{Lmt}$ showed absence of any punctate structures (figure 17B, right panel). Although, these experimental results do not give a direct evidence that LDHA was localised inside peroxisomes but it does validate the association of LDHA with LDHBx. Also, we previously showed that LDHBx-TGGmt co-localises with the peroxisome marker, therefore we conclude that LDHA was co-imported inside peroxisomes. 


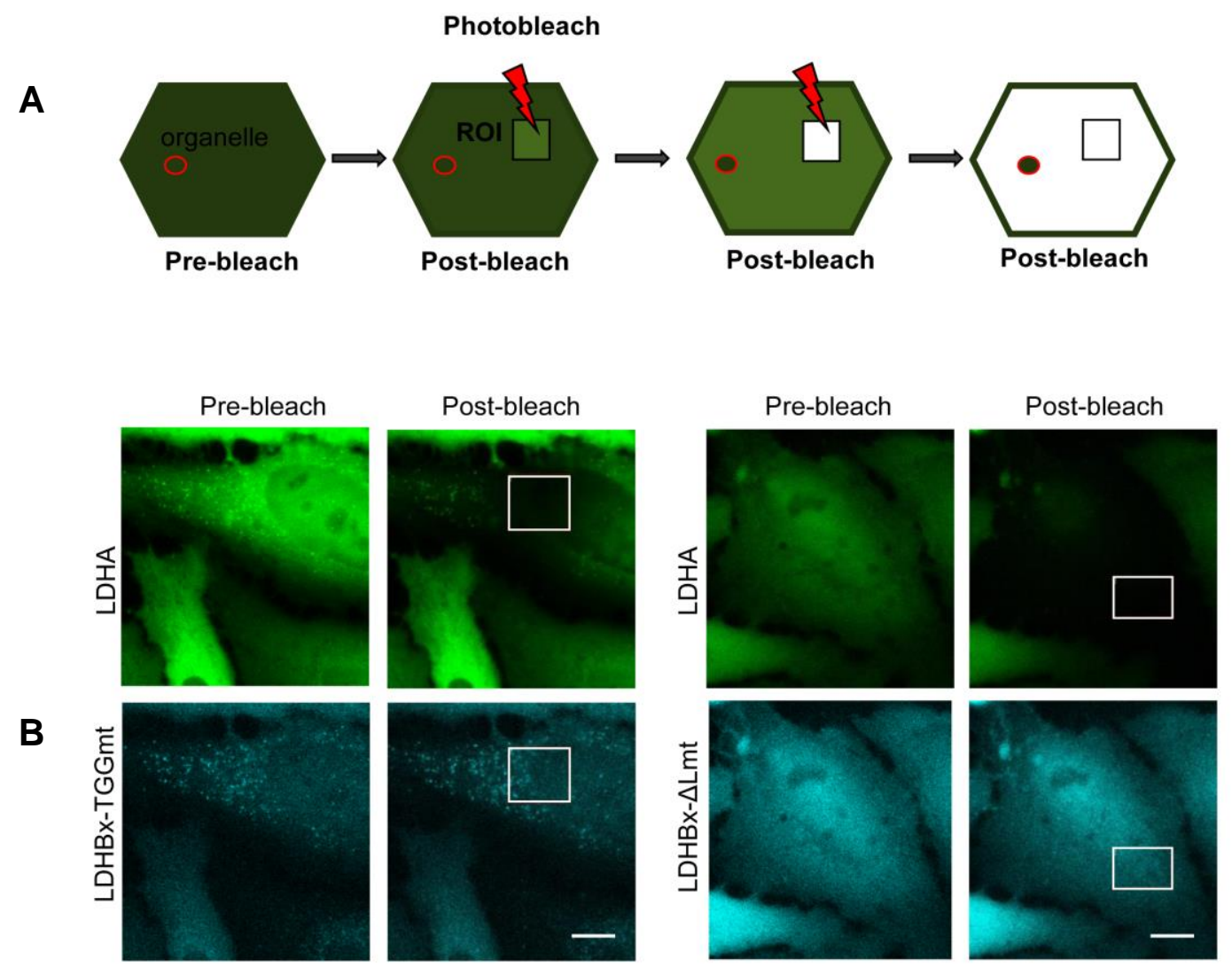

Figure 17: Fluorescence loss in photo-bleaching (FLIP) shows localisation of LDHBx with LDHA. A) schematic representation of photo-bleaching process is shown here. Cells were transfected with protein of interest with a fluorescent tag. A small region of interest, ROI (square) is selected which will be subjected to repeated photo-bleaching by an intense laser beam. A red circle represents any organelle inside the cells away from the ROI. Cells before bleaching is labelled as pre-bleach cell and after bleach as post-bleach. Unbleached fluorescent protein outside the ROI will constantly exchange with the bleached protein thus leading to an overall loss in fluorescence. Only those proteins which were protected inside cellular subcompartments that remained unaffected by the harmful laser beam will show fluorescence. B) pre and post bleached cell (left panel) transfected with EYFP-LDHA and ECFP-LDHBx-TGGmt fusion proteins is shown. Only EYFP molecules are bleached ensuring no damage to ECFP molecules. ROI is represented by a white box and this area is repeatedly photo-bleached. Depletion of EYFP outside ROI shows punctate LDHA similar to punctate read-through LDHBX-TGGmt. Similarly, pre and post bleached cells expressing EYFPLDHA and ECFP-LDHBx- $\Delta$ Lmt (right panel) is shown. Repeated bleaching of ROI shows no punctate LDHA. 


\subsection{Detection of potential interaction partners of LDHB}

With the aim of characterising RT extended LDHB we decided to identify the amino acid that was incorporated at the stop codon TGA. Tissue lysates prepared from rat organs- heart, liver, kidney, muscle and fat tissue were immunoprecipitated (IP) with anti-LDHB antibody (figure 18). Rat tissue were permeabilized with digitonin to release cytosolic proteins before lysing them in RIPA buffer. As control protein lysates were also prepared from tissues not permeabilized with digitonin. They were then precipitated with anti-LDHB antibody and the immuoprecipitates from digitonin treated and untreated cells were resolved on SDS gel. Separated proteins were stained with Coomassie dye and protein bands (approximately 35kD) were excised, de-stained and digested to elute out the proteins for mass spectrometric analysis (courtesy Dr. Olaf Jahn, MPI for Experimental Medicine). The protein amount in the eluate were too low to uncover the peptides derived from the sense-translation of the stop codon. The experiment however, allowed the identification of other proteins which were pulled down as complex with LDHB. After extensive sorting of proteins from the initial list in the given tissue type, a score system was assigned to them. For example, if protein ' $A$ ' was present in all five tissue types a score of 5 was assigned, if present in only three tissue types then 3 and so on. However, if a protein was absent in any tissue, then a score of 0 was assigned. Proteins that scored 0 were ignored and remaining proteins were organized on the basis of their presence or absence in both the digitonin treated and untreated sample. Only those proteins which were common to digitonin treated and untreated lists earned a total score of 2 which was also the threshold. As a result, a compact list of 29 proteins (table 2) was obtained and we observed GAPDH followed by LDHA among the top of the list. Interaction of LDHA with LDHB is well known so focus on the association of GAPDH with LDHB.
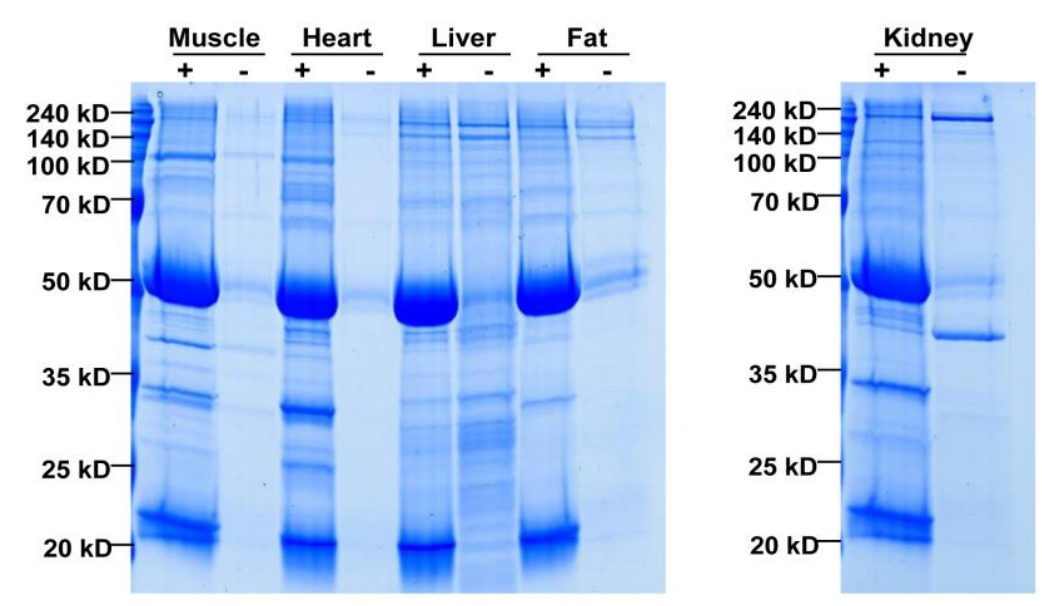
Results

Figure 18: Immunoprecipitation of rat tissue. Rat tissue from muscle, heart, liver, fat and kidney were isolated and permeabilized with digitonin for $10 \mathrm{~min}$ to release cytosolic proteins. Tissue lysates were then immunoprecipitated with anti-LDHB antibody and the immunoprecipitates were run on SDS gel. Coomassie stained picture of SDS gel with rat tissue lysates: muscle, heart, liver, fat and kidney permeabilized with digitonin indicated by $(+)$ and not permeabilized indicated by $(-)$ is shown. For the mass spectrometric analysis, $35 \mathrm{kD}$ size gel slice was excised from each sample and were processed. Tissues were immunoprecipitated in our research lab while the analysis was carried out in the department of Dr. Olaf Jahn.

\begin{tabular}{|c|c|}
\hline Number & LDHB interacting proteins \\
\hline 1 & Glyceraldehyde-3-phosphate dehydrogenase \\
\hline 2 & L-lactate dehydrogenase $\mathrm{A}$ chain \\
\hline 3 & $60 \mathrm{~S}$ acidic ribosomal protein $\mathrm{PO}$ \\
\hline 4 & 2-oxoisovalerate dehydrogenase subunit beta, mitochondrial \\
\hline 5 & 60S ribosomal protein L5 \\
\hline 6 & Actin, cytoplasmic 1 \\
\hline 7 & Guanine nucleotide-binding protein $\mathrm{G}(\mathrm{I}) / \mathrm{G}(\mathrm{S}) / \mathrm{G}(\mathrm{T})$ subunit beta-2 \\
\hline 8 & Guanine nucleotide-binding protein $\mathrm{G}(\mathrm{I}) / \mathrm{G}(\mathrm{S}) / \mathrm{G}(\mathrm{T})$ subunit beta-1 \\
\hline 9 & Anionic trypsin-1 \\
\hline 10 & Malate dehydrogenase, cytoplasmic \\
\hline 11 & NADH dehydrogenase [ubiquinone] 1 alpha sub complex subunit 9, mitochondrial \\
\hline 12 & Pyruvate dehydrogenase E1 component subunit beta, mitochondrial \\
\hline 13 & Ubiquitin thioesterase OTUB1 \\
\hline 14 & Prohibitin-2 \\
\hline 15 & Histone H1.4 \\
\hline 16 & 60S ribosomal protein L6 \\
\hline 17 & F-actin-capping protein subunit alpha-2 \\
\hline 18 & Serine/threonine-protein phosphatase PP1-beta catalytic subunit \\
\hline 19 & Guanine nucleotide-binding protein $\mathrm{G}(\mathrm{i})$ subunit alpha-2 \\
\hline 20 & Electron transfer flavoprotein subunit alpha, mitochondrial \\
\hline 21 & Translocon-associated protein subunit alpha \\
\hline 22 & ATPase family AAA domain-containing protein 1 \\
\hline 23 & Creatine kinase M-type \\
\hline 24 & Four and a half LIM domains protein 1 \\
\hline 25 & Voltage-dependent calcium channel gamma-1 subunit \\
\hline 26 & ADP/ATP translocase 1 \\
\hline 27 & ADP/ATP translocase 2 \\
\hline
\end{tabular}


Results

\begin{tabular}{|c|l|}
\hline 28 & Guanine nucleotide-binding protein $\mathrm{G}(\mathrm{I}) / \mathrm{G}(\mathrm{S}) / \mathrm{G}(\mathrm{T})$ subunit beta-3 \\
\hline 29 & NADH dehydrogenase [ubiquinone] 1 alpha sub complex subunit 10, mitochondrial \\
\hline
\end{tabular}

Table 2: LDHB interacting proteins. Mass spectrometric analysis of rat tissues (muscle, heart, liver, fat and kidney) after immunoprecipitation with anti-LDHB yielded following list of proteins which formed complex with LDHB.

Glyceraldehyde 3-phosphate dehydrogenase (GAPDH) is the abundant cytosolic protein present inside the cell which also uses $\mathrm{NAD}+\mathrm{NADH}$ as a substrate. It has been shown by various groups that GAPDH can localise to several compartments inside the cell. In addition to the cytoplasm, it may be found in the Golgi apparatus, endoplasmic reticulum (ER) and the nucleus (Sirover, 2005; Sirover, 2012; Tristan et al., 2011). Findings of the study group (Svedruzic and Spivey, 2006) demonstrated by PEG induced co-immunoprecipitation (Co-IP) and native gel electrophoresis demonstrated that LDH (both muscle form and heart form) interact with GAPDH. Studies have also shown co-localisation of LDH isozymes and GAPDH on cellular structures (Knull and Walsh, 1992). This evidence coupled with the pull down of GAPDH from rat tissue immunoprecipitates suggested that a functional relationship exist between LDH and GAPDH. To explore the endogenous specificity between the two proteins, Co-IP experiment was carried out. GAPDH and LDHB immunoprecipitates were prepared using rat organ tissues and as negative control for the IP, rat tissues not incubated with IP antibodies were used instead of the IgG control. This was done to check if the beads used in the IP interacts non/specifically with any other proteins of the tissue lysate. IP with anti-LDHB antibody of brain, heart, kidney and muscle tissues showed a CoIP of GAPDH. Except liver, all tissues showed a $37 \mathrm{kDa}$ band and it is clear from the input control that the protein from liver sample appears either insufficient or degraded. The bead control for anti-LDHB IP shows bands for the heart and muscle tissues which we think could be due to excess amount of protein (figure 19A). Anti-GAPDH immunoprecipitates of heart, liver, kidney and muscles demonstrated Co-IP of LDHB as indicated by 35kDa band (figure 19B).

We mentioned above that GAPDH was found in many different cellular compartments (Sirover, 2005; Sirover, 2012; Tristan et al., 2011) however, its association or occurrence inside peroxisomes in mammals is not known. Pathogenic fungi as well as parasite trypanosomes provide evidence for peroxisomal GAPDH (Ast et al., 2013) which led us to examine association of RT extended LDHBx with GAPDH and its import inside the peroxisomes. The two-hybrid assay described before was done to determine if GAPDH can also interact with read-through extended LDHB. The objective was to analyse interaction of GAPDH with LDHBx and thereby get 
transported into the peroxisomal matrix. For the analysis, GAPDH was cloned into an EYFP vector and it was co-expressed with LDHBx-TGGmt fused to ECFP tag. LDHBx-TGGmt was used because compared to LDHBx the TGG mutant shows more peroxisomal localisation and therefore it would be more informative. As GAPDH is a cytosolic protein without any PTS sequence it demonstrated a uniform distribution of fluorescence signal in the cytosol (figure 20A, unwashed). When permeabilized with digitonin, it showed a punctate pattern which overlapped with LDHBxTGGmt and their merge with peroxisome marker demonstrated co-localisation of GAPDH and LDHBx-TGGmt with PEX 14 (figure 20A, digitonin washed). Again, to verify if GAPDH localization inside peroxisomes was dependent on targeting signal of RT extended LDHBx, GAPDH was coexpressed with PTS1 substitution mutant, LDHBx-SSImt. The results showed that GAPDH and LDHBx-SSImt in unwashed cells were cytosolic (figure 20B, unwashed) whereas the digitonin washed cells showed neither LDHBx-SSImt nor GAPDH co-localising with PEX14 (figure 20B, digitonin washed). From these preliminary results, we assume that LDHBx can associate with GAPDH and under certain conditions it can piggy-back GAPDH inside peroxisomal matrix but we need more evidence to support this hypothesis.

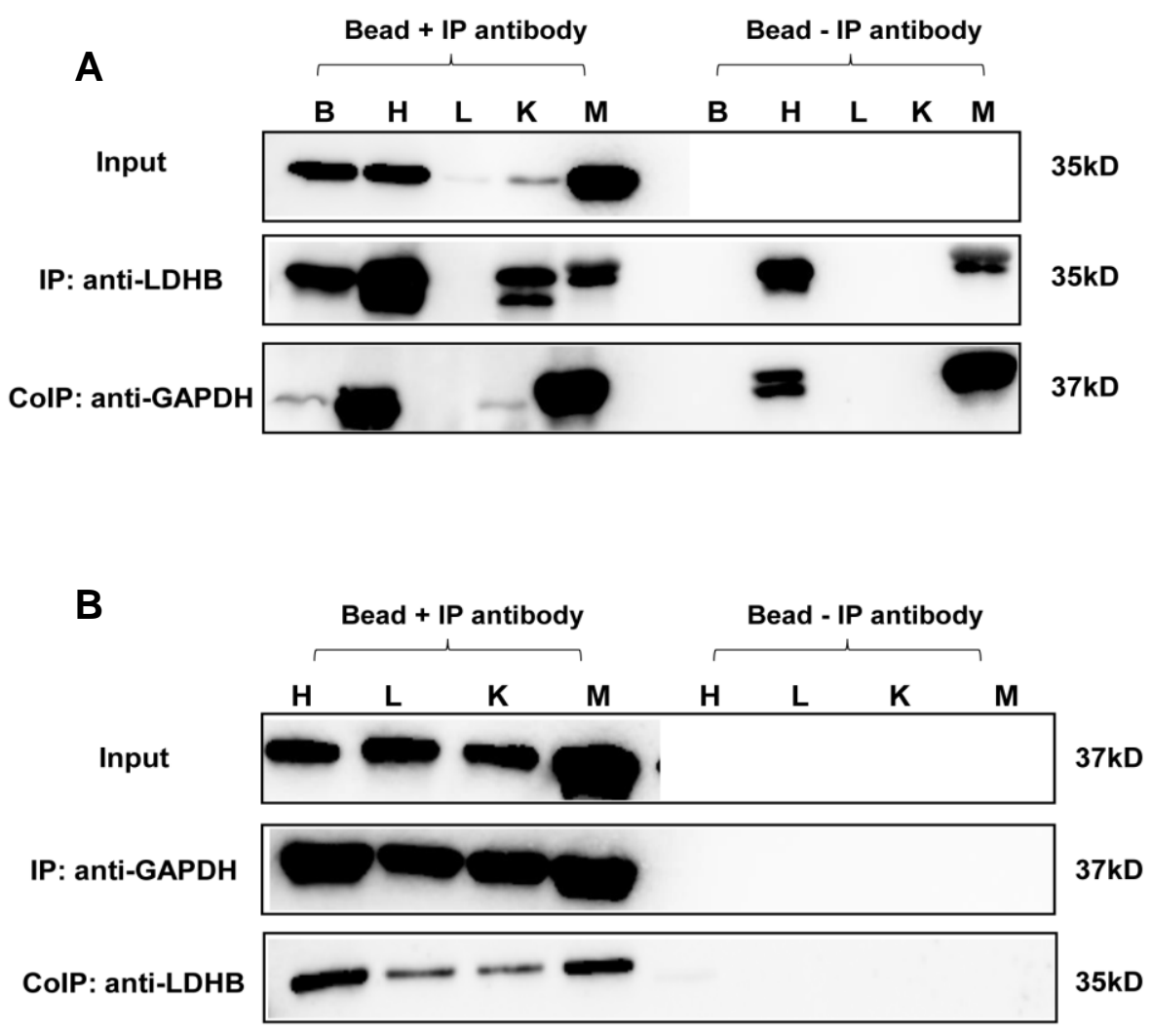


Figure 19: LDHB and GAPDH are interaction partners. A) Rat tissues: brain, heart, liver, kidney and muscle were immunoprecipitated with anti-LDHB antibody (IP panel). Instead of the IgG control we used Bead - antibody control where the tissue lysates were treated the same except its incubation with antiLDHB antibody. The precipitated proteins were then immunoblotted to check the pull down of GAPDH as indicated by the Co-IP panel. The input panel shows the amount of protein in the beginning of the experiment. B) Rat tissues heart, liver, kidney and muscle were immunoprecipitated with anti-GAPDH antibody (IP panel). As mentioned above Bead-IP antibody was the negative control. Precipitated proteins were immunoblotted to check the pull down of LDHB (Co-IP panel) while the input panel shows the protein level present before the immunoprecipitation.

A
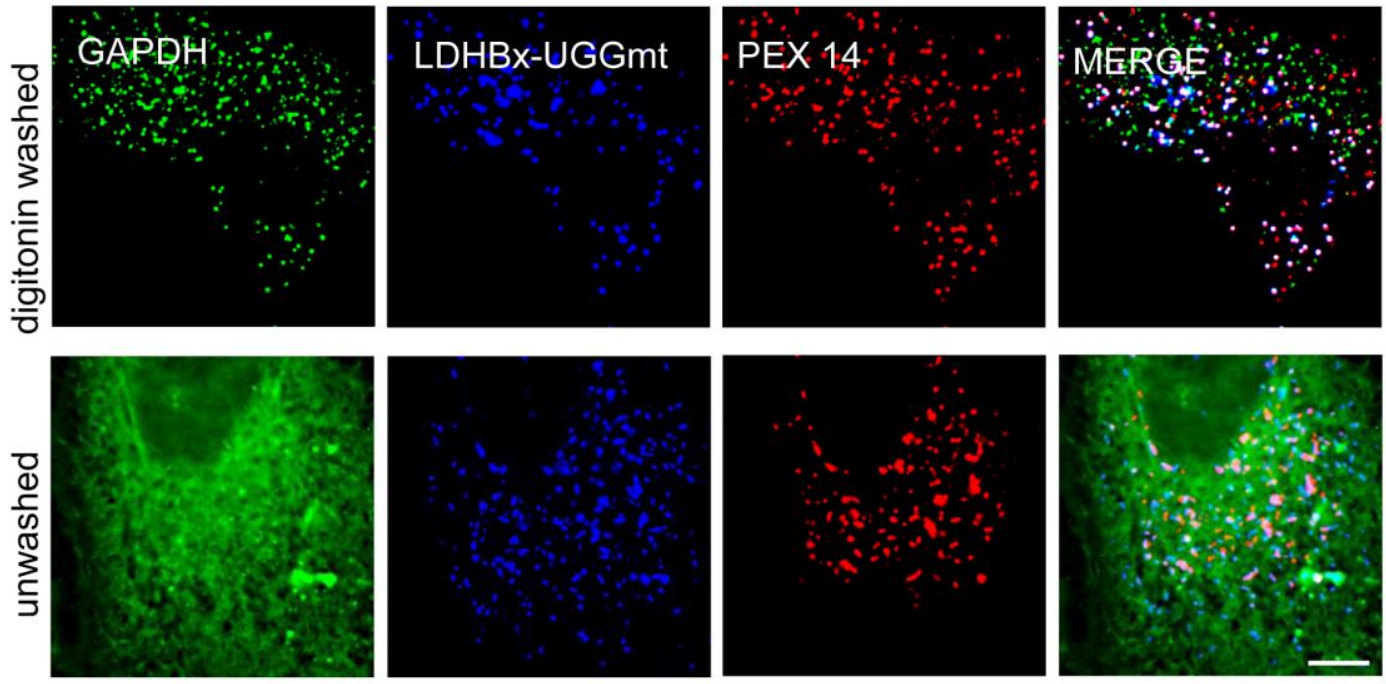

B
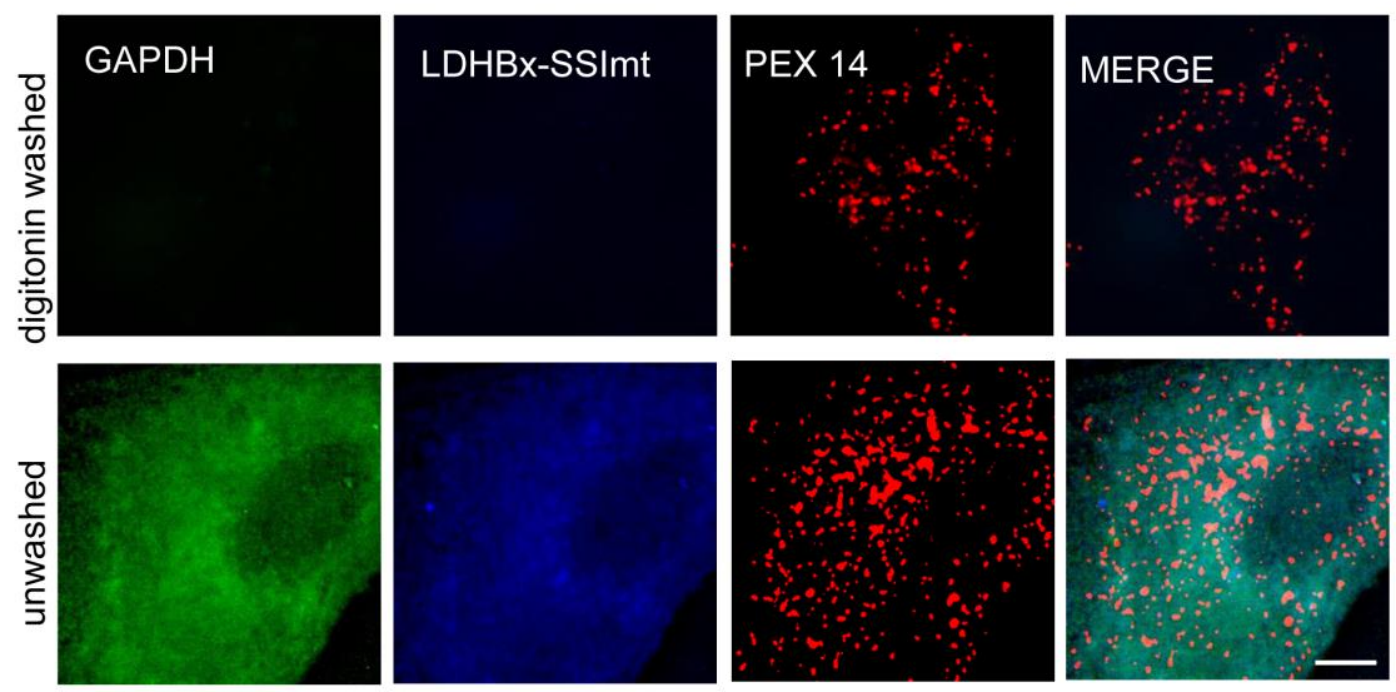

Figure 20. GAPDH localization inside peroxisomes is dependent on read-through LDHB. 
Results

A) EYFP tagged GAPDH (green) was co-expressed with ECFP tagged LDHBx-TGGmt (blue). Colocalisation of these proteins with PEX 14 was analysed by microscopy. Cytosolic distribution of GAPDH and punctate distribution of LDHBx-TGGmt was observed in unwashed cells. Digitonin permeablized cells demonstrated punctate GAPDH and LDHBX-TGG overlapping with PEX 14. B) EYFP tagged GAPDH (green) was co-expressed with ECFP tagged LDHBx-SSImt (blue). Unwashed cells showed cytosolic distribution of both GAPDH and LDHBx-SSImt while digitonin washed cells demonstrated absence of any fluorescence signal. Scale $10 \mu \mathrm{m}$. 


\section{Discussion}

Sorting of proteins to the matrix of peroxisome sub-compartment is usually mediated by either of the two targeting signals PTS1 or PTS2. Some proteins to achieve dual localisation make use of different strategies such as differential splicing, alternative transcriptional start sites or translational RT and acquire these targeting signal (Ast et al., 2013). However, some non-PTS proteins use non-classical transport mechanisms such as hetero-oligomeric complex with PTS1 containing protein otherwise called piggy-back import and get transported across the peroxisomal membrane (Islinger et al., 2009; van der Klei and Veenhuis, 2006). In this particular study we investigated targeting of otherwise cytosolic protein LDHB into peroxisomes via stop codon RT. We identified LDHB with a hidden yet conserved PTS1 while we developed an algorithm to predict potential peroxisomal proteins generated via RT.

\subsection{Establishing and optimizing a dual reporter assay for the experimental assessment of translational read-through}

With the aim of identifying genes with high RT, we developed a prediction algorithm based on RT frequencies of the three stop codons and their neighboring nucleotides. Our study began by evaluating the SCCs of a few human genes (table 1) using dual reporter assay. Basal RT in the range of $1.4 \%-8.8 \%$ was recorded for the following SCCs namely, $L D H B, M D 1, E D E M 3$, LENG1 and LEPRE1 which were predicted as high to intermediate RT genes. While the low RT genes demonstrated $0.3 \%-0.7 \%$ basal RT. There were some candidates in the high RT group such as ZNF-574, PRDM10, THG1L and some in the intermediate RT category namely, EDN1, IRAK3 and FBLX20 who showed RT values similar to low RT candidates (figure 6B). This suggested not all candidates predicted to be high or intermediate could be experimentally confirmed and hence it called for redefining the classification parameter and or test more candidates from the list also including a negative control so that actual RT values can be calculated. G418 treatment of candidates did show a significant increase in RT for most of the candidates showing true RT.

One striking observation made from these experiments was that values of percentage RT in my experiments were in the range of $0.3 \%-7.8 \%$ which in general is high compared to already known RT values of $0.01 \%-0.1 \%$ (Namy et al., 2001) and also to our published results $(0.1 \%-4 \%$ ) (Schueren et al., 2014). The difference in RT values could be due to the following two reasons: a) The sample preparation and activity measurements of the RT candidates were according to the first generation protocol. For our publication, we optimized our dual reporter assay by developing a combined fluorescence and luminescence method that was efficient in sample preparation and 
handling and above all luciferase substrate addition was automated and not manual thus preventing loss of signal. b) The positive control used in my experimental analysis for normalization of RT values was pDRVL construct (backbone vector consisting of dual reporters without any intervening SCC) whereas, in our publication, we normalized RT values against pDRVL-X-TGG (SCC of LDHB with tryptophan mutation instead of stop codon). This change of positive control for normalization of RT values undoubtedly showed variation which also explains why the percentage RT of LDHB SCC dropped by almost $50 \%$. (figure $7 B$ ).

Also, a correlation between predicted RTP and actual percentage RT could not be calculated from my experimental analysis as the LIN model (initial RTP model) based on which I initiated my study needed improvement. Though, for our publication an iterative and extended RTP model, LINiter and LINfs3 were developed which not only improved the RTP prediction of human genes but also suggested that three or four nucleotides which follow the stop codon (TGA CTA G) have a tremendous effect on basal RT. From the LINfs3 model, four candidates, AQP4, SYTL2, CACNA2D4 (high RTP) and DHX38 (low RTP) were tested in at least four different cell lines. Experimental results demonstrated that our new RTP model genuinely predicted high RT genes and it agreed with the results of Loughran group who experimentally verified AQP4 as high RT gene (Loughran et al., 2014).

\subsection{Identification of functional translational read-through by combining RTP prediction with PTS1 prediction}

The inability of stop codon to halt translation process may evolve the 3'extension of a protein and alter the behavior or function of original protein (Dunn et al., 2013). So to identify functional significance of RT extended proteins, we coupled RTP algorithm to a PTS1 predictor. LDHB was predicted with a high RTP and high PTS1 score (figure 5) and therefore we directed our investigation towards characterizing RT extended LDHBx. We first analysed the SCC of LDHB by dual reporter assay together with two stop codon mutations, TAA (stronger terminator) and TGG (tryptophan mutation) for comparative studies. TGG construct mimicked the situation when the stop codon is suppressed $100 \%$ and hence it was the positive control. The RT evaluations of TGA and TAA were normalized against it to observe the basal as well as G418 induced RT (figure 7B). TGA construct showed higher RT (basal and induced) compared to TAA and similar observations were made when they were analysed by western blot. Non-induced TGA showed luciferase band indicating RT protein while TAA did not. However, when they were induced with G418, RT protein was visible for both TGA and TAA suggesting suppression of their stop codon by the drug (figure 
7C). We here affirm that the natural stop TGA of LDHB is more slippery and a weaker terminator compared to TAA and its RT is positively affected by the 3' nucleotide context. We are not the first to make this observation as several studies in bees, nematodes and beetles also demonstrate TGA C as the most favorable stop codon context for RT except, mosquito and fruit fly where all three stop codons are equally preferred for RT(Jungreis et al., 2011).

\subsection{Analysis of LDHBx, the read-through sub-unit of LDHB}

We extended this study using full length protein (LDHBx) and this time we included two additional mutations of the stop codon LDHBx TGA T and LDHBx TAA T. We included them because we wanted to show the effect of 3'context nucleotide on RT. LDHBxTGG again served as the positive control and in situation where the stop codon is suppressed it would generate RT protein indicated by the Myc band. Of the many stop mutants only LDHBx TGA generated RT protein while the mutants LDHBx TAA, context mutants TGA T and TAA T did not generate RT proteins as shown by absence of Myc band (figure 8D). The RT extension of LDHBx harboured a hidden PTS1 which we examined by immunofluorescence studies. EYFP tagged fusion proteins were generated and were expressed in cells to check for their localisation. As the majority of proteins generated would be cytosolic, detection of extended LDHBx in sub-cellular compartment required removal of cytosol.

We developed a cytosol wash-out technique referred to as digitonin wash in our experiments that reduced background fluorescence immensely allowing clear view of peroxisomal proteins. Optimization of digitonin wash procedure was performed using EYFP and EYFP-PTS1 vectors. The cytosolic EYFP protein was removed completely from the cell while EYFP-PTS1 being peroxisomal was captured inside the organelle indicated by punctate structure co-localizing with PEX 14 (figure 9). This promising results encouraged us to examine LDHBx and we could demonstrate that a small fraction of RT extended proteins was protected inside peroxisomes (figure 10). The localization inside peroxisomes was verified by exchanging the stop codon TGA with TAA, a stronger terminator and also with a tryptophan encoding TGG mutation. LDHBxTGGmt showed peroxisomal localization while LDHBx-TAAmt showed absolutely no colocalisation with PEX14 marker (figure 11). Stiebler et al. analysed localisation of LDHB and $\mathrm{MDH} 1$ in an experiment where they expressed a construct with a GFP introduced between the high read-through motif and the targeting signal. They bleached the fluorescent molecules to observe the compartmentalized proteins (Stiebler et al., 2014). 
We then analysed if the hidden targeting signal in the RT extended proteins were involved in their localisation. Since movement of proteins from their site of synthesis to its proper location or destination is guided by information in its amino acid sequence. We investigated the PTS1 sequence in its C-terminal extension by mutational analysis. PTS1 targeting mutants LDHBx- $\triangle \mathrm{Lmt}$ (deleting $L$ in the $S R L$ ) and LDHBx-SSImt (changing the SRL to SSI) were generated and their expression was checked in the digitonin washed cells. We always included unwashed cells as plasmid transfection control, protein expression control and as control for the immunofluorescence technique. Import of LDHBx inside peroxisomes were disrupted when signal sequences were either deleted or replaced (figure 12). So we concluded that for peroxisomal localisation of LDHBx, the following two conditions are absolutely necessary: presence of a leaky stop codon, TGA which also happens to be its natural stop and an intact uninterrupted PTS1.

\subsection{Piggy-back import of LDHA inside peroxisomes}

We then investigated localisation of LDHA sub-unit inside peroxisomes because analytical subcellular fractionation studies from rat tissues have previously shown an association of LDHA and $\mathrm{LDHA}_{3} \mathrm{~B}$ isoforms with peroxisomes (Baumgart et al., 1996). Identification of small portions of LDHA inside peroxisomes by quantitative proteomics survey in human liver peroxisomes raised the question how they were transported across the peroxisomal membrane (Gronemeyer et al., 2013). We therefore proposed that LDHA tetramerized with LDHB subunit which harboured a PTS1 and then piggy-backed LDHA inside peroxisomes. It was proved by co-expressing EYFP tagged LDHA with/without ECFP tagged LDHBx TGGmt and PTS1 mutants. LDHA showed colocalisation with peroxisome marker only when LDHBx-TGGmt was present (figure 15). However, the dimerized LDHA fails to enter peroxisomes in the presence of PTS1 mutants (figure 16). Photo-bleaching experiment done in parallel also supported the hetero-oligomerization of LDHA and LDHBx. Usually, peroxisomal proteins display punctate structures as shown by EYFP-PTS1 or LDHBx-TGGmt and similar punctate pattern was observed for LDHA when co-expressed with LDHBX-TGGmt (figure 17) but a cytosolic distribution of LDHA was observed when co-expressed with LDHBx-SSImt or LDHBx- $\Delta \mathrm{L}$. The ability of RT extended LDHBx to co-import LDHA inside peroxisomal matrix exhibit the phenomenon of piggy-back import of peroxisomal proteins (Islinger et al., 2009; Thoms, 2015). Thus we have identified the connecting link which enabled a non-PTS protein LDHA to associate with LDHBx containing a PTS1 in its RT extension to get targeted to the peroxisomes. 


\subsection{Potential role for LDH inside peroxisomes}

Peroxisomes oxidize a broad range of lipids which constantly generate metabolites and cofactors that must be transported across the peroxisomal membrane. However, in vivo studies in Saccharomyces cerevisiae demonstrated that the peroxisomal membrane is impermeable to reducing equivalents (NADH) and end products of fatty acid beta-oxidation (van Roermund et al., 1995). For continued break down of fatty acids and proper functioning of peroxisomes, re-oxidation of $\mathrm{NADH}$ is necessary which must be mediated by a mandatory redox shuttle system. Several lines of evidence suggested existence of LDH inside peroxisomes as well as a lactate-pyruvate shuttle system (Gladden, 2004). Baumgart et.al demonstrated LDH activity in rat liver peroxisomes and revelation of the RT mediated peroxisome targeting mechanism adopted by this dehydrogenase to enter peroxisomes confirms its role as the possible site for $\mathrm{NAD}^{+}$regeneration (Schueren et al., 2014). The role of peroxisomal LDH in cofactor regeneration is highlighted by the observations made in isolated peroxisomes where the rate of $\mathrm{NADH}$ re-oxidation increased in the presence of pyruvate (LDH substrate) while it decreased when oxamate (LDH inhibitor) was present (Baumgart et al., 1996). Further evidence for existence of redox shuttle was obtained with the identification of mono-carboxylate transporters, MCT1 and MCT2 in peroxisomal membranes (Gladden, 2004; McClelland et al., 2003). A schematic representation of potential role of LDH inside peroxisomes is shown in the figure 21.

\subsection{The quest for amino acids introduced by read-through}

To get deeper insight on translational RT a systematic analysis of amino acids that may be incorporated at the stop codon was attempted. Rat tissue lysates treated with digitonin to remove excess cytosolic proteins were immunoprecipitated with anti-LDHB antibody (figure 18). As the immunoprecipitates did not provide sufficient RT extended LDHBx, the amino acid encoded by the stop codon could not be identified by this method. Results of similar studies suggested insertion of either tryptophan, cysteine or arginine at the TGA codon (Beier et al., 1984; Blanchet et al., 2014; Hirsh, 1971; Soll, 1974; Weiner and Weber, 1973). Another important topic of research is the identification of amino acid profile of different stop codons in the presence of RT inducing drugs. This may help in the understanding of decoding rules by the ribosome to read the genetic code and predict medically relevant nonsense suppressions (Beznoskova et al., 2016; Blanchet et al., 2014). Also, a large number of genetic diseases such as cystic fibrosis, Duchenne muscular dystrophy, $\beta$-thalassemia and many forms of cancers are caused by premature termination codons (PTCs) in their mRNA (Keeling and Bedwell, 2011). Understanding the 
molecular mechanism and identifying the factors that regulate stop codon suppression would provide us a wealth of information that can be exploited for improving RT therapies.

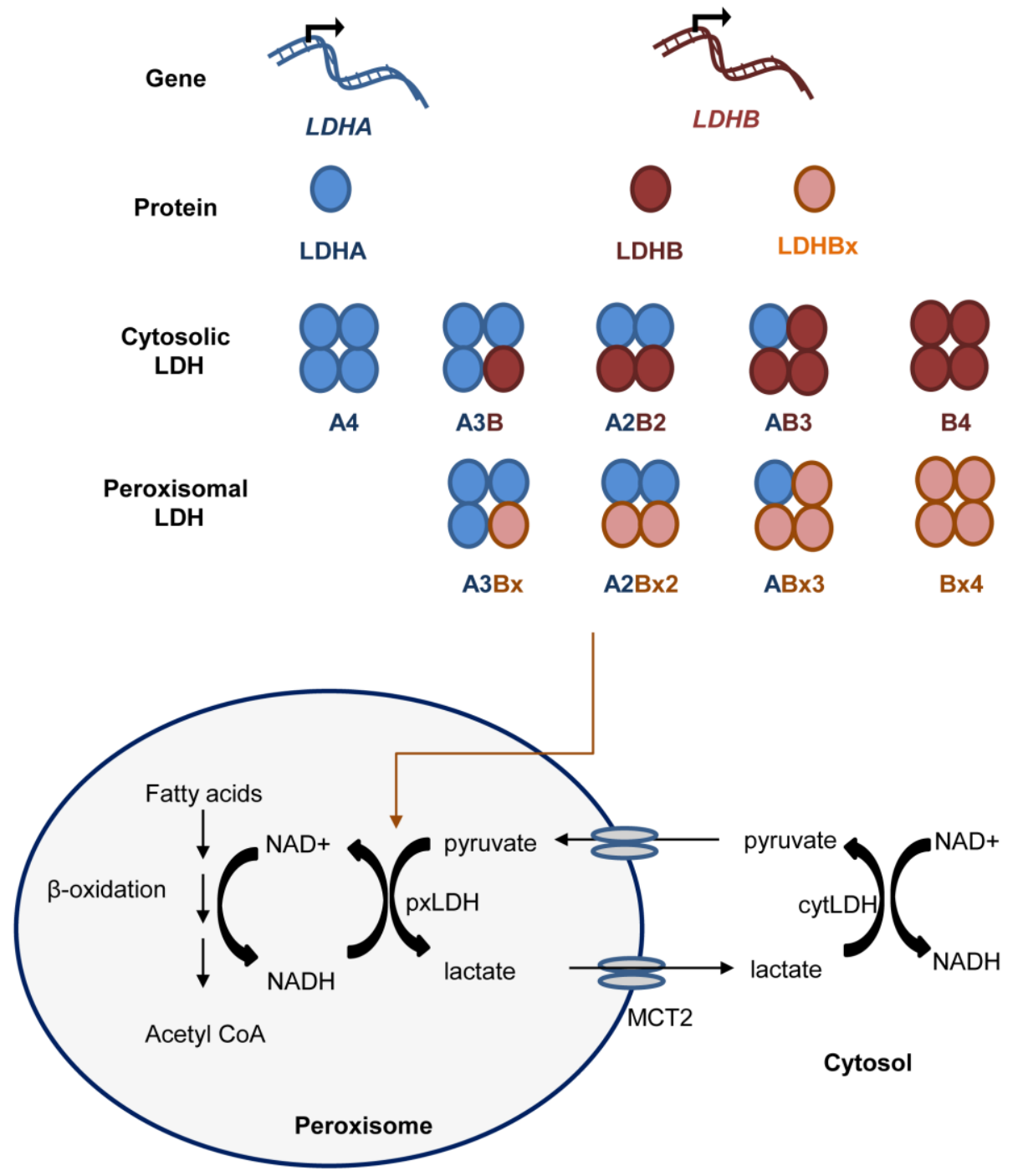

Figure 21. Role of LDH in recycling and shuttling of redox equivalents inside peroxisomes. LDH is a tetramer composed of two different subunits, LDHA and LDHB. They can assemble into five different combinations: A4 is comprised of four LDHA subunits; A3B contains three LDHA and one LDHB subunit; A2B2 contains two LDHA and two LDHB subunits; AB3 contains one LDHA and three LDHB subunits; and B4 contains four LDHB subunits. Stop codon read-through of LDHB generates an extended subunit, LDHBX which contains a peroxisome targeting signal. Therefore, four of the five isoforms can give rise to peroxisomal isoforms by inclusion of LDHBx instead of LDHB. Cytosolic pyruvate which is transported via monocarboxylate transporter (MCT2) into the peroxisomal matrix is converted to lactate by the 
peroxisomal LDH (pxLDH). As a result, re-oxidation of NADH to NAD+ occurs which allows continuation of the beta-oxidation process. Also, the lactate generated inside peroxisomes is transported via the MCT2 back to the cytosol where, it is converted by the cytosolic LDH (cytLDH) to pyruvate. Thus, peroxisomal LDH may be involved in recycling and shuttling of redox equivalents. The figure is adapted from (McClelland et al., 2003).

\subsection{GAPDH displays a potential for piggy-back import into peroxisomes}

Mass spectrometric analysis of anti-LDHB immunoprecipitates did provide us with a list of LDHB interacting proteins (table 2) which included LDHA, GAPDH and MDH among others. MDH which was also predicted by our RT algorithm as a high RT candidate was investigated separately and we found substantial evidence for peroxisomal MDH in humans (unpublished data). To prove the association of GAPDH and LDHB and to understand their binding kinetics at the molecular level interaction directed approach called surface plasmon resonance (SPR) was employed. We used commercially available purified LDHB from bovine heart and GAPDH from human erythrocytes to establish the binding parameters and the initial results showed interaction in low nanomolar range (data not shown). Alternatively, direct interaction between the two proteins were examined in rat tissues by subjecting them to immunoprecipitation them with anti-LDHB or anti-GAPDH antibodies. Co-immunoprecipitation of GAPDH or LDHB respectively provided us evidence for their association (figure 19). Besides, specific interaction between LDH isoforms and GAPDH studied by PEG induced co-immunoprecipitation and native gel electrophoresis (Svedruzic and Spivey, 2006) prompted us to explore GAPDH association with RT extended LDHBx. Consequently, co-localization experiments were conducted that offered us initial evidence about piggy-back import of GAPDH inside peroxisomes (figures 20). Identification of peroxisomal GAPDH in pathogenic fungi (Ast et al., 2013) and compartmentalization of first 7 glycolytic enzymes including GAPDH inside gylcosomes of Trypanosoma (Opperdoes, 1987) directed us to the examine peroxisomal localisation of GAPDH.

GAPDH widely known as a classical "housekeeping" gene or an internal control for analysis of "important" genes and proteins is in reality a multifunctional protein which is distributed over many cellular compartments. GAPDH catalyses the sixth step of glycolysis by converting glyceraldehyde 3 phosphate (G3P) to D-1,3-bisphospo glycerate and generate NADH from NAD+. In addition to its metabolic function, the enzyme acquires certain non-glycolytic functions and it was proposed that majority of these functions are acquired by undergoing post-translational modifications of either the NAD+binding domain or G3P-binding domain (Sirover, 1999; Tristan et al., 2011). For example, GAPDH functions as a metabolic switch when cells are under oxidative stress. The 
temporary inactivation of GAPDH is facilitated by S-glutathionylation of active site cysteine residue leading to the diversion of the glycolytic flux through pentose phosphate pathway. This in turn augments NADPH level in the cell that yields protection against ROS and RNS and balances the redox status (Ralser et al., 2007).

Again, S-nitrosylation of active site cysteine residue causes binding of GAPDH to an E3-ubiquitinligase (Siah1) whose translocation into the nucleus initiates apoptotic pathways (Hara et al., 2005). Identification of GAPDH as a regulator of caspase-independent cell death shows how metabolically active cells are protected by this dehydrogenase to survive mitochondrial insult (Colell et al., 2007). Other non-glycolytic roles include, maintenance and protection of telomeric DNA from rapid degradation (Sundararaj et al., 2004), association in microtubule bundling (Durrieu et al., 1987) and actin polymerization (Reiss et al., 1996). Also, cell cycle-regulated increase in GAPDH and uracil DNA glycosylase (UDG) (Mansur et al., 1993) as well as its interaction with apurinic/apyrimidinic endonuclease (APE1) highlights its significance in DNA repair mechanism (Azam et al., 2008). 


\section{Outlook}

Sub-cellular localization of LDH and GAPDH reflects how these highly conserved proteins are involved in a variety of biological processes. By maintaining several distinct pools in multiple cellular locations, they function as intra-cellular relay protein which appears to maintain cellular homeostasis. Peroxisomal localisation of LDH and piggy-back import of GAPDH challenges our understanding of the role of these glycolytic proteins and therefore as future work, we would like to do the following experiments:

- Determine the effect on peroxisomal lactate and quantify the lactate transporter activity of the peroxisomal membrane by employing a Forster Resonance Energy Transfer (FRET) based lactate sensor.

- Estimate differential response of peroxisomal and cytosolic NADH level during lactatepyruvate shuttle using fluorescent NADH sensor.

- Determine the effect of GAPDH on peroxisomal lactate and peroxisomal NADH and thereby identify a new role for GAPDH inside peroxisomes.

- Detailed analysis of cofactor binding sites to identify possible post-translational modification of GAPDH cofactor-binding site and identify to new cellular roles for this most abundant dehydrogenase during evolution. 


\section{Summary and Conclusion}

Peroxisomes are ubiquitous organelles involved in numerous metabolic pathways. The matrix of peroxisomes encloses proteins and enzymes that are primarily involved in oxidative metabolism. Unlike mitochondria or chloroplast, peroxisomes have a simple architecture and are devoid of DNA. Hence, peroxisomal proteins are synthesized on free poly-ribosomes, translated in the cytosol which are then transported into the organelle post-translationally. Specific peroxisome targeting signals (PTSs) help in the translocation of proteins across the peroxisomal membrane and majority of the signals are of type 1 (PTS1). Cytosolic lactate dehydrogenase B (LDHB) was predicted to contain an obscure peroxisome targeting signal in its read-through extension. To investigate the stop codon and nucleotide context of LDHB, a read-through assay was carried out using a dual reporter vector. The stop codon and its context nucleotides were cloned in between the reporter genes - $\mathrm{N}$-Venus and $\mathrm{C}$-luciferase and read-through was measured as the ratio of luciferase/Venus signal. Based on this assay it was concluded that the natural stop codon context (TGA CTA G) of LDHB has a high tendency to undergo read-through. Corresponding results were obtained by western blot analysis which demonstrated full length LDHB with natural stop (TGA) is leaky and is more likely to undergo read-through compared to other stop codon mutations.

Peroxisomal localization of LDHB was analyzed by co-localization studies using fluorescent tagged LDHB fusion proteins. In view of the fact that cytosolic fluorescence would mask the signal from peroxisome sub-compartment cytosol permeabilization with digitonin was carried out. This enabled visualization of peroxisomal LDHB as punctate structures. Co-localization of punctate LDHB with peroxisome marker PEX14 suggested that read-through extended LDHB is dually localised. This was also verified by co-localization of endogenous LDHB with peroxisome marker. Also, when the stop mutant or PTS1 mutants of tagged LDHB were checked for peroxisome localization it was concluded that for an efficient protein targeting, LDHB requires the combination of a leaky stop codon (TGA) and typical PTS1 (SRL). The read-through extended LDHB also demonstrated the classic piggy-back import adopted by some peroxisomal proteins to enter the matrix. LDHA, the other lactate dehydrogenase sub-unit, when co-expressed with PTS1containing LDHB demonstrated punctate structure which co-localised with PEX 14. However, there was absence of punctate LDHA when stop mutant (TAA) or PTS1 mutants of LDHB were expressed suggesting the intact peroxisome targeting signal and leaky stop for LDHA co-import.

Finally, experiments conducted to identify amino acids encoded by the stop codon of read-through extended LDHB, led to the investigation of LDH-GAPDH association. Preliminary data from co- 
immunoprecipitation studies and immunofluorescence proposed read-through LDHB may import GAPDH inside peroxisomal matrix which implies examining the role of LDH-GAPDH in maintaining redox homeostasis inside the peroxisome sub-compartment. 


\section{References}

Ast, J., A.C. Stiebler, J. Freitag, and M. Bolker. 2013. Dual targeting of peroxisomal proteins. Front Physiol. 4:297.

Azam, S., N. Jouvet, A. Jilani, R. Vongsamphanh, X. Yang, S. Yang, and D. Ramotar. 2008. Human glyceraldehyde-3-phosphate dehydrogenase plays a direct role in reactivating oxidized forms of the DNA repair enzyme APE1. J Biol Chem. 283:30632-30641.

Baghirova, S., B.G. Hughes, M.J. Hendzel, and R. Schulz. 2015. Sequential fractionation and isolation of subcellular proteins from tissue or cultured cells. MethodsX. 2:440-445.

Baumgart, E., H.D. Fahimi, A. Stich, and A. Volkl. 1996. L-lactate dehydrogenase A4- and A3B isoforms are bona fide peroxisomal enzymes in rat liver. Evidence for involvement in intraperoxisomal NADH reoxidation. J Biol Chem. 271:3846-3855.

Baumgart, E., I. Vanhorebeek, M. Grabenbauer, M. Borgers, P.E. Declercq, H.D. Fahimi, and M. Baes. 2001. Mitochondrial alterations caused by defective peroxisomal biogenesis in a mouse model for Zellweger syndrome (PEX5 knockout mouse). Am J Pathol. 159:1477-1494.

Bedwell, D.M., A. Kaenjak, D.J. Benos, Z. Bebok, J.K. Bubien, J. Hong, A. Tousson, J.P. Clancy, and E.J. Sorscher. 1997. Suppression of a CFTR premature stop mutation in a bronchial epithelial cell line. Nat Med. 3:1280-1284.

Beier, H., M. Barciszewska, G. Krupp, R. Mitnacht, and H.J. Gross. 1984. TAG readthrough during TMV RNA translation: isolation and sequence of two tRNAs with suppressor activity from tobacco plants. EMBO J. 3:351-356.

Beier, H., and M. Grimm. 2001. Misreading of termination codons in eukaryotes by natural nonsense suppressor tRNAs. Nucleic Acids Res. 29:4767-4782.

Bertram, G., S. Innes, O. Minella, J. Richardson, and I. Stansfield. 2001. Endless possibilities: translation termination and stop codon recognition. Microbiology. 147:255-269.

Beznoskova, P., S. Gunisova, and L.S. Valasek. 2016. Rules of TGA-N decoding by near-cognate tRNAs and analysis of readthrough on short uORFs in yeast. RNA. 22:456-466.

Beznoskova, P., S. Wagner, M.E. Jansen, T. von der Haar, and L.S. Valasek. 2015. Translation initiation factor elF3 promotes programmed stop codon readthrough. Nucleic Acids Res. 43:5099-5111.

Bidou, L., V. Allamand, J.P. Rousset, and O. Namy. 2012. Sense from nonsense: therapies for premature stop codon diseases. Trends Mol Med. 18:679-688.

Blanchet, S., D. Cornu, M. Argentini, and O. Namy. 2014. New insights into the incorporation of natural suppressor tRNAs at stop codons in Saccharomyces cerevisiae. Nucleic Acids Res. 42:10061-10072.

Bonetti, B., L. Fu, J. Moon, and D.M. Bedwell. 1995. The efficiency of translation termination is determined by a synergistic interplay between upstream and downstream sequences in Saccharomyces cerevisiae. J Mol Biol. 251:334-345.

Boyer, S.H., D.C. Fainer, and E.J. Watson-Williams. 1963. Lactate dehydrogenase variant from human blood: evidence for molecular subunits. Science. 141:642-643.

Bradley, C., and R. Craigie. 2003. MoMLV reverse transcriptase regulates its own expression. Cell. 115:250251.

Braverman, N.E., G.V. Raymond, W.B. Rizzo, A.B. Moser, M.E. Wilkinson, E.M. Stone, S.J. Steinberg, M.F. Wangler, E.T. Rush, J.G. Hacia, and M. Bose. 2015. Peroxisome biogenesis disorders in the Zellweger spectrum: An overview of current diagnosis, clinical manifestations, and treatment guidelines. Mol Genet Metab.

Brooks, D.A., V.J. Muller, and J.J. Hopwood. 2006. Stop-codon read-through for patients affected by a lysosomal storage disorder. Trends Mol Med. 12:367-373.

Brown, L.A., and A. Baker. 2008. Shuttles and cycles: transport of proteins into the peroxisome matrix (review). Mol Membr Biol. 25:363-375. 
Cassan, M., and J.P. Rousset. 2001. TAG readthrough in mammalian cells: effect of upstream and downstream stop codon contexts reveal different signals. BMC Mol Biol. 2:3.

Colell, A., J.E. Ricci, S. Tait, S. Milasta, U. Maurer, L. Bouchier-Hayes, P. Fitzgerald, A. Guio-Carrion, N.J. Waterhouse, C.W. Li, B. Mari, P. Barbry, D.D. Newmeyer, H.M. Beere, and D.R. Green. 2007. GAPDH and autophagy preserve survival after apoptotic cytochrome $c$ release in the absence of caspase activation. Cell. 129:983-997.

Dabrowski, M., Z. Bukowy-Bieryllo, and E. Zietkiewicz. 2015. Translational readthrough potential of natural termination codons in eucaryotes--The impact of RNA sequence. RNA Biol. 12:950-958.

Dammai, V., and S. Subramani. 2001. The human peroxisomal targeting signal receptor, Pex5p, is translocated into the peroxisomal matrix and recycled to the cytosol. Cell. 105:187-196.

Danpure, C.J. 1997. Variable peroxisomal and mitochondrial targeting of alanine: glyoxylate aminotransferase in mammalian evolution and disease. Bioessays. 19:317-326.

del Rio, L.A., L.M. Sandalio, F.J. Corpas, J.M. Palma, and J.B. Barroso. 2006. Reactive oxygen species and reactive nitrogen species in peroxisomes. Production, scavenging, and role in cell signaling. Plant Physiol. 141:330-335.

Dirkx, R., I. Vanhorebeek, K. Martens, A. Schad, M. Grabenbauer, D. Fahimi, P. Declercq, P.P. Van Veldhoven, and M. Baes. 2005. Absence of peroxisomes in mouse hepatocytes causes mitochondrial and ER abnormalities. Hepatology. 41:868-878.

Dixit, E., S. Boulant, Y. Zhang, A.S. Lee, C. Odendall, B. Shum, N. Hacohen, Z.J. Chen, S.P. Whelan, M. Fransen, M.L. Nibert, G. Superti-Furga, and J.C. Kagan. 2010. Peroxisomes are signaling platforms for antiviral innate immunity. Cell. 141:668-681.

Drent, M., N.A. Cobben, R.F. Henderson, E.F. Wouters, and M. van Dieijen-Visser. 1996. Usefulness of lactate dehydrogenase and its isoenzymes as indicators of lung damage or inflammation. Eur Respir J. 9:1736-1742.

Du, L., R. Damoiseaux, S. Nahas, K. Gao, H. Hu, J.M. Pollard, J. Goldstine, M.E. Jung, S.M. Henning, C. Bertoni, and R.A. Gatti. 2009. Nonaminoglycoside compounds induce readthrough of nonsense mutations. J Exp Med. 206:2285-2297.

Du, M., J.R. Jones, J. Lanier, K.M. Keeling, J.R. Lindsey, A. Tousson, Z. Bebok, J.A. Whitsett, C.R. Dey, W.H. Colledge, M.J. Evans, E.J. Sorscher, and D.M. Bedwell. 2002. Aminoglycoside suppression of a premature stop mutation in a Cftr-/- mouse carrying a human CFTR-G542X transgene. J Mol Med (Berl). 80:595-604.

Dunn, J.G., C.K. Foo, N.G. Belletier, E.R. Gavis, and J.S. Weissman. 2013. Ribosome profiling reveals pervasive and regulated stop codon readthrough in Drosophila melanogaster. Elife. 2:e01179.

Durrieu, C., F. Bernier-Valentin, and B. Rousset. 1987. Microtubules bind glyceraldehyde 3-phosphate dehydrogenase and modulate its enzyme activity and quaternary structure. Arch Biochem Biophys. 252:32-40.

Elgersma, Y., A. Vos, M. van den Berg, C.W. van Roermund, P. van der Sluijs, B. Distel, and H.F. Tabak. 1996. Analysis of the carboxyl-terminal peroxisomal targeting signal 1 in a homologous context in Saccharomyces cerevisiae. J Biol Chem. 271:26375-26382.

Engelberg-Kulka, H., and R. Schoulaker-Schwarz. 1988. Stop is not the end: physiological implications of translational readthrough. J Theor Biol. 131:477-485.

Floquet, C., I. Hatin, J.P. Rousset, and L. Bidou. 2012. Statistical analysis of readthrough levels for nonsense mutations in mammalian cells reveals a major determinant of response to gentamicin. PLoS Genet. 8:e1002608.

Freitag, J., J. Ast, and M. Bolker. 2012. Cryptic peroxisomal targeting via alternative splicing and stop codon read-through in fungi. Nature. 485:522-525.

Gao, H., Z. Zhou, U. Rawat, C. Huang, L. Bouakaz, C. Wang, Z. Cheng, Y. Liu, A. Zavialov, R. Gursky, S. Sanyal, M. Ehrenberg, J. Frank, and H. Song. 2007. RF3 induces ribosomal conformational changes responsible for dissociation of class I release factors. Cell. 129:929-941. 
Gladden, L.B. 2004. Lactate metabolism: a new paradigm for the third millennium. J Physiol. 558:5-30.

Glover, J.R., D.W. Andrews, and R.A. Rachubinski. 1994. Saccharomyces cerevisiae peroxisomal thiolase is imported as a dimer. Proc Natl Acad Sci U S A. 91:10541-10545.

Goodwin, J.S., and A.K. Kenworthy. 2005. Photobleaching approaches to investigate diffusional mobility and trafficking of Ras in living cells. Methods. 37:154-164.

Grabenbauer, M., K. Satzler, E. Baumgart, and H.D. Fahimi. 2000. Three-dimensional ultrastructural analysis of peroxisomes in HepG2 cells. Absence of peroxisomal reticulum but evidence of close spatial association with the endoplasmic reticulum. Cell Biochem Biophys. 32 Spring:37-49.

Gronemeyer, T., S. Wiese, R. Ofman, C. Bunse, M. Pawlas, H. Hayen, M. Eisenacher, C. Stephan, H.E. Meyer, H.R. Waterham, R. Erdmann, R.J. Wanders, and B. Warscheid. 2013. The proteome of human liver peroxisomes: identification of five new peroxisomal constituents by a label-free quantitative proteomics survey. PLoS One. 8:e57395.

Haanstra, J.R., E.B. Gonzalez-Marcano, M. Gualdron-Lopez, and P.A. Michels. 2015. Biogenesis, maintenance and dynamics of glycosomes in trypanosomatid parasites. Biochim Biophys Acta.

Hara, M.R., N. Agrawal, S.F. Kim, M.B. Cascio, M. Fujimuro, Y. Ozeki, M. Takahashi, J.H. Cheah, S.K. Tankou, L.D. Hester, C.D. Ferris, S.D. Hayward, S.H. Snyder, and A. Sawa. 2005. S-nitrosylated GAPDH initiates apoptotic cell death by nuclear translocation following Siah1 binding. Nat Cell Biol. 7:665674.

Hayashi, M., M. Yagi, K. Nito, T. Kamada, and M. Nishimura. 2005. Differential contribution of two peroxisomal protein receptors to the maintenance of peroxisomal functions in Arabidopsis. J Biol Chem. 280:14829-14835.

Henke, B., W. Girzalsky, V. Berteaux-Lecellier, and R. Erdmann. 1998. IDP3 encodes a peroxisomal NADPdependent isocitrate dehydrogenase required for the beta-oxidation of unsaturated fatty acids. $J$ Biol Chem. 273:3702-3711.

Hettema, E.H., W. Girzalsky, M. van Den Berg, R. Erdmann, and B. Distel. 2000. Saccharomyces cerevisiae pex3p and pex $19 p$ are required for proper localization and stability of peroxisomal membrane proteins. EMBO J. 19:223-233.

Hirsh, D. 1971. Tryptophan transfer RNA as the TGA suppressor. J Mol Biol. 58:439-458.

Howard, M.T., B.H. Shirts, L.M. Petros, K.M. Flanigan, R.F. Gesteland, and J.F. Atkins. 2000. Sequence specificity of aminoglycoside-induced stop condon readthrough: potential implications for treatment of Duchenne muscular dystrophy. Ann Neurol. 48:164-169.

Ishihara, N., M. Nomura, A. Jofuku, H. Kato, S.O. Suzuki, K. Masuda, H. Otera, Y. Nakanishi, I. Nonaka, Y. Goto, N. Taguchi, H. Morinaga, M. Maeda, R. Takayanagi, S. Yokota, and K. Mihara. 2009. Mitochondrial fission factor Drp1 is essential for embryonic development and synapse formation in mice. Nat Cell Biol. 11:958-966.

Islinger, M., S. Grille, H.D. Fahimi, and M. Schrader. 2012. The peroxisome: an update on mysteries. Histochem Cell Biol. 137:547-574.

Islinger, M., K.W. Li, J. Seitz, A. Volkl, and G.H. Luers. 2009. Hitchhiking of Cu/Zn superoxide dismutase to peroxisomes--evidence for a natural piggyback import mechanism in mammals. Traffic. 10:17111721.

Ivashchenko, O., P.P. Van Veldhoven, C. Brees, Y.S. Ho, S.R. Terlecky, and M. Fransen. 2011. Intraperoxisomal redox balance in mammalian cells: oxidative stress and interorganellar crosstalk. Mol Biol Cell. 22:1440-1451.

Jackson, R.J., C.U. Hellen, and T.V. Pestova. 2012. Termination and post-termination events in eukaryotic translation. Adv Protein Chem Struct Biol. 86:45-93.

Jedd, G. 2011. Fungal evo-devo: organelles and multicellular complexity. Trends Cell Biol. 21:12-19.

Johnson, T.L., and L.J. Olsen. 2001. Building new models for peroxisome biogenesis. Plant Physiol. 127:731739. 
Jungreis, I., M.F. Lin, R. Spokony, C.S. Chan, N. Negre, A. Victorsen, K.P. White, and M. Kellis. 2011. Evidence of abundant stop codon readthrough in Drosophila and other metazoa. Genome Res. 21:20962113.

Kalel, V.C., W. Schliebs, and R. Erdmann. 2015. Identification and functional characterization of Trypanosoma brucei peroxin 16. Biochim Biophys Acta. 1853:2326-2337.

Keeling, K.M., and D.M. Bedwell. 2011. Suppression of nonsense mutations as a therapeutic approach to treat genetic diseases. Wiley Interdiscip Rev RNA. 2:837-852.

Keeling, K.M., D.A. Brooks, J.J. Hopwood, P. Li, J.N. Thompson, and D.M. Bedwell. 2001. Gentamicinmediated suppression of Hurler syndrome stop mutations restores a low level of alpha-Liduronidase activity and reduces lysosomal glycosaminoglycan accumulation. Hum Mol Genet. 10:291-299.

Keeling, K.M., J. Lanier, M. Du, J. Salas-Marco, L. Gao, A. Kaenjak-Angeletti, and D.M. Bedwell. 2004. Leaky termination at premature stop codons antagonizes nonsense-mediated mRNA decay in $\mathrm{S}$. cerevisiae. RNA. 10:691-703.

Kim, P.K., and E.H. Hettema. 2015. Multiple pathways for protein transport to peroxisomes. $J$ Mol Biol. 427:1176-1190.

Knull, H.R., and J.L. Walsh. 1992. Association of glycolytic enzymes with the cytoskeleton. Curr Top Cell Regul. 33:15-30.

Kopperschlager, G., and J. Kirchberger. 1996. Methods for the separation of lactate dehydrogenases and clinical significance of the enzyme. J Chromatogr B Biomed Appl. 684:25-49.

Lanyon-Hogg, T., S.L. Warriner, and A. Baker. 2010. Getting a camel through the eye of a needle: the import of folded proteins by peroxisomes. Biol Cell. 102:245-263.

Legakis, J.E., and S.R. Terlecky. 2001. PTS2 protein import into mammalian peroxisomes. Traffic. 2:252260.

Li, Y.J., S.C. Tsoi, H. Mannen, and S. Shoei-lung Li. 2002. Phylogenetic analysis of vertebrate lactate dehydrogenase (LDH) multigene families. J Mol Evol. 54:614-624.

Lingner, T., A.R. Kataya, G.E. Antonicelli, A. Benichou, K. Nilssen, X.Y. Chen, T. Siemsen, B. Morgenstern, P. Meinicke, and S. Reumann. 2011. Identification of novel plant peroxisomal targeting signals by a combination of machine learning methods and in vivo subcellular targeting analyses. Plant Cell. 23:1556-1572.

Liu, X., C. Ma, and S. Subramani. 2012. Recent advances in peroxisomal matrix protein import. Curr Opin Cell Biol. 24:484-489.

Loftfield, R.B., and D. Vanderjagt. 1972. The frequency of errors in protein biosynthesis. Biochem J. 128:1353-1356.

Loh, P.G., and H. Song. 2010. Structural and mechanistic insights into translation termination. Curr Opin Struct Biol. 20:98-103.

Loughran, G., M.Y. Chou, I.P. Ivanov, I. Jungreis, M. Kellis, A.M. Kiran, P.V. Baranov, and J.F. Atkins. 2014. Evidence of efficient stop codon readthrough in four mammalian genes. Nucleic Acids Res. 42:8928-8938.

Ma, C., and S. Subramani. 2009. Peroxisome matrix and membrane protein biogenesis. IUBMB Life. 61:713722.

Mansur, N.R., K. Meyer-Siegler, J.C. Wurzer, and M.A. Sirover. 1993. Cell cycle regulation of the glyceraldehyde-3-phosphate dehydrogenase/uracil DNA glycosylase gene in normal human cells. Nucleic Acids Res. 21:993-998.

Markert, C.L. 1963. Lactate Dehydrogenase Isozymes: Dissociation and Recombination of Subunits. Science. 140:1329-1330.

Maruyama, J., S. Yamaoka, I. Matsuo, N. Tsutsumi, and K. Kitamoto. 2012. A newly discovered function of peroxisomes: involvement in biotin biosynthesis. Plant Signal Behav. 7:1589-1593. 
Mast, F.D., R.A. Rachubinski, and J.D. Aitchison. 2015. Signaling dynamics and peroxisomes. Curr Opin Cell Biol. 35:131-136.

McClelland, G.B., S. Khanna, G.F. Gonzalez, C.E. Butz, and G.A. Brooks. 2003. Peroxisomal membrane monocarboxylate transporters: evidence for a redox shuttle system? Biochem Biophys Res Commun. 304:130-135.

McNew, J.A., and J.M. Goodman. 1994. An oligomeric protein is imported into peroxisomes in vivo. J Cell Biol. 127:1245-1257.

McNew, J.A., and J.M. Goodman. 1996. The targeting and assembly of peroxisomal proteins: some old rules do not apply. Trends Biochem Sci. 21:54-58.

Mitkevich, V.A., A.V. Kononenko, I.Y. Petrushanko, D.V. Yanvarev, A.A. Makarov, and L.L. Kisselev. 2006. Termination of translation in eukaryotes is mediated by the quaternary eRF1*eRF3*GTP*Mg2+ complex. The biological roles of eRF3 and prokaryotic RF3 are profoundly distinct. Nucleic Acids Res. 34:3947-3954.

Miyata, N., and Y. Fujiki. 2005. Shuttling mechanism of peroxisome targeting signal type 1 receptor Pex5: ATP-independent import and ATP-dependent export. Mol Cell Biol. 25:10822-10832.

Mohamed, L.A., H. Tachikawa, X.D. Gao, and H. Nakanishi. 2015. Yeast cell-based analysis of human lactate dehydrogenase isoforms. J Biochem. 158:467-476.

Mottagui-Tabar, S., A. Bjornsson, and L.A. Isaksson. 1994. The second to last amino acid in the nascent peptide as a codon context determinant. EMBO J. 13:249-257.

Mottagui-Tabar, S., M.F. Tuite, and L.A. Isaksson. 1998. The influence of 5 ' codon context on translation termination in Saccharomyces cerevisiae. Eur J Biochem. 257:249-254.

Namy, O., G. Duchateau-Nguyen, I. Hatin, S. Hermann-Le Denmat, M. Termier, and J.P. Rousset. 2003. Identification of stop codon readthrough genes in Saccharomyces cerevisiae. Nucleic Acids Res. 31:2289-2296.

Namy, O., I. Hatin, and J.P. Rousset. 2001. Impact of the six nucleotides downstream of the stop codon on translation termination. EMBO Rep. 2:787-793.

Nilsson, M., and M. Ryden-Aulin. 2003. Glutamine is incorporated the nonsense codons TAG and TAA in a suppressor-free Escherichia coli strain. Biochim Biophys Acta. 1627:1-6.

Opperdoes, F.R. 1987. Compartmentation of carbohydrate metabolism in trypanosomes. Annu Rev Microbiol. 41:127-151.

Parkes, J.A., S. Langer, A. Hartig, and A. Baker. 2003. PTS1-independent targeting of isocitrate lyase to peroxisomes requires the PTS1 receptor Pex5p. Mol Membr Biol. 20:61-69.

Peduto, A., M.R. Baumgartner, N.M. Verhoeven, D. Rabier, M. Spada, M.C. Nassogne, B.T. Poll-The, G. Bonetti, C. Jakobs, and J.M. Saudubray. 2004. Hyperpipecolic acidaemia: a diagnostic tool for peroxisomal disorders. Mol Genet Metab. 82:224-230.

Perez, B., P. Rodriguez-Pombo, M. TGArte, and L.R. Desviat. 2012. Readthrough strategies for therapeutic suppression of nonsense mutations in inherited metabolic disease. Mol Syndromol. 3:230-236.

Pesce, A., R.H. McKay, F. Stolzenbach, R.D. Cahn, and N.O. Kaplan. 1964. The Comparative Enzymology of Lactic Dehydrogenases. I. Properties of the Crystalline Beef and Chicken Enzymes. J Biol Chem. 239:1753-1761.

Petrova, V.Y., D. Drescher, A.V. Kujumdzieva, and M.J. Schmitt. 2004. Dual targeting of yeast catalase A to peroxisomes and mitochondria. Biochem J. 380:393-400.

Pieuchot, L., and G. Jedd. 2012. Peroxisome assembly and functional diversity in eukaryotic microorganisms. Annu Rev Microbiol. 66:237-263.

Pinto, M.P., C.P. Grou, I.S. Alencastre, M.E. Oliveira, C. Sa-Miranda, M. Fransen, and J.E. Azevedo. 2006. The import competence of a peroxisomal membrane protein is determined by Pex19p before the docking step. J Biol Chem. 281:34492-34502.

Platta, H.W., and R. Erdmann. 2007. Peroxisomal dynamics. Trends Cell Biol. 17:474-484. 
Platta, H.W., S. Grunau, K. Rosenkranz, W. Girzalsky, and R. Erdmann. 2005. Functional role of the AAA peroxins in dislocation of the cycling PTS1 receptor back to the cytosol. Nat Cell Biol. 7:817-822.

Poll-The, B.T., and J. Gartner. 2012. Clinical diagnosis, biochemical findings and MRI spectrum of peroxisomal disorders. Biochim Biophys Acta. 1822:1421-1429.

Purdue, P.E., and P.B. Lazarow. 2001. Peroxisome biogenesis. Annu Rev Cell Dev Biol. 17:701-752.

Ralser, M., M.M. Wamelink, A. Kowald, B. Gerisch, G. Heeren, E.A. Struys, E. Klipp, C. Jakobs, M. Breitenbach, H. Lehrach, and S. Krobitsch. 2007. Dynamic rerouting of the carbohydrate flux is key to counteracting oxidative stress. J Biol. 6:10.

Reiss, N., A. Oplatka, J. Hermon, and Z. Naor. 1996. Phosphatidylserine directs differential phosphorylation of actin and glyceraldehyde-3-phosphate dehydrogenase by protein kinase C: possible implications for regulation of actin polymerization. Biochem Mol Biol Int. 40:1191-1200.

Reumann, S., D. Buchwald, and T. Lingner. 2012. PredPlantPTS1: A Web Server for the Prediction of Plant Peroxisomal Proteins. Front Plant Sci. 3:194.

Sacksteder, K.A., J.M. Jones, S.T. South, X. Li, Y. Liu, and S.J. Gould. 2000. PEX19 binds multiple peroxisomal membrane proteins, is predominantly cytoplasmic, and is required for peroxisome membrane synthesis. J Cell Biol. 148:931-944.

Saraya, R., M. Veenhuis, and I.J. van der Klei. 2010. Peroxisomes as dynamic organelles: peroxisome abundance in yeast. FEBS J. 277:3279-3288.

Schrader, M., N.A. Bonekamp, and M. Islinger. 2012. Fission and proliferation of peroxisomes. Biochim Biophys Acta. 1822:1343-1357.

Schueren, F., T. Lingner, R. George, J. Hofhuis, C. Dickel, J. Gartner, and S. Thoms. 2014. Peroxisomal lactate dehydrogenase is generated by translational readthrough in mammals. Elife. 3:e03640.

Schulz, I. 1990. Permeabilizing cells: some methods and applications for the study of intracellular processes. Methods Enzymol. 192:280-300.

Sirover, M.A. 1999. New insights into an old protein: the functional diversity of mammalian glyceraldehyde-3-phosphate dehydrogenase. Biochim Biophys Acta. 1432:159-184.

Sirover, M.A. 2005. New nuclear functions of the glycolytic protein, glyceraldehyde-3-phosphate dehydrogenase, in mammalian cells. J Cell Biochem. 95:45-52.

Sirover, M.A. 2012. Subcellular dynamics of multifunctional protein regulation: mechanisms of GAPDH intracellular translocation. J Cell Biochem. 113:2193-2200.

Smith, J.J., and J.D. Aitchison. 2013. Peroxisomes take shape. Nat Rev Mol Cell Biol. 14:803-817.

Soll, L. 1974. Mutational alterations of tryptophan-specific transfer RNA that generate translation suppressors of the TAA, TAG and TGA nonsense codons. J Mol Biol. 86:233-243.

South, S.T., and S.J. Gould. 1999. Peroxisome synthesis in the absence of preexisting peroxisomes. J Cell Biol. 144:255-266.

Stansfield, I., K.M. Jones, P. Herbert, A. Lewendon, W.V. Shaw, and M.F. Tuite. 1998. Missense translation errors in Saccharomyces cerevisiae. J Mol Biol. 282:13-24.

Steffan, J.S., and L. McAlister-Henn. 1992. Isolation and characterization of the yeast gene encoding the MDH3 isozyme of malate dehydrogenase. J Biol Chem. 267:24708-24715.

Steinberg, S.J., G. Dodt, G.V. Raymond, N.E. Braverman, A.B. Moser, and H.W. Moser. 2006. Peroxisome biogenesis disorders. Biochim Biophys Acta. 1763:1733-1748.

Stiebler, A.C., J. Freitag, K.O. Schink, T. Stehlik, B.A. Tillmann, J. Ast, and M. Bolker. 2014. Ribosomal readthrough at a short TGA stop codon context triggers dual localization of metabolic enzymes in Fungi and animals. PLoS Genet. 10:e1004685.

Subramani, S. 1998. Components involved in peroxisome import, biogenesis, proliferation, turnover, and movement. Physiol Rev. 78:171-188.

Sundararaj, K.P., R.E. Wood, S. Ponnusamy, A.M. Salas, Z. Szulc, A. Bielawska, L.M. Obeid, Y.A. Hannun, and B. Ogretmen. 2004. Rapid shortening of telomere length in response to ceramide involves the 
inhibition of telomere binding activity of nuclear glyceraldehyde-3-phosphate dehydrogenase. $J$ Biol Chem. 279:6152-6162.

Svedruzic, Z.M., and H.O. Spivey. 2006. Interaction between mammalian glyceraldehyde-3-phosphate dehydrogenase and L-lactate dehydrogenase from heart and muscle. Proteins. 63:501-511.

Szewczyk, E., A. Andrianopoulos, M.A. Davis, and M.J. Hynes. 2001. A single gene produces mitochondrial, cytoplasmic, and peroxisomal NADP-dependent isocitrate dehydrogenase in Aspergillus nidulans. J Biol Chem. 276:37722-37729.

Thoms, S. 2015. Import of proteins into peroxisomes: piggybacking to a new home away from home. Open Biol. 5.

Thoms, S., S. Gronborg, and J. Gartner. 2009. Organelle interplay in peroxisomal disorders. Trends Mol Med. 15:293-302.

Thoms, S., I. Harms, K.U. Kalies, and J. Gartner. 2012. Peroxisome formation requires the endoplasmic reticulum channel protein Sec61. Traffic. 13:599-609.

Titorenko, V.I., and R.A. Rachubinski. 2004. The peroxisome: orchestrating important developmental decisions from inside the cell. J Cell Biol. 164:641-645.

Tork, S., I. Hatin, J.P. Rousset, and C. Fabret. 2004. The major 5' determinant in stop codon read-through involves two adjacent adenines. Nucleic Acids Res. 32:415-421.

Tristan, C., N. Shahani, T.W. Sedlak, and A. Sawa. 2011. The diverse functions of GAPDH: views from different subcellular compartments. Cell Signal. 23:317-323.

Uchida, N., S. Hoshino, H. Imataka, N. Sonenberg, and T. Katada. 2002. A novel role of the mammalian GSPT/eRF3 associating with poly(A)-binding protein in Cap/Poly(A)-dependent translation. $J$ Biol Chem. 277:50286-50292.

van der Klei, I.J., and M. Veenhuis. 2006. PTS1-independent sorting of peroxisomal matrix proteins by Pex5p. Biochim Biophys Acta. 1763:1794-1800.

van der Zand, A., I. Braakman, and H.F. Tabak. 2010. Peroxisomal membrane proteins insert into the endoplasmic reticulum. Mol Biol Cell. 21:2057-2065.

van Roermund, C.W., Y. Elgersma, N. Singh, R.J. Wanders, and H.F. Tabak. 1995. The membrane of peroxisomes in Saccharomyces cerevisiae is impermeable to $\mathrm{NAD}(\mathrm{H})$ and acetyl-CoA under in vivo conditions. EMBO J. 14:3480-3486.

von der Haar, T., and M.F. Tuite. 2007. Regulated translational bypass of stop codons in yeast. Trends Microbiol. 15:78-86.

Wanders, R.J., and H.R. Waterham. 2006. Biochemistry of mammalian peroxisomes revisited. Annu Rev Biochem. 75:295-332.

Weiner, A.M., and K. Weber. 1973. A single TGA codon functions as a natural termination signal in the coliphage q beta coat protein cistron. J Mol Biol. 80:837-855.

Yang, X., P.E. Purdue, and P.B. Lazarow. 2001. Eci1p uses a PTS1 to enter peroxisomes: either its own or that of a partner, Dci1p. Eur J Cell Biol. 80:126-138.

Yoshinaka, Y., I. Katoh, T.D. Copeland, and S. Oroszlan. 1985. Murine leukemia virus protease is encoded by the gag-pol gene and is synthesized through suppression of an amber termination codon. Proc Natl Acad Sci U S A. 82:1618-1622.

Zavialov, A.V., L. Mora, R.H. Buckingham, and M. Ehrenberg. 2002. Release of peptide promoted by the GGQ motif of class 1 release factors regulates the GTPase activity of RF3. Mol Cell. 10:789-798. 


\section{Rosemol George}

Klinik für Kinder- und Jugendmedizin

Abteilung Neuropädiatrie

Universitätsmedizin Göttingen

Robert-Koch-Straße 40

37075 Göttingen

\section{Career objective}

To be involved in work where I can apply my academic and professional skills, expand my knowledge and pursue a highly rewarding career.

\section{Profile}

- Science graduate with excellent sales and customer-service experience.

- Capability to work in an international team with diverse cultural background.

- Highly organized with excellent interpersonal and presentation skills.

- English: native speaker, German language: Level A1.

\section{Education}

- PhD in Molecular Medicine, University of Gottingen, Germany.

Feb 2013 -Aug 2016

- MRes in Molecular Medicine, University of Glasgow, Scotland.

2010

Sep 2009 - Sep

MSc in Biotechnology, Periyar University, India.

Jul 2006 - Apr

2008

- $\quad$ BSc in Microbiology, University of Pune, India.

May 2003 - Mar 2006

\section{List of publications}

1. "Peroxisomal lactate dehydrogenase is generated by translational readthrough in mammals". First author, eLIFE September 2014.

2. "Dual reporter systems for the analysis of translational readthrough in mammals".

Co- author, Peroxisome protocol, Springer book (under preparation). 
- Research fellow, University of Göttingen, Germany.

Oct 2011 - Nov 2012

- Customer tele-relations, Santander bank, Glasgow, UK.

Nov 2010 - Jun 2011

- Research intern, University of Glasgow, UK.

Apr 2011 - Aug 2011

- Customer Care Executive, IBM, Pune, India.

Sep 2008 - May 2009

\section{Achievements and accomplishments}

- Vice-Speaker of the PhD students enrolled in scholarship programme, Graduiertenkolleg (GRK) 1034, University of Göttingen.

- Floor-speaker of international students' apartment for two consecutive years, Mahatma Gandhi Haus, Göttingen.

\section{References}

- Prof. Dr. Jutta Gärtner

Universitätsmedizin der Georg-August-Universität Göttingen

Email: gaertnj@med.uni-goettingen.de

- Dr. Andrew Hamilton

University of Glasgow

Email: Andrew.Hamilton@glasgow.ac.uk

- Dr. Katherine West

University of Glasgow

Email: Katherine.West@glasgow.ac.uk 